\title{
ZUSAS
}

science for a changing world

Prepared in cooperation with the Bureau of Land Management

\section{Geophysical Investigation of Red Devil Mine Using Direct-Current Resistivity and Electromagnetic Induction, Red Devil, Alaska, August 2010}

By Bethany L. Burton and Lyndsay B. Ball

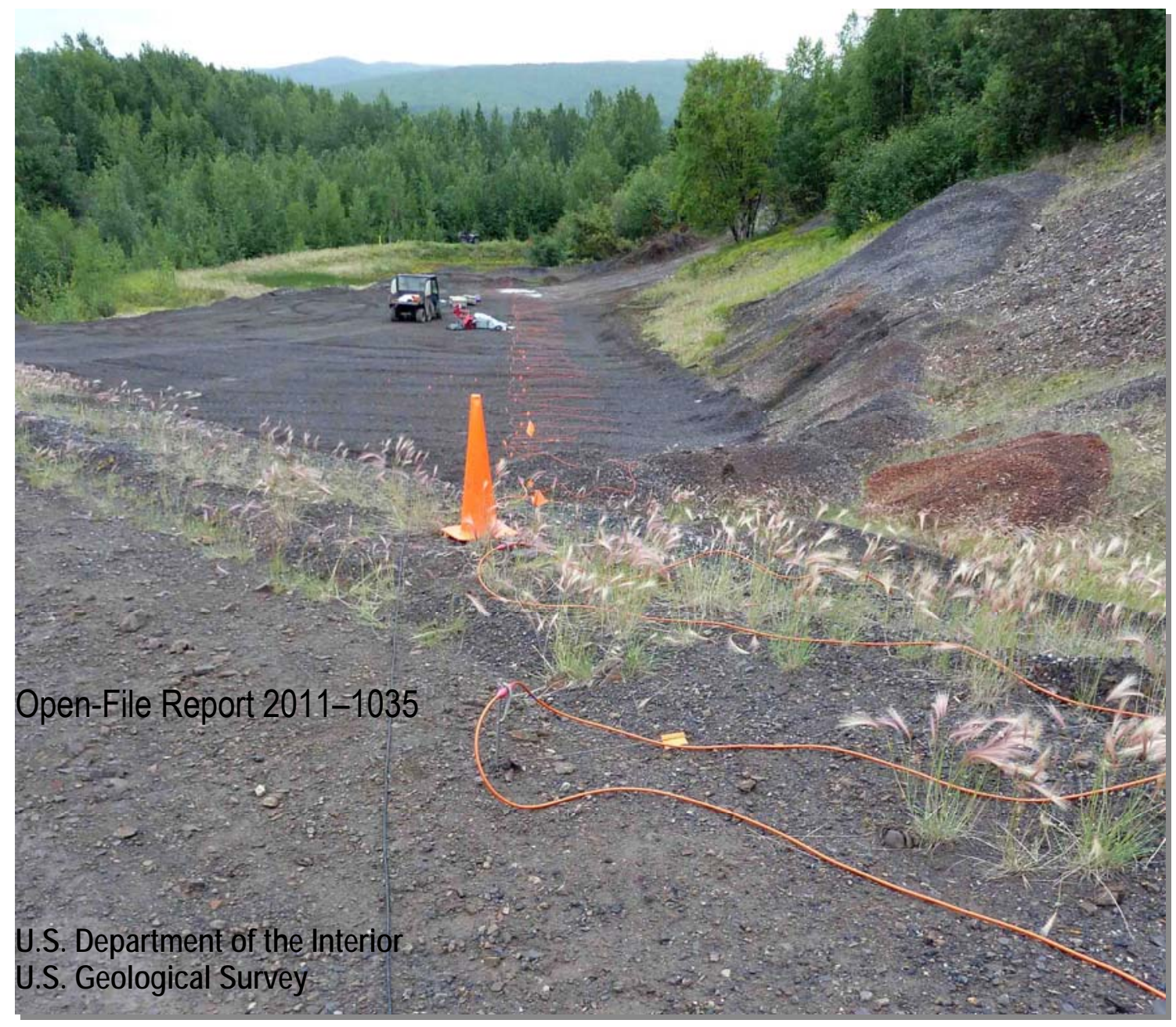


Cover: Looking northeast along DC resistivity line 1 at Red Devil mine. Photo by Bethany L. Burton. 


\section{U.S. Department of the Interior \\ KEN SALAZAR, Secretary}

\section{U.S. Geological Survey \\ Marcia K. McNutt, Director}

U.S. Geological Survey, Reston, Virginia: 2011

For product and ordering information:

World Wide Web: http://www.usgs.gov/pubprod

Telephone: 1-888-ASK-USGS

For more information on the USGS—-the Federal source for science about the Earth,

its natural and living resources, natural hazards, and the environment:

World Wide Web: http://www.usgs.gov

Telephone: 1-888-ASK-USGS

Suggested citation:

Burton, B.L., and Ball, L.B., 2011, Geophysical investigation of Red Devil mine using directcurrent resistivity and electromagnetic induction, Red Devil, Alaska, August 2010: U.S. Geological Survey Open-File Report 2011-1035, 53 p.

Any use of trade, product, or firm names is for descriptive purposes only and does not imply endorsement by the U.S. Government.

Although this report is in the public domain, permission must be secured from the individual copyright owners to reproduce any copyrighted material contained within this report. 



\section{Contents}

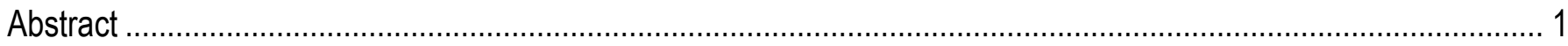

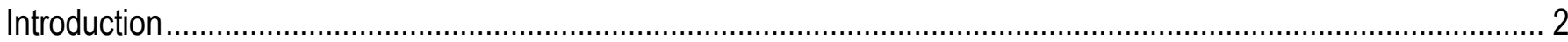

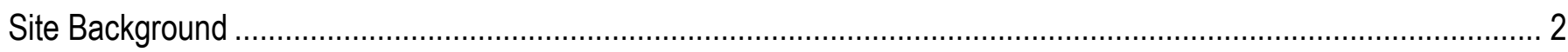

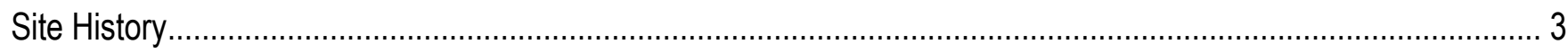

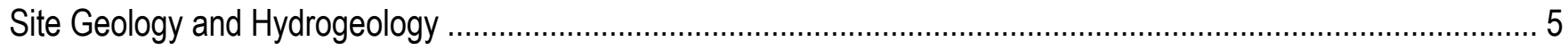

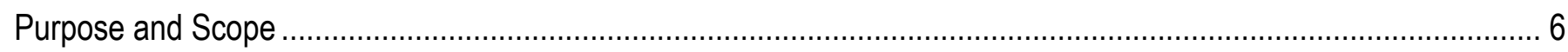

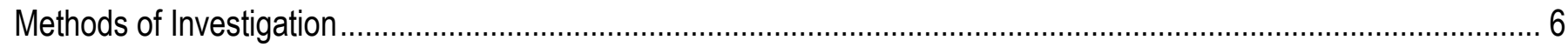

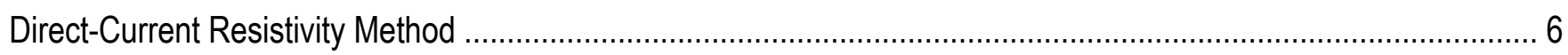

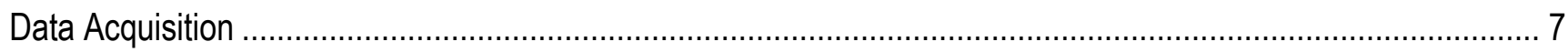

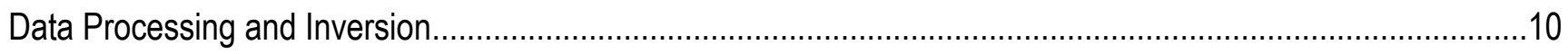

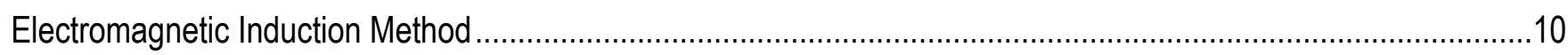

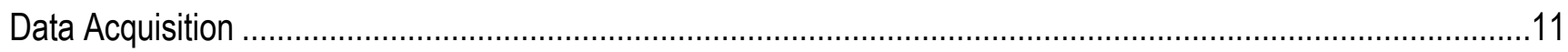

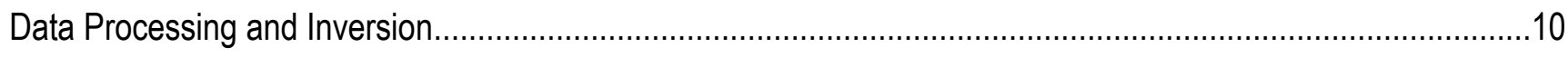

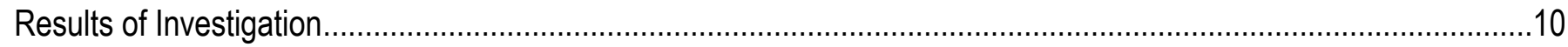

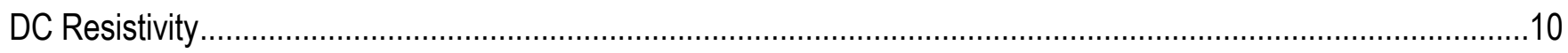

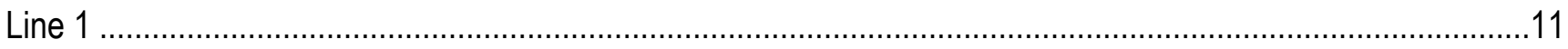

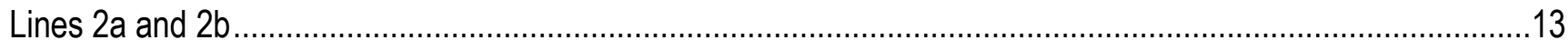

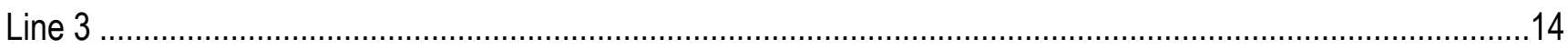

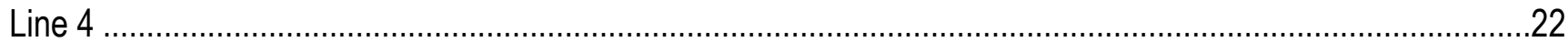

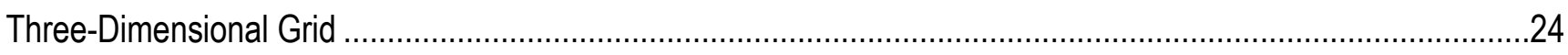

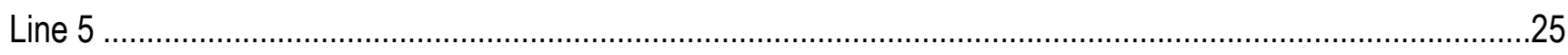

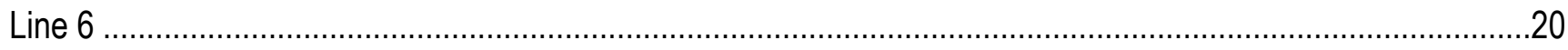

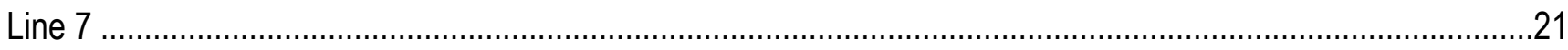


Electromagnetic Induction.

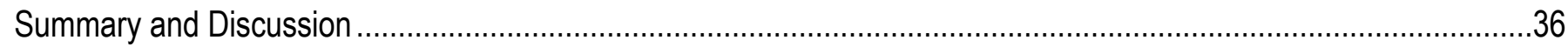

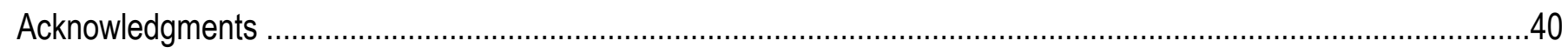

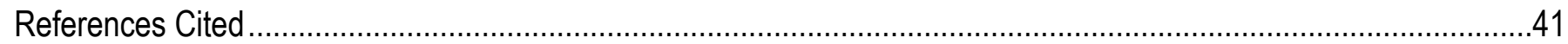

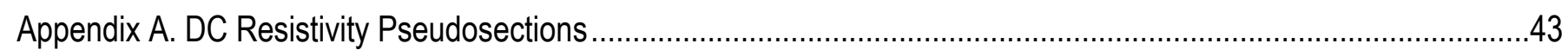

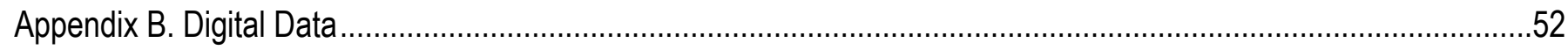




\section{Figures}

1. Index map showing location of Red Devil mine ……..................................................................... 3

2. Aerial photograph of Red Devil mine showing location of site features ................................................. 4

3. Aerial photograph of Red Devil mine showing location of geophysical surveys and

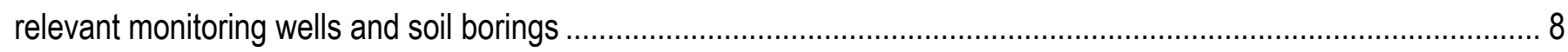

4. Photograph of shoulder-slung electromagnetic induction system .................................................... 11

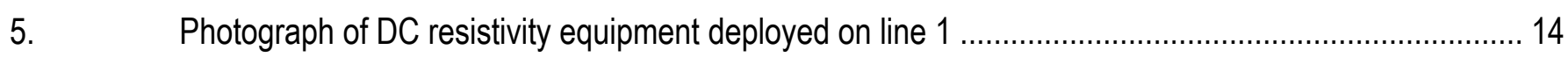

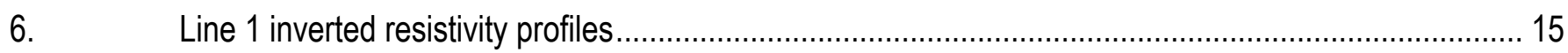

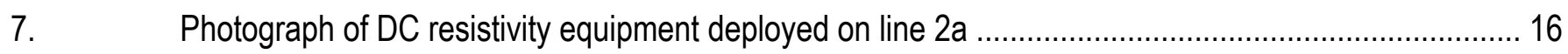

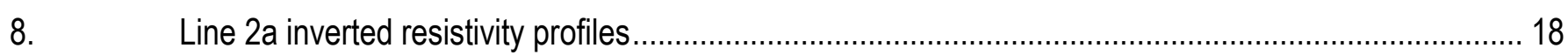

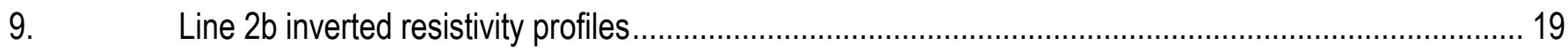

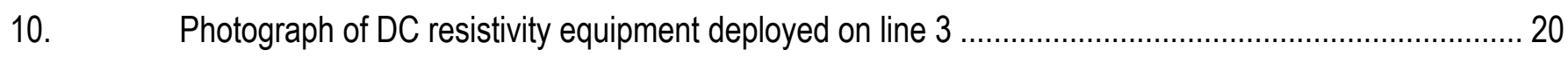

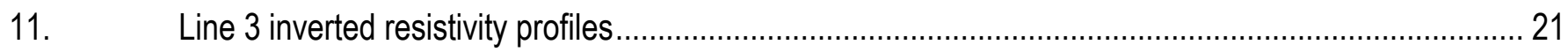

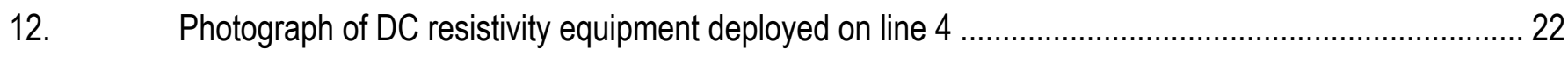

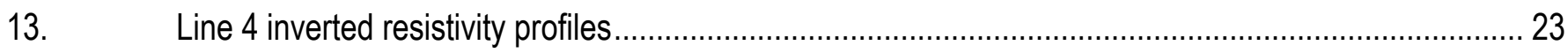

14. Photographs of DC resistivity equipment deployed on the three-dimensional grid and

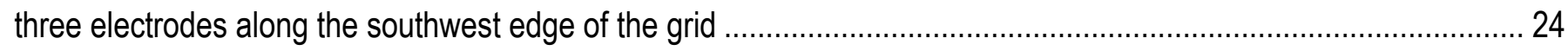

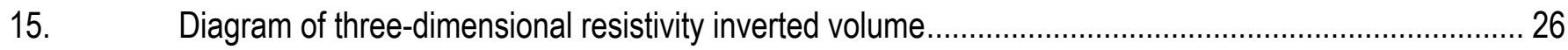

16. Photographs of DC resistivity equipment deployed on line 5

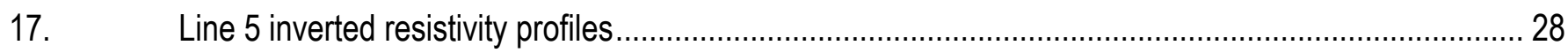

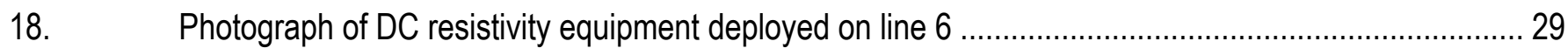

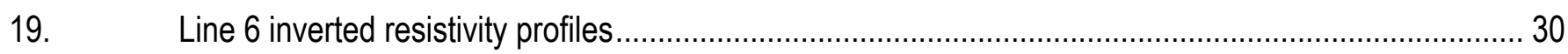

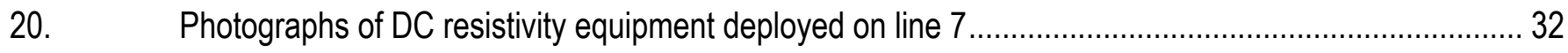

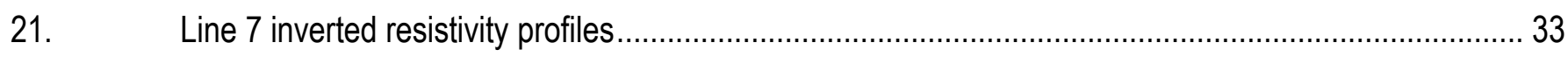


22. Map showing apparent conductivity data for $93,030 \mathrm{~Hz}$

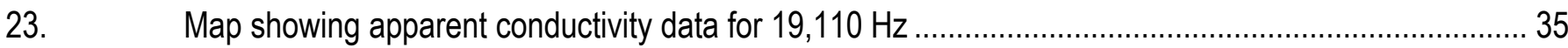

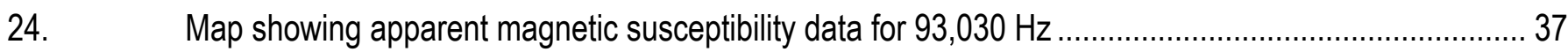

25. Map showing locations of annotated anomalies from the DC resistivity profiles and

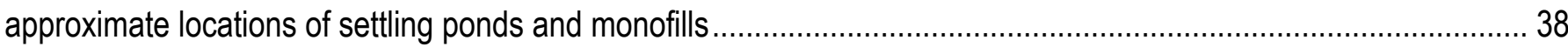

\section{Tables}

1. Summary of two-dimensional DC resistivity line acquisition parameters............................................. 9

2. Summary of three-dimensional DC resistivity grid acquisition parameters ........................................... 9 


\section{Conversion Factors}

\section{[SI to Inch/Pound]}

\begin{tabular}{lcl}
\hline & Multiply & \\
\hline & Length & To obtain \\
\hline centimeter $(\mathrm{cm})$ & 0.3937 & inch (in.) \\
meter $(\mathrm{m})$ & 3.281 & foot $(\mathrm{ft})$ \\
meter $(\mathrm{m})$ & 1.094 & yard $(\mathrm{yd})$ \\
kilometer $(\mathrm{km})$ & 0.6214 & mile $(\mathrm{mi})$ \\
\hline & Area & \\
\hline square meter $\left(\mathrm{m}^{2}\right)$ & 10.76 & square foot $\left(\mathrm{ft}^{2}\right)$ \\
\hline & Volume & \\
\hline cubic centimeter $\left(\mathrm{cm}^{3}\right)$ & 0.06102 & cubic inch $\left(\mathrm{in}^{3}\right)$ \\
cubic meter $\left(\mathrm{m}^{3}\right)$ & 1.307951 & cubic yard $\left(\mathrm{yd}^{3}\right)$ \\
\hline & Mass & \\
\hline megagram $(\mathrm{Mg})$ & 1.102 & ton, short $(2,000 \mathrm{lb})$ \\
megagram $(\mathrm{Mg})$ & 0.9842 & ton, long $(2,240 \mathrm{lb})$ \\
metric ton $(\mathrm{t})$ & 1.102 & ton, short $(2,000 \mathrm{lb})$ \\
Megagram $(\mathrm{Mg})$ & 1.102 & ton, short $(2,000 \mathrm{lb})$ \\
\hline
\end{tabular}

Temperature in degrees Celsius $\left({ }^{\circ} \mathrm{C}\right)$ may be converted to degrees Fahrenheit $\left({ }^{\circ} \mathrm{F}\right)$ as follows:

$$
{ }^{\circ} \mathrm{F}=\left(1.8 \times{ }^{\circ} \mathrm{C}\right)+32 .
$$

Vertical coordinate information is referenced to the North American Vertical Datum of 1988

(NAVD 88).

Horizontal coordinate information is referenced to the North American Datum of 1983 (NAD 83).

Elevation, as used in this report, refers to distance above the vertical datum. 



\title{
Geophysical Investigation of Red Devil Mine Using Direct- Current Resistivity and Electromagnetic Induction Methods, Red Devil, Alaska, August 2010
}

\author{
By Bethany L. Burton and Lyndsay B. Ball
}

\begin{abstract}
Red Devil Mine, located in southwestern Alaska near the Village of Red Devil, was the state's largest producer of mercury and operated from 1933 to 1971. Throughout the lifespan of the mine, various generations of mills and retort buildings existed on both sides of Red Devil Creek, and the tailings and waste rock were deposited across the site. The mine was located on public Bureau of Land Management property, and the Bureau has begun site remediation by addressing mercury, arsenic, and antimony contamination caused by the minerals associated with the ore deposit (cinnabar, stibnite, realgar, and orpiment). In August 2010, the U.S. Geological Survey completed a geophysical survey at the site using direct-current resistivity and electromagnetic induction surface methods. Eight twodimensional profiles and one three-dimensional grid of direct-current resistivity data as well as about $5.7 \mathrm{~km}$ of electromagnetic induction profile data were acquired across the site. On the basis of the geophysical data and few available soil borings, there is not sufficient electrical or electromagnetic contrast to confidently distinguish between tailings, waste rock, and weathered bedrock. A water table is interpreted along the two-dimensional direct-current resistivity profiles based on correlation with monitoring well water levels and a relatively consistent decrease in resistivity typically at 2-6 meters depth. Three settling ponds used in the last few years of mine operation to capture silt and sand from a flotation ore processing technique possessed conductive values above the interpreted water level but more resistive values below the water level. The cause of the increased resistivity below the water table is unknown, but the increased resistivity may indicate that a secondary mechanism is affecting the resistivity structure under these ponds if the depth of the ponds is expected to extend below the water level. The electromagnetic induction data clearly identified the three monofills and indicate, in conjunction with the three-dimensional resistivity data, additional possible landfill features on the north side of Red Devil Creek. No obvious shallow feature was identified as a possible source for a spring that is feeding into Red Devil Creek from the north bank. However, a discrete, nearly vertical conductive feature observed on the direct-current resistivity line that passes within 5 meters of the spring may be worth investigating. Additional deep soil borings that better differentiate between tailings, waste rock, and weathered bedrock may be very useful in more confidently identifying these rock types in the direct-current resistivity data.
\end{abstract}




\section{Introduction}

Mercury ore deposits and mines are located throughout southwestern Alaska (Webber and others, 1947). Several of the minerals associated with these mercury-rich deposits, including the target mineral cinnabar $(\mathrm{HgS})$, are sources of potential contamination of the surrounding soil, plants, and water and pose subsequent health risks to humans and wildlife. Mercury $(\mathrm{Hg})$ is a heavy metal that is toxic to various degrees to any organism in all forms in which it exists. The inorganic forms of mercury that include cinnabar, liquid mercury $\left(\mathrm{Hg}^{0}\right)$, and mercuric ion $\left(\mathrm{Hg}^{2+}\right)$ can be converted to the more highly toxic organic form of methylmercury $(\mathrm{meHg})$ by aerobic and anaerobic bacteria. These bacteria often occur in mercury-contaminated soils and stream environments (Bailey and Gray, 1997; Rytuba, 2000). Elevated levels of the heavy metals arsenic (As) and antimony ( $\mathrm{Sb}$ ) from ore-related minerals and lead $(\mathrm{Pb})$ from the mercury production process also pose potential health and environmental risks. The tailings and production byproducts present at these mine sites can be a source of contamination owing to the increased rock surface area that is exposed to weathering and erosional processes.

Red Devil mine, located near the Kuskokwim River (figs. 1 and 2), was Alaska's largest mercury producer and operated intermittently between 1933 and 1971, during which time 36,000 flasks (1,224 metric tons) of mercury were produced (Bailey and Gray, 1997). The mine was officially abandoned in 1981, at which time groundwater pumping ceased, and the mine workings below the natural water table flooded (Weston, 1989). Throughout the mine's development and operation, land ownership remained with the Bureau of Land Management (BLM), but the land has been selected for conveyance to Alaska Native corporations under authority of the Alaska Native Claims Settlement Act of 1971. In 1986, site inspections began under the Comprehensive Environmental Response, Compensation, and Liability Act of 1980 (CERCLA), commonly referred to as the Superfund program. Since this time, the BLM, under its CERCLA authority, has begun remediation by beginning to address $\mathrm{Hg}, \mathrm{As}, \mathrm{Sb}, \mathrm{Pb}$, and petroleum contamination at the site. To reassess potential risks to human health and environment that still exist after the remediation activity since 1999, a Remedial Investigation/Feasibility Study was initiated in accordance with CERCLA in 2009 (Bureau of Land Management, 2009).

In August 2010, in cooperation with the BLM and in conjunction with the Remedial Investigation/Feasibility Study, the U.S. Geological Survey (USGS) completed a surface-based geophysical survey at Red Devil mine to aid in the remediation efforts. Direct-current (DC) resistivity and frequency-domain electromagnetic induction (EMI) methods were employed to determine tailings and waste rock thicknesses across the site and to identify additional unknown sources of potential contamination.

\section{Site Background}

The Red Devil mine is located approximately 2 kilometers $(\mathrm{km})$ southeast of the village of Red Devil, Alaska, along the south bank of the Kuskokwim River. The village of Red Devil is located about $400 \mathrm{~km}$ west of Anchorage, Alaska, and $260 \mathrm{~km}$ northeast of Bethel, Alaska (fig. 1). Located within the Kuskokwim Mountain Range, the region is heavily forested. The climate is continental with a total average annual precipitation of 51 centimeters $(\mathrm{cm})$ including $216 \mathrm{~cm}$ of snowfall. Annual temperatures range from -50 to $32^{\circ} \mathrm{C}$ (Alaska Division of Community and Regional Affairs, 2010). 


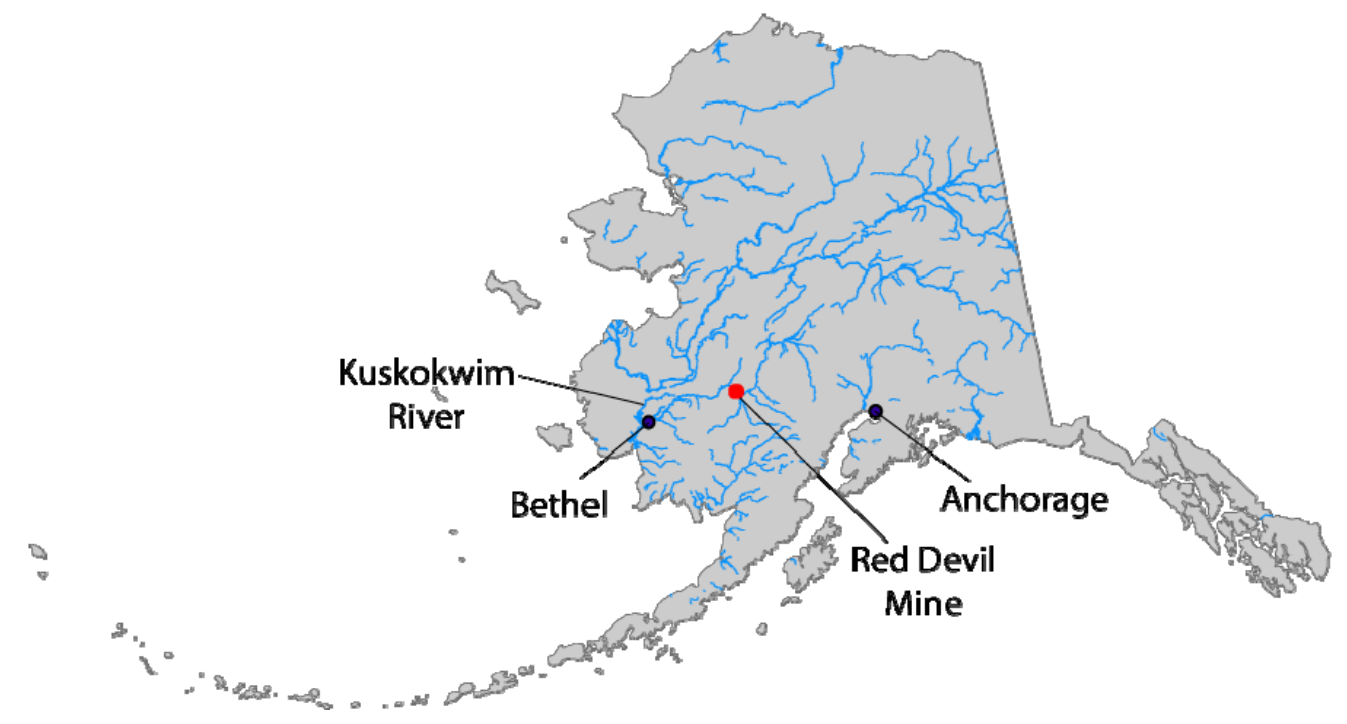

Figure 1. Index map showing the location of Red Devil mine.

Red Devil Creek bisects the site with the mining operations and mine camp on the north side and the second generation processing and retort operations to the south (fig. 2). The creek flows northeast into the Kuskokwim River and is bordered on both banks through sections of the site by tailings and waste rock. Mine tailings are the rock left over after the ore has been processed, and in the case of retort processing, are commonly referred to as calcines and have a characteristic red color due to the oxidation of iron sulfides caused by the roasting process (Rytuba, 2000). Waste rock has ore concentrations that are uneconomical to extract or is not mineralized and so has not been processed. Both tailings and waste rock are distributed throughout the site and used as fill to recontour the land to support the mine-site buildings (Weston, 1989).

\section{Site History}

The mined mineralized zone, located on the north side of the creek, covered an area of approximately 40,500 square meters $\left(\mathrm{m}^{2}\right)$ and extended about 190 meters $(\mathrm{m})$ below the ground surface. By 1958 , about $2,900 \mathrm{~m}$ of mine workings had been created including shafts, adits, drifts, crosscuts, winzes, and stopes (MacKevett and Berg, 1963).

The mine was primarily operated using underground mining methods but did include exploratory surface trenching and hydraulic sluicing of overburden in the earlier years of development (MacKevett and Berg, 1963). Except for the last few years of production when the concentrated ore was shipped to Japan for further processing, the ore was fully processed on site using retorts and furnaces (Tryck, Nyman, and Hayes, Inc., 1987). The processing method involved heating the ore to $600-700^{\circ} \mathrm{C}$ to vaporize the mercury and collect elemental liquid mercury through a condensing process (Rytuba, 2000). The original mill equipment, located on the north side of Red Devil Creek, was destroyed in October 1954 and rebuilt in 1955 on the south side of the creek (Tryck, Nyman, and Hayes, Inc., 1987). Owing to several episodes of mining and milling operations throughout the lifespan of the mine, the 


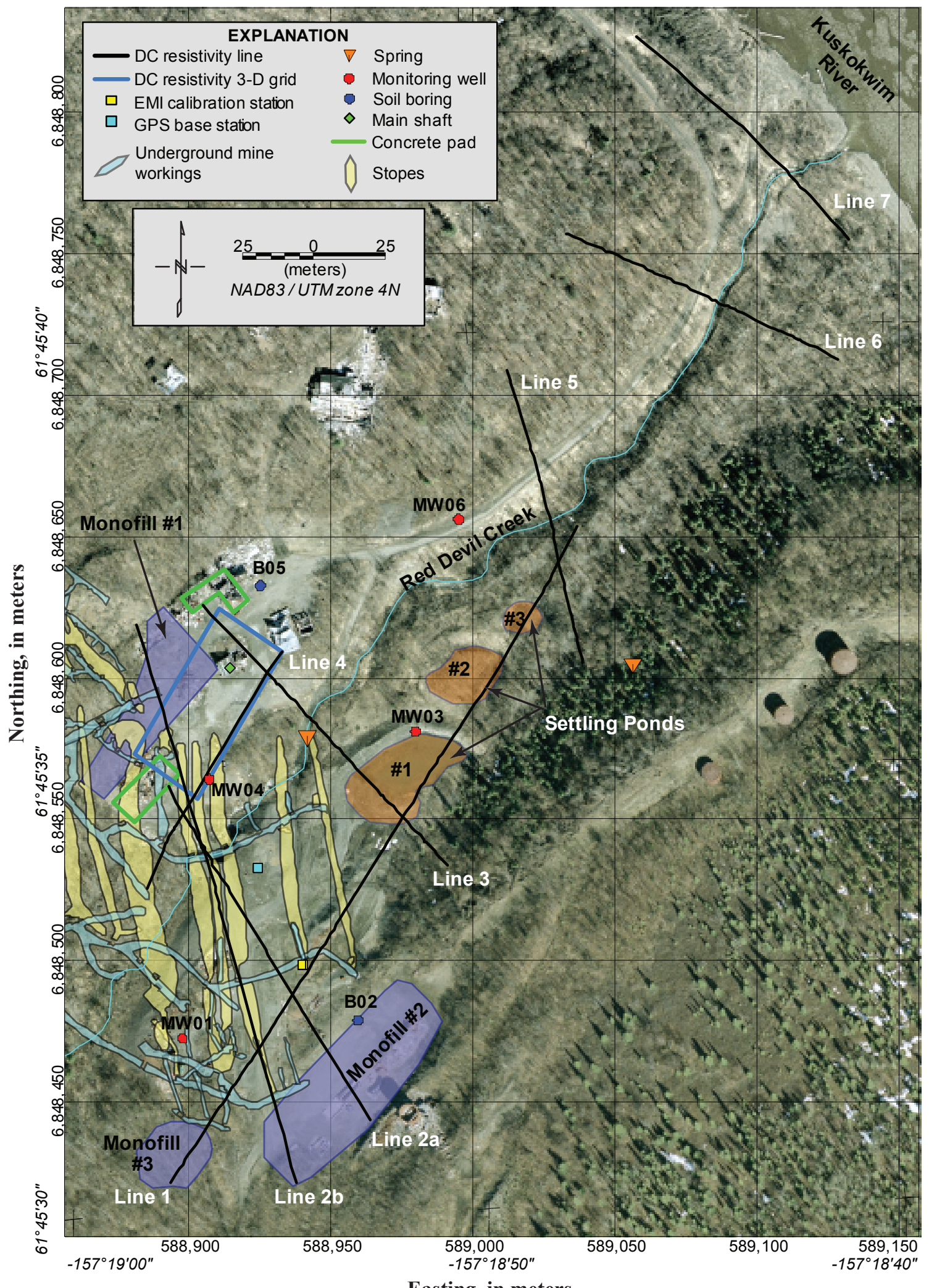

Easting, in meters

Figure 2. Aerial photograph of Red Devil mine showing the locations of site features including the three settling ponds, three monofills, concrete pads, monitoring wells and soil borings, two springs, and underground mine workings (M. Longtine, Ecology and Environment, Inc., June 2010) relative to the DC resistivity profiles and three-dimensional grid. The base photograph was taken in 2001 prior to the construction of the monofills, and no above-ground structures remained at the site at the time of the geophysical survey. The monofill and settling pond outlines are approximate and based on historical photographs. 
resulting tailings were deposited in various locations around the mine site and differ in composition and texture (Weston, 1989).

Furnacing and retorting ceased in 1963, but a flotation unit was operated from 1970 to 1971 to concentrate the cinnabar before shipment to Japan. Lead acetate was used as a foaming agent in the concentration process to increase cinnabar recovery rates. Sand and silt were deposited through a chute from the flotation system into a series of three cascading settling ponds (fig. 2) with minimal effluent released with the particulates, because it was valuable and therefore continually recycled for additional processing (Tryck, Nyman, and Hayes, Inc., 1987).

Site remediation from 2000 to 2005 included demolition of existing structures, creation of several monofills, or landfills, the removal of waste or contaminant sources, demolition of five aboveground storage tanks, and excavation of 1,070 cubic meters of petroleum-contaminated soil from the former above-ground storage tank area. In 2002, monofill \#1 was created near the main shaft on the north side of the creek and filled with onsite nonhazardous debris and building materials. Two building foundation concrete pads still exist in this area as well. Monofill \#2 is located on top of the site of the demolished retort and flotation mill and contains treated contaminated material including retort building debris, tailings, and other items of contaminated waste from the immediate area. This monofill has an impermeable liner and cap. An additional, smaller monofill \#3 was established in 2003 and located west of monofill \#2. It contains the steel remains of the mill hopper and above-ground storage tanks (Bureau of Land Management, 2010).

\section{Site Geology and Hydrogeology}

The Red Devil mine is located in Cretaceous Kuskokwim Group rocks, a thick sequence of postaccretionary, marine turbidite facies of interbedded greywacke (hard, poorly sorted, angular, impure sandstone) and shale with a predominantly 30 to 45 degree northwest strike and variable dip between 45 and 55 degrees southwest (Webber and others, 1947; MacKevett and Berg, 1963). These rocks are locally overlain by loess and alluvium consisting of Kuskokwim River floodplain and Red Devil Creek fluvial deposits and minor amounts of slope wash. The loess deposits range in thickness from a few centimeters to $9 \mathrm{~m}$, and fluvial deposits up to $6 \mathrm{~m}$ thick have been observed. The fluvial deposits include gravel, sand, and silt, and they generally postdate the loess (MacKevett and Berg, 1963).

The dominant faults strike northwest, possess predominantly right-lateral motion, and generally parallel bedding planes. Although individual faults are difficult to trace for long distances because of the highly fractured nature of the rocks and the lack of outcrops, it is believed that these are an en echelon system of faults (MacKevett and Berg, 1963).

The ore is present in veins, vein breccias, and massive replacements localized along and near intersections between northeast-trending late Cretaceous and early Tertiary hydrothermally altered mafic dikes and northwest-trending faults. The ore deposits in this region are thought to be late Miocene or early Pliocene (11.6 to $3.6 \mathrm{Ma}$ ) in age and hydrothermally developed as a result of the northwesttrending faulting. Mineralized veins are mostly small (typically less than 1-cm wide) and discontinuous, but veins as much as 1-m wide and 10-m long are present. Principal metallic minerals are cinnabar and stibnite $\left(\mathrm{Sb}_{2} \mathrm{~S}_{3}\right)$; minor amounts of realgar $\left(\mathrm{As}_{4} \mathrm{~S}_{4}\right)$, orpiment $\left(\mathrm{As}_{2} \mathrm{~S}_{3}\right)$, and pyrite $\left(\mathrm{FeS}_{2}\right)$ are also found. High-grade ore contained as much as 30 percent $\mathrm{Hg}$, but most ore averaged about 2 to 5 percent $\mathrm{Hg}$ (Webber and others, 1947; MacKevett and Berg, 1963).

Groundwater in the vicinity of Red Devil mine is likely to occur in an unconfined aquifer composed of mine-related overburden, alluvial and loess deposits, and the fractured sedimentary rocks of the Kuskokwim Group. General hydraulic head contours were interpreted from water levels taken in 
five monitoring wells during September 2010 (Mark Longtine, written commun., Nov. 2, 2010), the elevation of two springs, and the general land-surface topography. Hydraulic head gradients were assumed to be uniform between wells, and the creek and river were assumed to be hydrologically connected with the aquifer. These contours show that the groundwater-flow direction near the mine is generally northeast towards the Kuskokwim River. The presence of faults, veins, dikes, and subsurface mine workings may create permeability heterogeneities that would affect the distribution of hydraulic head, groundwater-flow directions, and travel times. These heterogeneities are difficult to identify and are not considered in the general hydraulic head contours used to help interpret the DC resistivity data.

\section{Purpose and Scope}

In August 2010, the USGS, in cooperation with the BLM, completed a surface-based geophysical survey at the Red Devil mine site using DC resistivity and frequency-domain EMI methods. The goals of the survey were to determine if (1) there is sufficient contrast in electrical properties between the surface tailings and bedrock to quantify the volume of tailings present, (2) a substantial deposit of tailings exists across the Red Devil Creek delta at its intersection with the Kuskokwim River, (3) mine workings in the vicinity of monofill \#1 on the north side of Red Devil Creek could be resolved, (4) the source of the spring depositing iron precipitates ("yellow boy") into Red Devil Creek below monofill \#1 could be determined, and (5) contamination exists from the three settling ponds on the south side of Red Devil Creek below the mill. To this end, eight DC resistivity profiles were acquired across the main processing area of the mine site and one three-dimensional DC resistivity grid was acquired across the vicinity of monofill \#1. In addition, frequency-domain EMI data were collected in two grids on the north and south sides of Red Devil Creek.

\section{Methods of Investigation}

\section{Direct-Current Resistivity Method}

Resistivity is an intrinsic material property that is defined by resistance to the flow of electric current in that material. Resistivity measurements are made by injecting a known current into the subsurface using two current electrodes and measuring the resulting voltage difference between two potential electrodes. For each profile, a linear array of stainless steel electrodes spaced at regular intervals is placed in the ground, and many different combinations of current and potential electrodes are used. Information about lateral variability in the subsurface is gained as the measuring electrodes are translated across the array, while information about greater depths is obtained by increasing the separation between the electrodes. For the three-dimensional grid, the electrodes were arranged in a rectangular grid pattern with consistent in-line and cross-line distances. As with the profiles, different electrode combinations are used for the measurements, but the active electrodes for a given measurement are not confined to a single row or column within the grid. On the basis of Ohm's law, the resistance is computed by taking the ratio of the measured voltage and the transmitted current. The apparent resistivity of the material, expressed in ohm-m, can then be determined by multiplying each resistance value by the corresponding geometric factor, which is based on the electrode geometry and spacing (Butler, 2005).

The main factors that affect the resistivity of a material are the amount of interconnected pore water present, the water quality (level of total dissolved solids, TDS), and the amount of mineralogical 
clay present. In the unsaturated zone, if no mineralogical clay is present, a fine-grained material (for example, silt or clay) will generally retain more interconnected water due to capillary forces than a coarse-grained material (for example, sand or gravel). The fine-grained material will therefore have a lower resistivity compared to coarser grained materials. For cemented sedimentary rock such as shale or greywacke, the primary (intragranular) effective porosity and secondary (fracture) effective porosity can differ widely on the basis of the interconnectedness of pores and open fractures and joints. Water quality is an important factor because the concentration of ions in the water affects its ability to conduct electricity. Materials containing water with high TDS will have a lower resistivity than materials containing water with low TDS. Even a small amount of mineralogical clay minerals can sharply decrease the overall bulk resistivity of a material, because current is conducted both through ion mobilization in the pore fluid (electrolytically) as well as through cation exchange in the clay (electronically). Because of the relation between grain size, water quality (TDS), and resistivity, the resistivity method may be a useful tool in differentiating surficial mine tailings and bedrock as well as delineating contaminant plumes emanating from the abandoned settling ponds. Reynolds (1997), Sharma (1997), and Butler (2005) provide more detailed descriptions of the resistivity method and resistivity values for common geologic materials.

\section{Data Acquisition}

DC resistivity data were acquired using an Advanced Geosciences, Inc. SuperSting R8 resistivity/induced polarization meter with a maximum of 112 electrodes. Each solid stainless steel electrode is about $45 \mathrm{~cm}$ long and $1 \mathrm{~cm}$ in diameter. The 8-channel resistivity meter uses a command file to acquire measurements from predetermined electrode and potential electrode configurations. Measurements were made for a period of 0.8 seconds, equivalent to about 2 hertz $(\mathrm{Hz})$, during which the polarity of the current electrodes is reversed in order to minimize electrode polarization effects to further improve contact resistance. The resistivity meter is powered by two 12-volt batteries and is capable of injecting up to 2,000 milliamperes (mA) of current into the ground. At this site, transmitted currents were generally between 10 and $800 \mathrm{~mA}$.

All electrodes were hammered into the ground as far as possible to minimize electrical contact resistance between the electrode and ground. It is important to note that the site was extremely wet during the majority of this survey. Ponded surface water was present throughout much of the survey, so the addition of the saltwater solution to the electrodes to further reduce contact resistances was not deemed necessary unless particularly high contact resistances were measured. High contact resistances can cause lower-quality data because of greater difficulties in both injecting current into the ground and measuring accurate voltages. Overall, the observed contact resistances were low to moderate at this site, typically ranging from 0.5 to $5 \mathrm{k}$ $\mathrm{ohm}$. For the three-dimensional grid acquired over monofill \#1, three electrodes were located on the rectangular concrete pad on the southwestern edge of the grid, which required that these electrodes be placed on a small pile (about $1,000 \mathrm{~cm}^{3}$ ) of bentonite mud instead of being driven into the ground to decrease the contact resistance.

An inverse Schlumberger array geometry was used for all eight profiles (fig. 3), which allows for rapid data acquisition and provides a good balance between lateral and vertical sensitivity to resistivity changes. With this geometry, the four electrodes used for each measurement are symmetric about a central location, with the current electrode pair located nearer to the central location. Line lengths were varied on the basis of available accessible space, and electrode spacing varied between 1 and $2 \mathrm{~m}$ on the basis of the project objectives while maintaining high levels of lateral and vertical sensitivity. A summary of the acquisition parameters for the eight profiles are provided in table 1. 


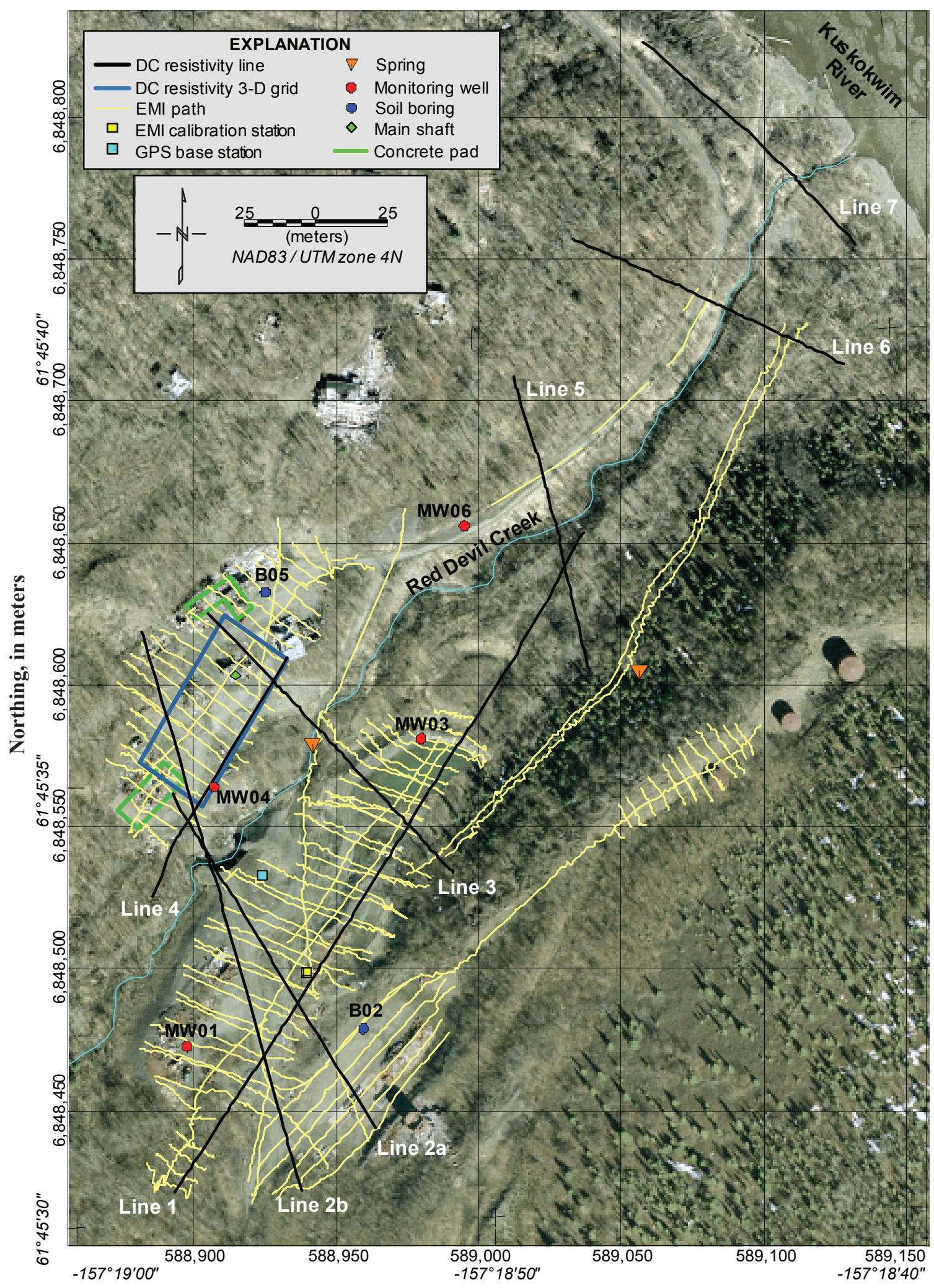

Easting, in meters

Figure 3. Aerial photograph of Red Devil mine showing the locations of the geophysical surveys and relevant monitoring wells and soil borings. 
Table 1. Summary of two-dimensional DC resistivity line acquisition parameters.

\begin{tabular}{|c|c|c|c|c|c|c|}
\hline Line & $\begin{array}{l}\text { Total line } \\
\text { length }\end{array}$ & Geometry & Heading & $\begin{array}{l}\text { Total number } \\
\text { of electrodes }\end{array}$ & $\begin{array}{l}\text { Electrode } \\
\text { spacing }\end{array}$ & Date acquired \\
\hline 1 & $278 \mathrm{~m}$ & $\begin{array}{l}2 \text { overlapping } 112- \\
\text { electrode spreads at } \\
\text { electrode } 29\end{array}$ & SW - NE & 140 & $2 \mathrm{~m}$ & $\begin{array}{l}\text { 8-Aug-10 \& } \\
\text { 9-Aug-10 }\end{array}$ \\
\hline $2 \mathrm{a}$ & $144 \mathrm{~m}$ & 173 -electrode spread & SE - NW & 73 & $2 \mathrm{~m}$ & 12-Aug-10 \\
\hline $2 b$ & $210 \mathrm{~m}$ & 1 106-electrode spread & SE - NW & 106 & $2 \mathrm{~m}$ & 12-Aug-10 \\
\hline 3 & $132 \mathrm{~m}$ & $\begin{array}{l}11 \text { 112-electrode spread w/ } 1 \\
\text { 21-electrode roll }\end{array}$ & SE - NW & 133 & $1 \mathrm{~m}$ & 10-Aug-10 \\
\hline 4 & $97 \mathrm{~m}$ & 198 -electrode spread & SW - NE & 98 & $1 \mathrm{~m}$ & 7-Aug-10 \\
\hline 5 & $111 \mathrm{~m}$ & 1 112-electrode spread & SE - NW & 112 & $1 \mathrm{~m}$ & 10-Aug-10 \\
\hline 6 & $111 \mathrm{~m}$ & 1 112-electrode spread & SE - NW & 112 & $1 \mathrm{~m}$ & 11-Aug-10 \\
\hline 7 & $104 \mathrm{~m}$ & 1 105-electrode spread & SE - NW & 105 & $1 \mathrm{~m}$ & 14-Aug-10 \\
\hline
\end{tabular}

For the three-dimensional grid, a radial dipole-dipole array geometry with 110 electrodes was employed (fig. 3). The electrodes were deployed as 10 parallel strings along the longest axis of the rectangular grid (southwest-northeast trending), each with 11 electrodes. The in-line electrode spacing was $6 \mathrm{~m}$ and the cross-line spacing was $3 \mathrm{~m}$. This geometry was chosen to maximize the surveyed area and therefore the depth of investigation while minimizing interference from the two large concrete pads. The acquisition geometry parameters are summarized in table 2 .

Table 2. Summary of three-dimensional DC resistivity grid acquisition parameters.

\begin{tabular}{cccccc}
\hline Geometry & $\begin{array}{c}\text { Number of } \\
\text { electrodes }\end{array}$ & $\begin{array}{c}\text { In-line electrode } \\
\text { spacing }\end{array}$ & $\begin{array}{c}\text { Cross-line } \\
\text { electrode spacing }\end{array}$ & $\begin{array}{c}\text { Total grid size } \\
\text { [electrodes] }\end{array}$ & Array type \\
\hline Rectangular grid & 110 & $6 \mathrm{~m}$ & $3 \mathrm{~m}$ & $\begin{array}{c}60 \times 27 \mathrm{~m} \\
{[11 \mathrm{NE} \times 10 \mathrm{NW}]}\end{array}$ & $\begin{array}{c}\text { Radial } \\
\text { dipole-dipole }\end{array}$ \\
\hline
\end{tabular}

The three-dimensional grid was acquired in response to the resistivity character observed on the north side of Red Devil Creek on two-dimensional lines 2a, 2b, and 3. There appeared to be imaging artifacts from improper resolution of three-dimensional objects in the two-dimensional profiles. In a two-dimensional inverted model, the resistivity values are allowed to vary in one direction (parallel to the line) but are assumed to be constant perpendicular to the line. This assumption is therefore valid when the profiles are perpendicular to the strike of elongated structures or geologic layers. When a profile is acquired across a discrete three-dimensional object, however, the object is typically not well resolved and the resulting modeled shape is dependent on the sensitivity pattern of the electrode array (Loke, 2010). In the case of two-dimensional DC resistivity lines 2a, 2b, and 3, these imaging artifacts are often manifested as arcuate anomalies or as alternating highly resistive or conductive values. 
All electrode locations were positioned using a Leica GPS1200 differential global positioning system (GPS) in the cleared areas and supplemented with a Sokkisha SET2 electronic total station in the forested areas. The GPS base station was set up over a single unknown position throughout the survey (figs. 2 and 3), and the raw observational data were converted to receiver independent exchange (RINEX) format and submitted to the National Geodetic Survey's Online Positioning User Service (OPUS) to determine the true location, including elevation. The rover GPS data were corrected by first postprocessing the base and rover raw observational data using Leica Geo Office ver. 7.0 and second by applying horizontal and vertical translations on the basis of the OPUS base station location solution.

\section{Data Processing and Inversion}

The raw DC resistivity data consist of measured voltage and injected current values and the down-line locations of the electrodes used for each measurement. For each of these measurements, an apparent resistivity is calculated using the raw data, Ohm's law, and the assumption of a homogeneous and isotropic half-space. In most cases, the subsurface is heterogeneous and sometimes anisotropic, and it requires that apparent resistivity data be inverted to determine a best-fit earth resistivity model of the subsurface.

The DC resistivity profile data were inverted using the robust inversion method in EarthImager $2 \mathrm{D}$ version 2.3.3 build 586. The robust method is based on the assumption of an exponential distribution of data errors and minimizes an L1-norm parameter that is a combination of the model data misfit and stabilizing function. The method typically performs well on datasets containing low-quality data and resolves resistivity boundaries well (Advanced Geosciences, Inc., 2008a). Topographic information was incorporated into the inversion in order to account for the influence of the irregular earth surface on the distribution of subsurface electrical currents, which is an important step towards determining a more accurate subsurface resistivity model. The inversions were allowed to run a maximum of 10 iterations with a stop criterion of 3 percent or less root-mean-square error between the measured and calculated forward model values or an L2-norm value of 1.0 or less. If neither of the stopping criteria was met, the lowest-quality data were removed using a percent-data misfit threshold. This threshold was chosen on the basis of a good balance between the noise levels of the data and on the overall percentage of data that would be removed at that data misfit level. The inversion was then run another time with the edited data. The raw data plots (pseudosections) for all eight profiles are placed in appendix A, and the raw and inverted ASCII data are placed within this report and described in appendix B.

The three-dimensional DC resistivity dataset acquired in the vicinity of the main shaft and monofill \#1 was inverted using the finite difference smooth model in EarthImager 3D version 1.5.4.361 (Advanced Geosciences, Inc., 2008b). Topographic information was not incorporated during the inversion process, but the survey area was relatively flat with a consistent, gentle slope that should not affect the inversion results. The inversion procedure for the three-dimensional dataset was similar to that described for the two-dimensional datasets. The raw and inverted ASCII datasets are included with this report, and the data formats are included in appendix B.

\section{Electromagnetic Induction Method}

The EMI method uses time-varying, induced electrical and magnetic fields to indirectly measure subsurface conductivity, which is the reciprocal of resistivity. EMI typically requires two coils of wire, one transmitter coil and one receiver coil, separated by some distance. Alternating current is supplied to the transmitter coil at some frequency, which creates an alternating magnetic field, of which the lines are perpendicular to the plane of the coil. This primary magnetic field induces electric, or eddy, currents 
in subsurface conductors that in turn induce a secondary, alternating magnetic field that is superimposed on the primary magnetic field measured by the receiver coil of the EMI instrument. The measured output values are typically the in-phase (real) and quadrature (90 degrees out-of-phase; imaginary) components of the secondary field normalized to the primary field, with units of parts per million (ppm). The amplitude of the secondary magnetic field for a given coil configuration is dependent on the electromagnetic properties and geometry of the subsurface conductor. The quadrature component is linearly proportional to ground conductivity values if the instrument is considered to be within the low induction number environment, which is dependent on ground conductivity, measured frequency, and transmitter-receiver offset (Spies and Frischknecht, 1991). The in-phase component is dependent on the magnetic susceptibility of the subsurface and therefore particularly sensitive to buried metallic objects.

The depth of investigation can be increased by increasing the separation distance between the coils or by decreasing the frequency of the primary current. Additional information on the EMI method is presented in Frischknecht and others (1991), West and Macnae (1991), and Lowrie (1997).

\section{Data Acquisition}

The EMI survey was acquired with a Geophex GEM-2 multi-frequency, dual-coil induction instrument. This is a single component, $1.66 \mathrm{~m}$ fixed-coil spacing instrument that uses multiple frequencies to vary the depth of investigation. Data were acquired in the co-planar, horizontal coil mode (fig. 4). The GEM-2 instrument can be used to measure relative variations in ground conductivity versus lateral position and depth for the top 10 to $15 \mathrm{~m}$ of subsurface material.

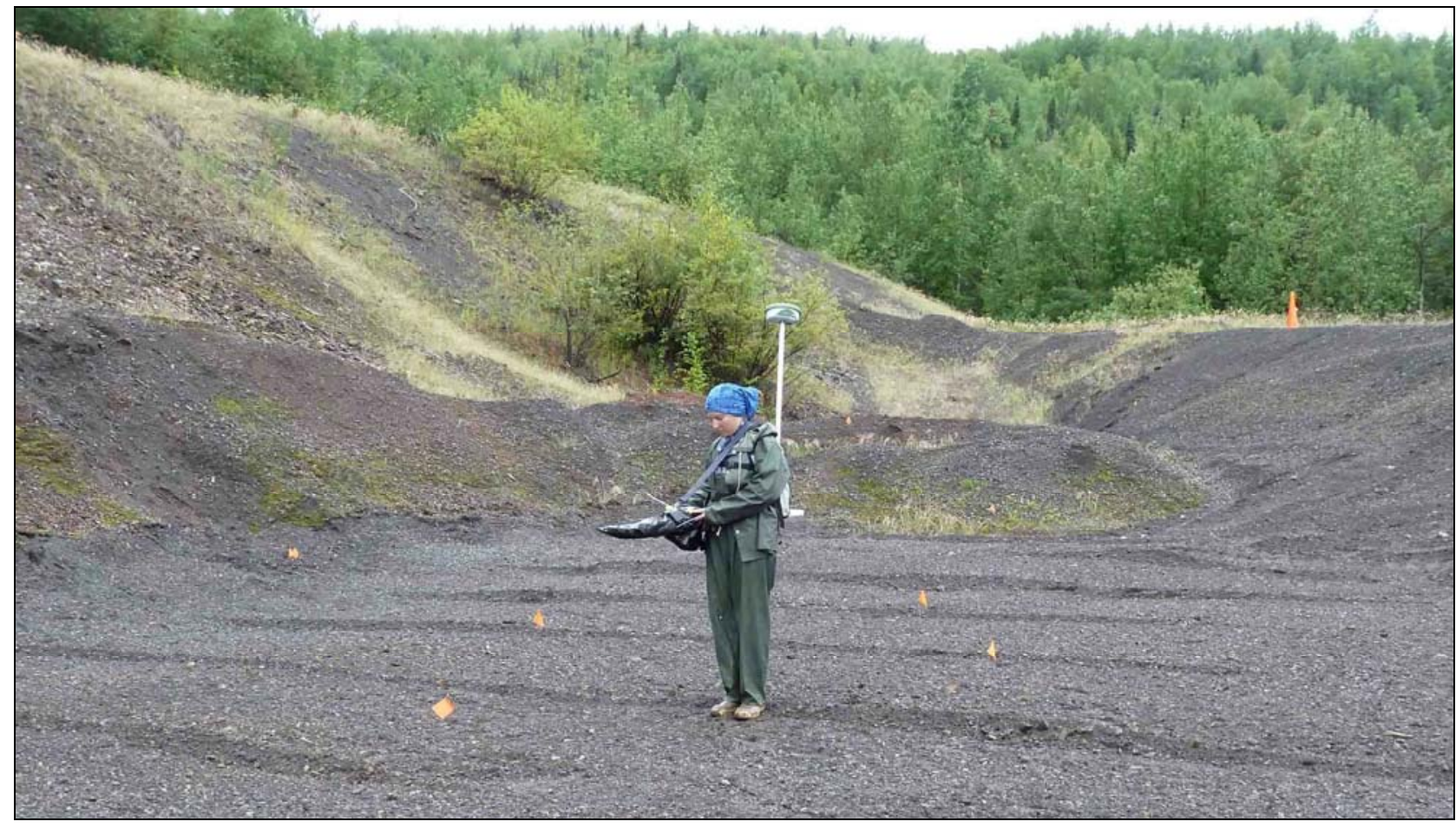

Figure 4. Photograph of the shoulder-slung electromagnetic induction system in horizontal co-planar mode integrated with a backpack-mounted global positioning system. The operator is standing at the calibration station facing north. 
Seven frequencies of EMI data were acquired: 3,930, 6,630, 11,310, 19,110, 32,430, 54,930, and 93,030 Hz. Data were acquired with the EMI instrument carried $1 \mathrm{~m}$ above the ground surface and integrated with the GPS. The EMI and GPS data acquisition rates were $10 \mathrm{~Hz}$ and $1 \mathrm{~Hz}$, respectively.

Approximately $5.7 \mathrm{~km}$ of data were acquired in the accessible areas in the main working areas of the site. The data were acquired in a snaking grid style with lines spaced roughly $5 \mathrm{~m}$ apart. Data were acquired throughout three data acquisition events over the course of two days.

In order to properly process and potentially invert the data, an instrument calibration procedure was followed according to Abraham and others (2006). A calibration station location was selected (figs. 2 and 3 ) on the basis of its proximity to the survey area, relative distance from known infrastructure (for example, monofills or other observed surface debris) to minimize interference, and relatively level ground surface within several meters of the station in all directions. The calibration station was occupied repeatedly during each acquisition event, including pre and post-survey, with the operator remaining stationary at the station for 2-3 minutes.

\section{Data Processing and Inversion}

EMI data editing included (1) removal of instrument drift during the surveys using the calibration station data and (2) the application of a 20-point low-pass filter to remove high-frequency noise on the quadrature and in-phase data (Abraham and others, 2006). Apparent conductivity and magnetic susceptibility values were computed from the drift-leveled and filtered quadrature and inphase data for each frequency using a conversion utility named Invertor by Geophex. Magnetic susceptibility is a measure of the degree to which the subsurface can be magnetized with the application of a magnetic field and is useful for mapping subsurface metallic objects or magnetic minerals. Lowerfrequency electromagnetic energy penetrates deeper into the subsurface (maximum 10-15 $\mathrm{m}$ in resistive ground), and higher-frequency electromagnetic energy provides higher resolution near the surface (upper 2-3 m). Depth of investigation decreases with increasing ground conductivity. The apparent conductivity data can be inverted to produce conductivity, or resistivity, depth images similar to those produced by the DC resistivity methods, but the EMI data from this instrument typically require calibration from additional data at the site, such as the DC resistivity data. This calibration procedure was not done with these datasets, however, owing to time constraints. The relative variations observed in the EMI are useful for mapping anomalies, but the absolute apparent conductivity and magnetic susceptibility values calculated without calibration are not realistic. The EMI data are therefore presented in this report as frequency-dependent, relative apparent conductivity and magnetic susceptibility data. The raw ASCII EMI dataset is included with this report, and the data format is included in appendix B.

\section{Results of Investigation}

\section{Resistivity}

The DC resistivity profiles and three-dimensional dataset were interpreted with the aid of digitized soil borings from 2000 (Harding Lawson Associates/Wilder Construction, 2001). The majority of the 86 soil borings was relatively shallow (less than $2 \mathrm{~m}$ ) and was concentrated on the future site of monofill \#2. The borings associated with monitoring wells MW01, MW03, MW04, and MW06 and soil borings B02 and B05 were deeper and provided the most useful information with regard to interpreting the DC resistivity data (figs. 2 and 3). 
Although the soil-boring logs provided engineering soil texture and grain size classifications as well as additional descriptions, the information provided did not definitively differentiate between tailings or waste rock and alluvium, loess, or weathered bedrock that may have been present before the mining activity. There also does not appear to be a strong, consistent contrast in the electrical properties in the shallow subsurface that is indicative of tailings or waste rock.

However, a mappable contrast between unsaturated and saturated sediments and rock is possible by using the estimated hydraulic head contours determined from the September 2010 measured water levels (Mark Longtine, written commun., Nov. 2, 2010) as a guideline. The unsaturated zone is generally more resistive than the underlying saturated zone, but there are several instances in this dataset where the trend is reversed, and possible interpretations are discussed where this is observed.

A distinct bedrock contact is not consistently identifiable but has been interpreted on several of the profiles. Where indicated, the bedrock was interpreted on the basis of its increased resistivity (greater than $200 \mathrm{ohm}-\mathrm{m}$ ) and is assumed to indicate a more competent surface. Although this is still relatively conductive for a competent rock, there appear to be relatively thick sections of either intensely fractured or weathered bedrock that possess lower resistivities and are electrically similar to the overlying overburden.

There are also many anomalies, both resistive and conductive, that are present throughout the dataset that are not interpretable without additional information. Many of these discrete anomalies are present in the upper $5 \mathrm{~m}$ and may be due to unidentified buried items. The underground mine workings that are present in the western half of the survey area (fig. 2) are deeper than the maximum depth of investigation of both methods and are not expected to directly affect the data. The estimated depth of investigation, also referred to as the median depth of investigation, is based on the array geometry and maximum electrode spacing and is approximately equal to one-fifth of the maximum electrode spacing for an inverse Schlumberger array. The median depth of investigation refers to the depth at which the overlying section has the same influence on the measured potential as the underlying section (Loke, 2010). Although the sensitivity of the inverted model to variations in layer thicknesses and resistivity values decreases with depth, it does not become zero at the median depth of investigation. Resolution of features or interfaces below this depth, however, is reduced.

For this survey, the maximum electrode spacing used for a single measurement with a full 112electrode layout with an electrode spacing of $1 \mathrm{~m}$ is $100 \mathrm{~m}$, which is equivalent to about a $20 \mathrm{~m}$ median depth of investigation. When less than a full layout of electrodes is used, the investigation depth is shallower, and when the nominal electrode spacing of the profile is increased to $2 \mathrm{~m}$, the investigation depth is likewise doubled.

The DC resistivity inversion profiles are presented and discussed individually. All profiles (or resistivity sections) are presented at the same scale with no vertical exaggeration and with the same color scale. The lower horizontal axis is downline distance along the line azimuth and the upper horizontal axis is the projected northing or easting coordinates along the line. For each profile, two identical inverted models are shown: one that is not interpreted and one that shows the interpretations and annotations. Interpreted water levels are shown for all profiles as well as bedrock contacts for selected profiles.

\section{Line 1}

Line 1 is a southwest-northeast trending profile that begins at monofill \#3, crosses the post-1955 retort area and three settling ponds, and ends just south of Red Devil Creek (fig. 5). The resistivity section generally exhibits three layers: a resistive (greater than $200 \mathrm{ohm}-\mathrm{m}$ ) 3-5 m thick surface layer 
overlying a less resistive layer (40-100 ohm-m) that varies in thickness from 1-8 $\mathrm{m}$, all overlying what is interpreted to be more competent bedrock that exhibits resistivity values greater than 200 ohm-m (fig. 6). The variations observed in the bedrock may be due to varying fracture intensities. The surface layer is interpreted to be unsaturated unconsolidated overburden and the middle layer is interpreted to be saturated overburden or weathered bedrock. The water level appears to follow a smoothed topographic contour. The fact that the interpreted water level on line 1 is about $2.5 \mathrm{~m}$ higher than the well MW01 water level is consistent with an average hydraulic gradient of about 0.1 and a separation distance of about $25 \mathrm{~m}$.

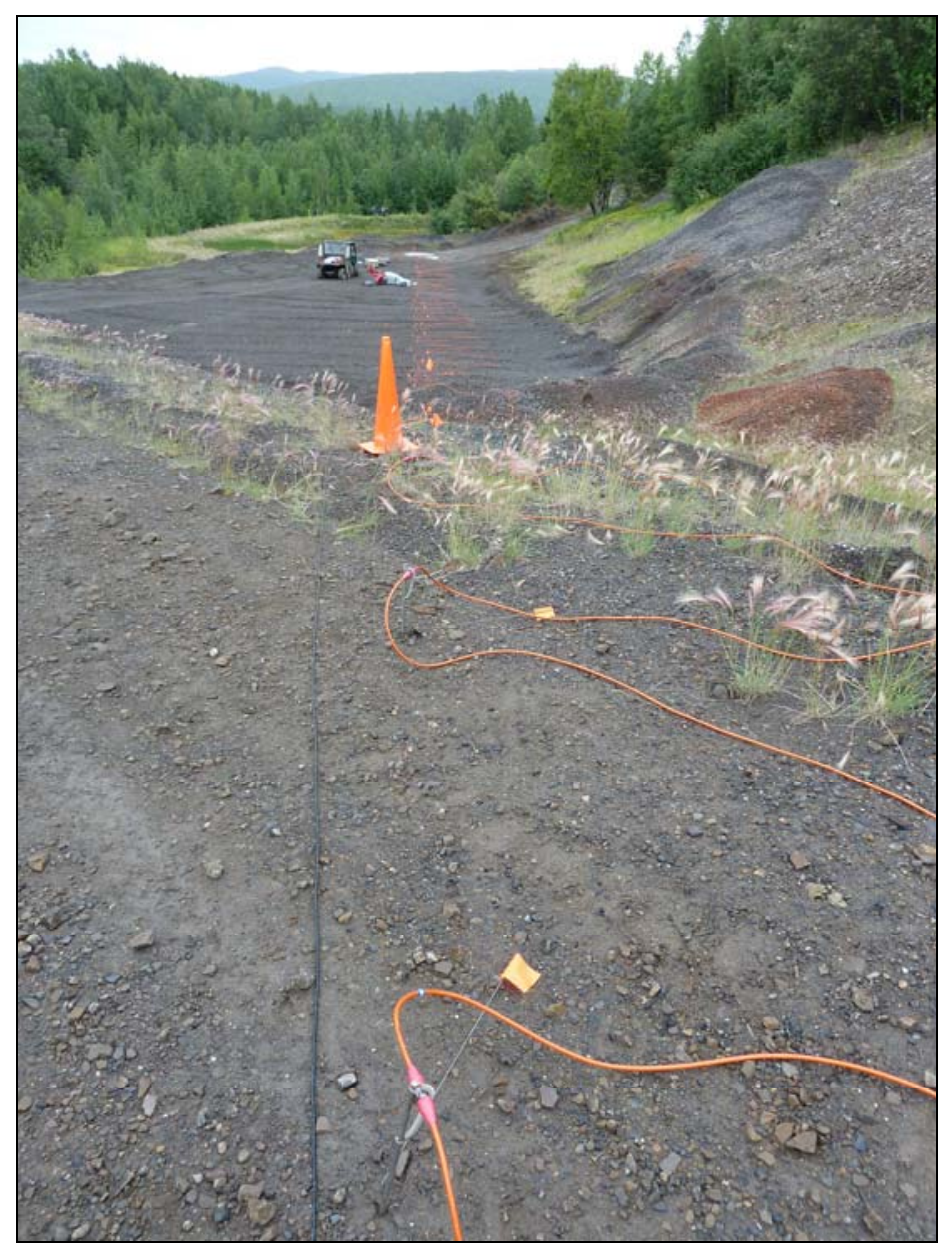

Figure 5. Photograph of the DC resistivity equipment deployed on line 1, looking northeast toward settling pond \#1.

Monofill \#3 is located from 0-20 $\mathrm{m}$ downline distance and appears to be about $6 \mathrm{~m}$ deep with a resistive layer overlying a more conductive zone. The exact depth and electrical signature may not be properly resolved because of the metallic material present in the monofill.

The three settling ponds exhibit discrete conductive anomalies (less than $80 \mathrm{ohm}-\mathrm{m}$ ) across each pond in the unsaturated zone that is truncated at each berm on the downgradient side. These anomalies are interesting, however, because they become more resistive below the water table. If the anomalies were due to the presence of concentrated deposits of silt and sand from the flotation process, then these 


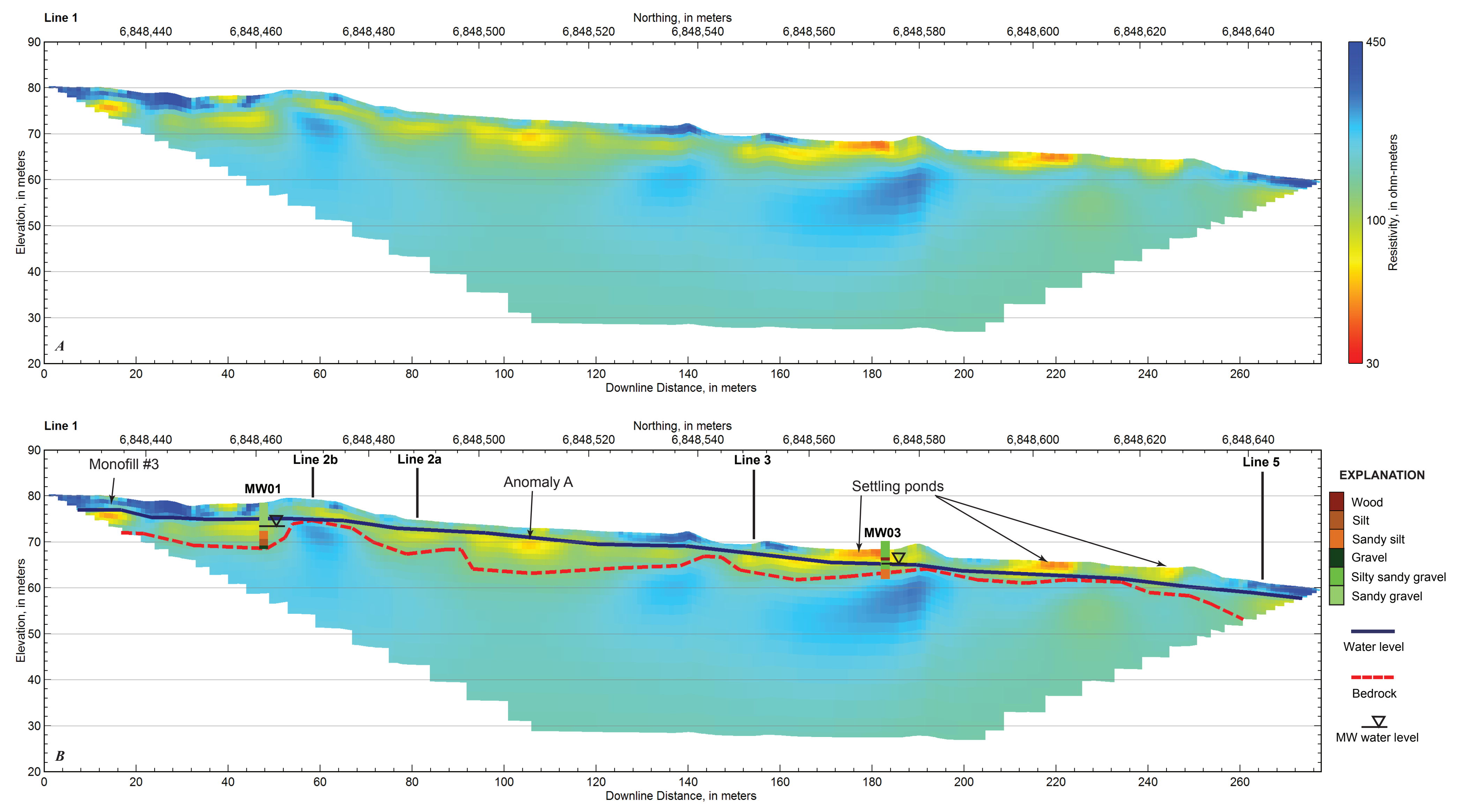

Figure 6. Line 1 inverted resistivity profiles that are $(A)$ uninterpreted and $(B)$ have interpretive annotations and soil boring logs displayed for wells MW01 and MW03. The locations of the cross-line intersections are shown. 
sediments would be expected to become more conductive when saturated if the base of these ponds extended below the water table. One possibility is that the conductive anomalies indicate the presence of a contaminant that undergoes a change in electrical properties under different saturation conditions. These anomalies may also indicate that a contaminant is mobile under saturated conditions, and that it has been carried away or substantially diluted by groundwater flow.

Anomaly A is a moderately conductive anomaly $92-112 \mathrm{~m}$ downline distance that becomes more prominent below the water table. This is the area over which the petroleum-contaminated soil was stored on an impermeable liner for several years before removal just prior to the geophysical surveys. This anomaly is interesting because it is also observed in the apparent conductivity EMI data, which will be presented in the electromagnetic induction results section.

\section{Lines $2 a$ and $2 b$}

Lines $2 \mathrm{a}$ and $2 \mathrm{~b}$ are obliquely intersecting profiles that generally trend southeast-northwest and together span the north-south extent of the survey site from monofill \#2, across Red Devil Creek, and over monofill \#1 (figs. 2 and 3). Two lines were necessary to span this area because of the location of a narrow clearing across the creek through which equipment could be deployed. A bridge used to stand at this clearing, and there are now large piles of loose waste rock on the south side of the creek (fig. 7).

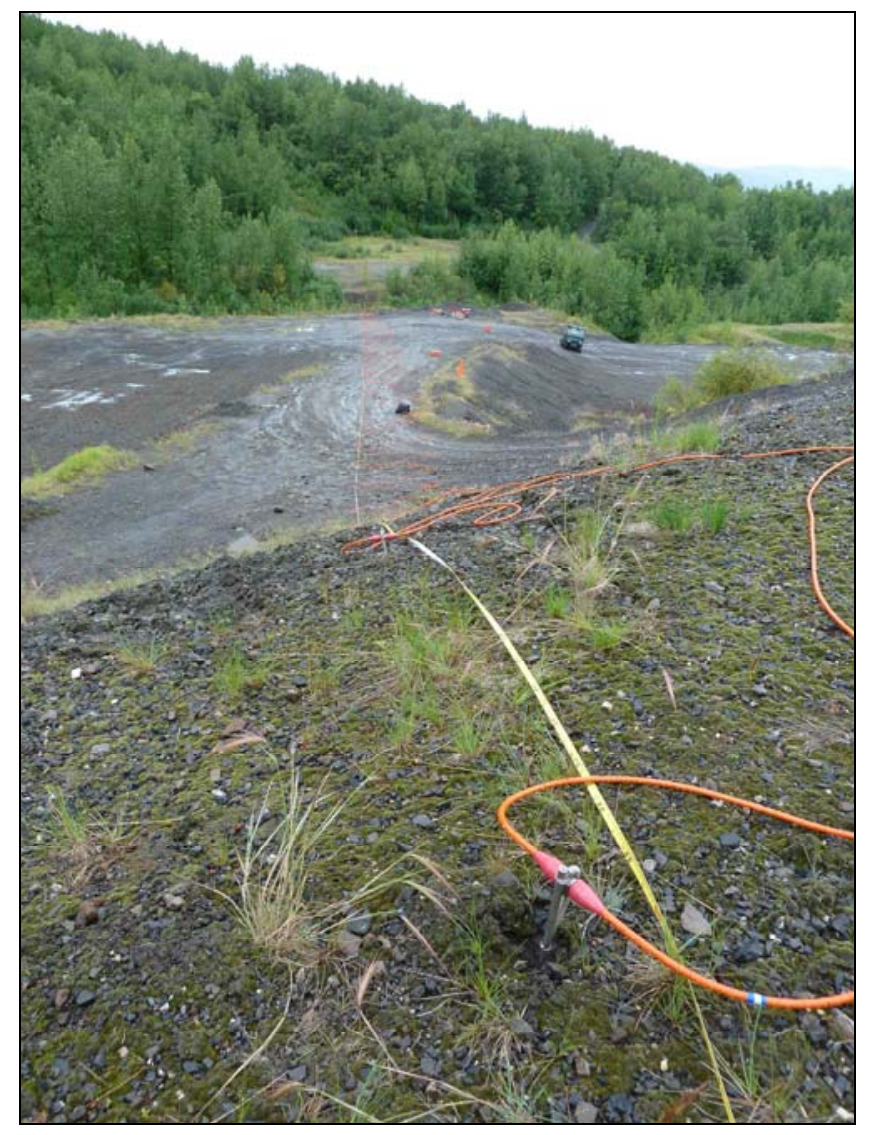

Figure 7. Photograph of the DC resistivity equipment deployed on line 2a taken from monofill \#2, looking northwest. 
On the south side of Red Devil Creek, the interpreted water level on both lines $2 \mathrm{a}$ and $2 \mathrm{~b}$ generally follows topography and is $2-4 \mathrm{~m}$ deep (figs. 8 and 9). The presence of a surface conductor in the top $2 \mathrm{~m}$ on the slope leading up to monofill \#2 from 22-28 $\mathrm{m}$ downline distance on line $2 \mathrm{a}$ and from 20-40 $\mathrm{m}$ downline distance on line $2 \mathrm{~b}$ may indicate that the water level becomes much shallower, there is a change in rock type or texture (becoming finer grained material), or there is change in soil or water quality causing the resistivity to decrease (anomaly B). The presence of the liner surrounding monofill \#2 causes the monofill to be imaged as a resistor, and the conductive anomaly adjacent to the monofill (figs. 8 and 9), may be a result of imaging artifacts due to the liner.

The interpretation of water levels in the DC resistivity data on the north side of Red Devil Creek is difficult. The water level measured in well MW04 is below the level of the creek and indicates that this stretch of the creek is a losing stream. The well MW04 water level, however, is difficult to correlate with the resistivity data. The blue water level interpretation on Figures 8 and 9 attempts to uphold the measured water level in MW04, but an alternate, shallower water level is also presented that more closely follows topography and is more consistent with the resistivity transitions observed on the south side of the creek. Unfortunately, there are no other water level measurements on this side of the creek to aid in the interpretation, and the three-dimensional effects observed on the profile, including monofill $\# 1$, obscure the water level on the northern end of Line $2 b$ (fig. 9).

There are several discrete conductive anomalies below the water table on the south side of the creek (anomaly C) that are generally consistent between both resistivity lines. The largest anomaly from 88-100 $\mathrm{m}$ downline distance on line $2 \mathrm{a}$ is not observed on line $2 \mathrm{~b}$. The causes of these anomalies are not known but are interpreted to be either within the alluvium or weathered bedrock.

Anomaly D is a very strong discrete conductor (less than $30 \mathrm{ohm}-\mathrm{m}$ ) that is centered below the creek and present in both lines $2 \mathrm{a}$ and $2 \mathrm{~b}$. Its cause is unknown, but it is not believed to be an artifact of the presence of the creek or of the steep slopes on either side of the creek.

\section{Line 3}

The southeastern end of line 3 starts at the base of the outcrop exposed by the road cut, continues down a steep, loose dirt slope, crosses settling pond \#1 and Red Devil Creek, and passes about $7 \mathrm{~m}$ northeast of the main shaft on the north side of the creek (fig. 10). This line is closest to the spring that is feeding into Red Devil Creek and is depositing iron precipitate, also referred to as yellow boy, on the creek bed below (fig. 3). The spring is surfacing about $1 \mathrm{~m}$ above the creek water level, and its source is unknown.

On the basis of the resistivity section and the measured water level in well MW03, the interpreted water level diverges from the ground surface below the settling pond to the level of Red Devil Creek and then rises again on the north side of the creek (fig. 11). The distinctive bisected layering centered on the settling pond berm (48 $\mathrm{m}$ downline distance) is most likely a result of the construction process, and artifacts may be produced in the resistivity images if debris, such as the noted wood layer in the lithology log, is buried. As discussed earlier, discrete, three-dimensional objects in the subsurface are not well resolved using two-dimensional resistivity profiles. Well MW03 is located on the berm northeast of line 3 and its measured water level does correlate with the elevated conductive zone centered below the berm on the line 3 resistivity section. The interpreted water level as shown on figure 11, however, transitions more smoothly across this peak and follows the top of a conductive layer (40-100 ohm-m) that is interpreted to be the saturated alluvium or weathered bedrock.

As presented for lines $2 \mathrm{a}$ and $2 \mathrm{~b}$, two water levels are shown on the north side of the creek. The blue water level is consistent with the well MW04 measurements, and the alternate water level follows a contact between a resistive layer overlying a highly conductive layer that is about $3 \mathrm{~m}$ above the well MW04 water level. The lithology logs for both well MW04 and soil boring B05 indicate a silty sandy 

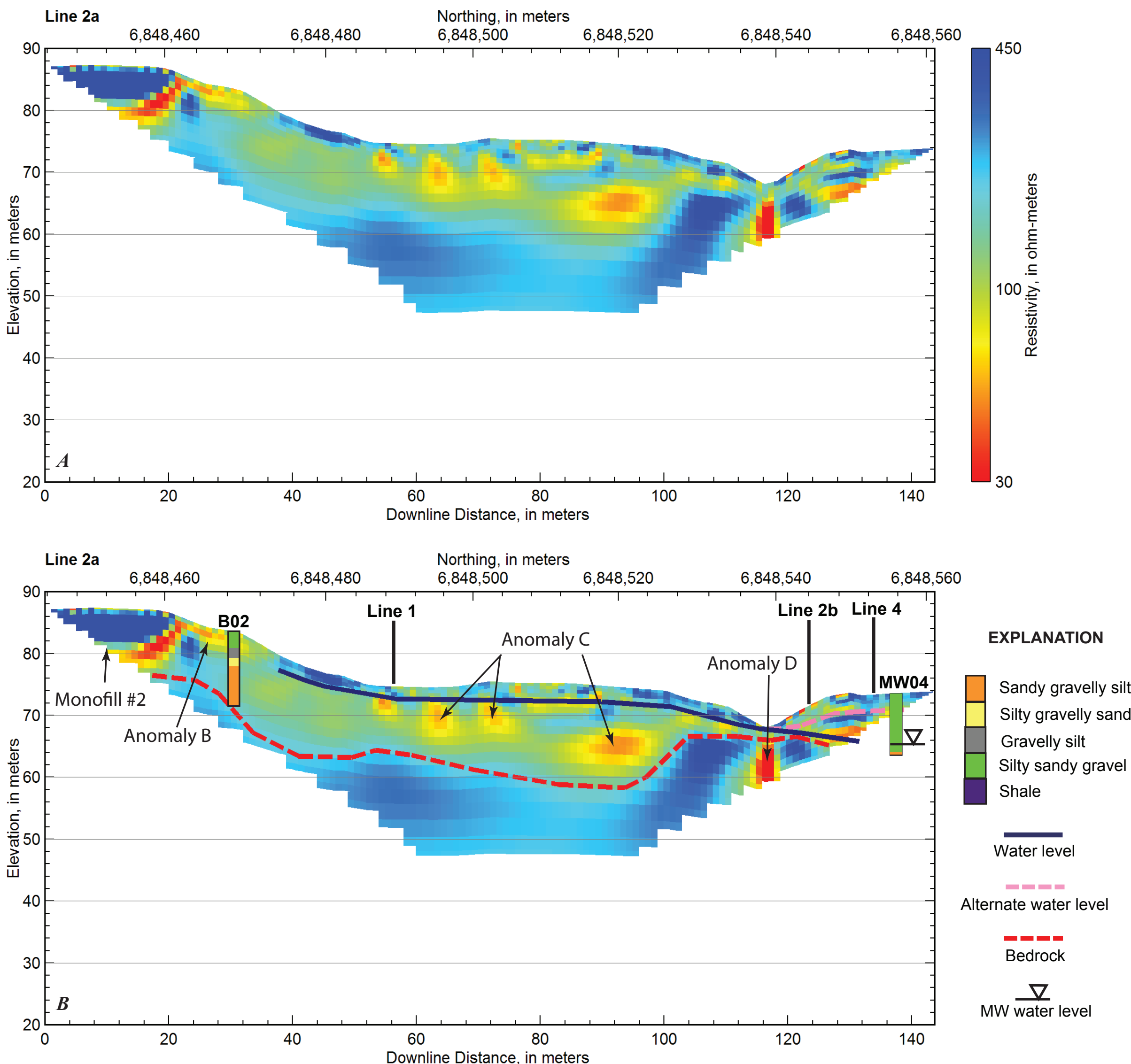

Figure 8. Line 2a inverted resistivity profiles that are $(A)$ uninterpreted and $(B)$ have interpretive annotations and soil boring logs displayed for wells B02 and MW04. The locations of the cross-line intersections are shown. The blue water level interpretation abides by the MW04 measured water level, and the pink dashed alternate water level is based on similar resistivity transitions observed on the south side of the creek. 

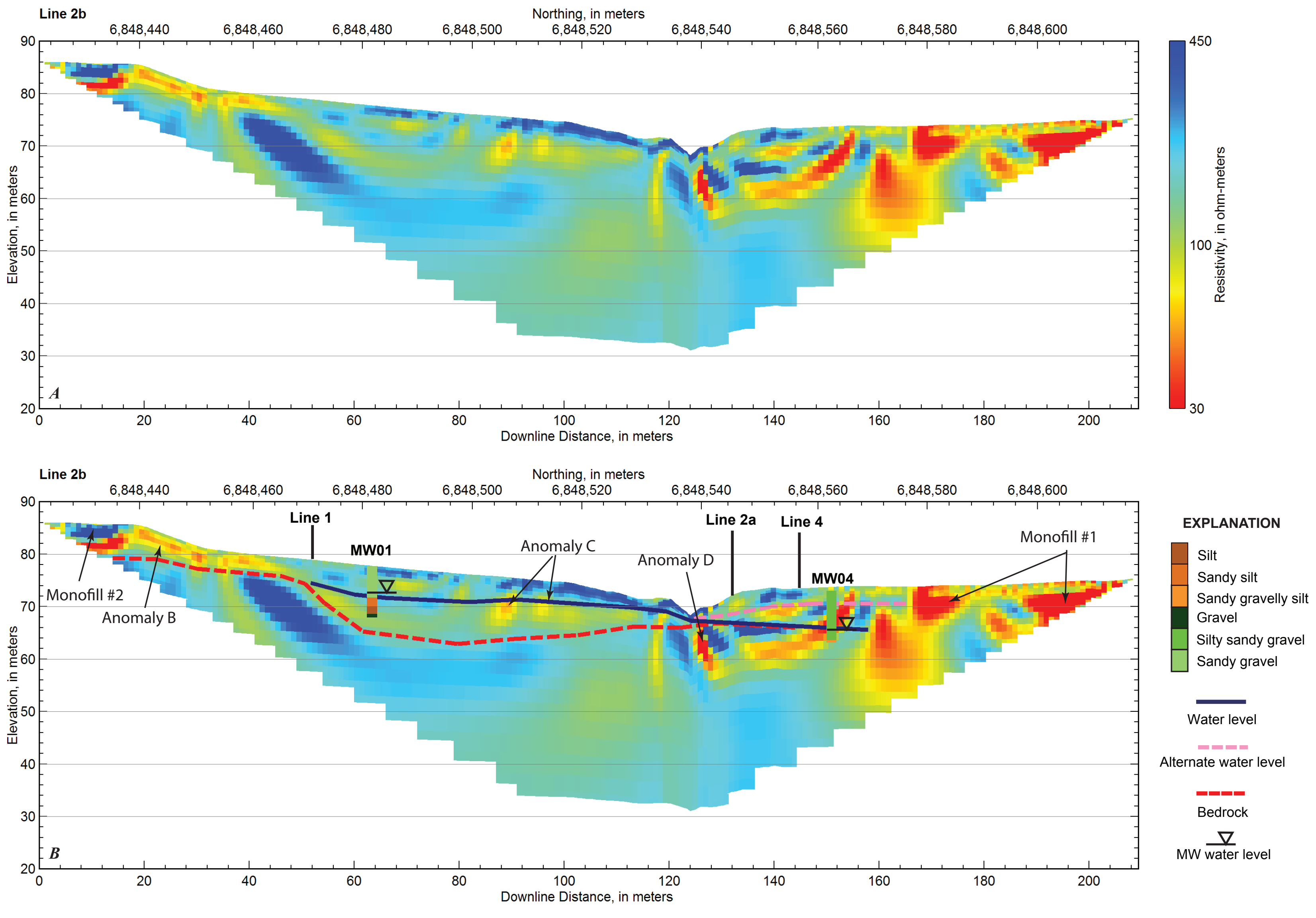

Figure 9. Line $2 \mathrm{~b}$ inverted resistivity profiles that are $(A)$ uninterpreted and $(B)$ have interpretive annotations and soil boring logs displayed for wells MW01 and MW04. The locations of the cross-line intersections are shown. The blue water level interpretation abides by the MW04 measured water level, and the pink dashed alternate water level is based on similar resistivity transitions observed on the south side of the creek. 


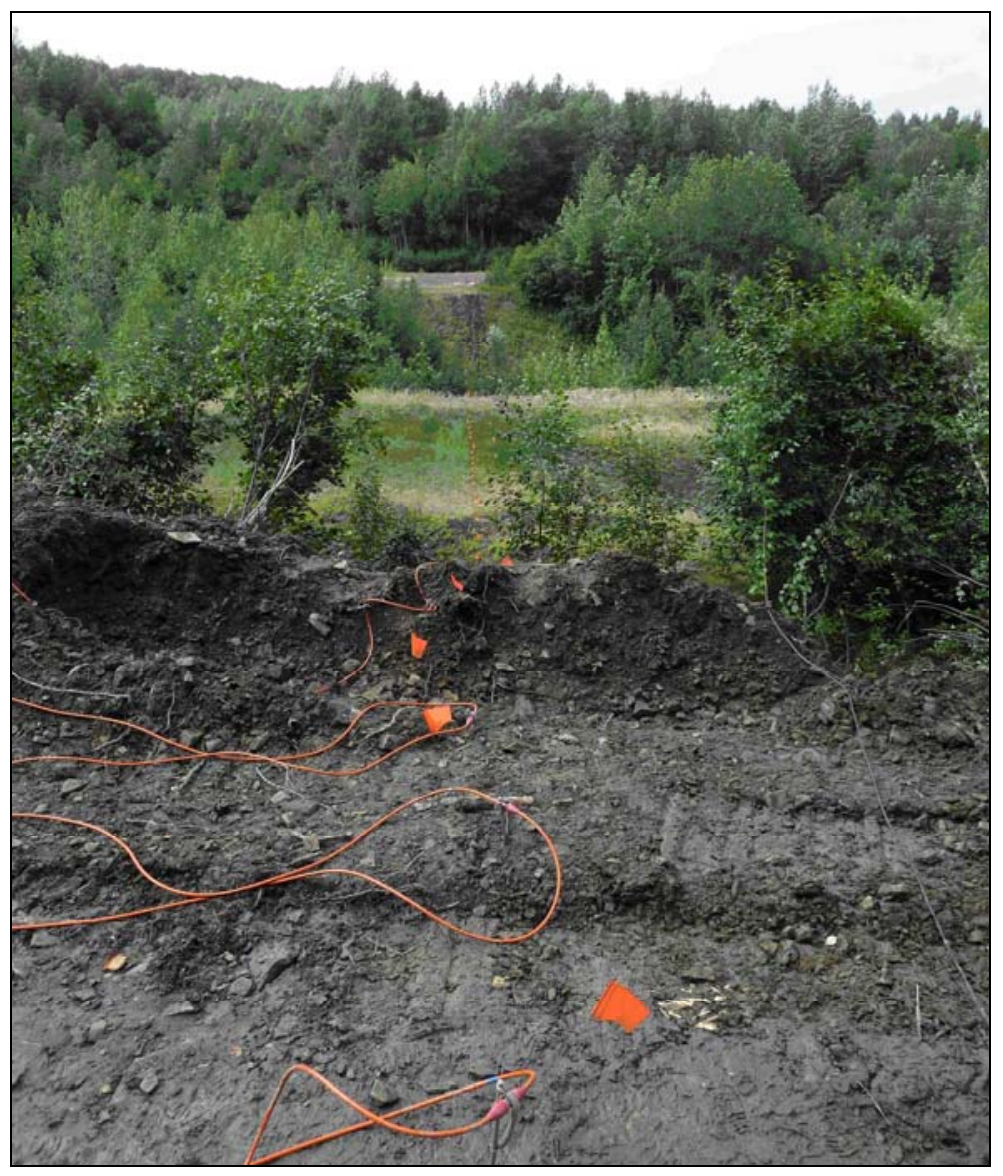

Figure 10. Photograph of the DC resistivity equipment deployed on line 3 taken from monofill \#2, looking northwest.

gravel layer throughout the sections with sandstone encountered at the base of B05. No water level was indicated for B05 (Harding Lawson Associates/Wilder Construction, 2001). The relatively flat alternating layers observed on the north side of the creek on line 3 may be indicating changes in water content due to subtle variations in grain sizes that were not observed during drilling.

The highly conductive layer (less than $30 \mathrm{ohm}-\mathrm{m}$ ) from $84-110 \mathrm{~m}$ downline distance that is interpreted as the saturated layer below the alternate water level (fig. 11) is interesting because of its proximity to the spring. The character and shape of this feature, however, do not resemble a point source feeding the spring but rather a feature that would promote more widespread seepage across the slope leading down to the creek. Although the survey area was wet during most of the survey from the frequent rain, seepage was not observed on this slope and it has not been previously reported. There is a discrete, nearly vertical, conductive anomaly that extends to within $2 \mathrm{~m}$ of the surface (anomaly E) that is closer to the creek level and has a character more indicative of a point source. Anomaly D that was observed on lines $2 \mathrm{a}$ and $2 \mathrm{~b}$ is also observed on line 3 , and it is therefore a feature below the creek that extends for a minimum length of $60 \mathrm{~m}$.

A competent bedrock contact is not interpreted along this profile, because the resistivity values at depth are generally lower as compared to lines $1,2 \mathrm{a}$, and $2 \mathrm{~b}$, and there is no additional evidence as to the depth of bedrock in this area. The interpreted bedrock contact at the line 1 intersection is at $63 \mathrm{~m}$ elevation, which is just below the depth of investigation of line 3 at this location and is therefore 

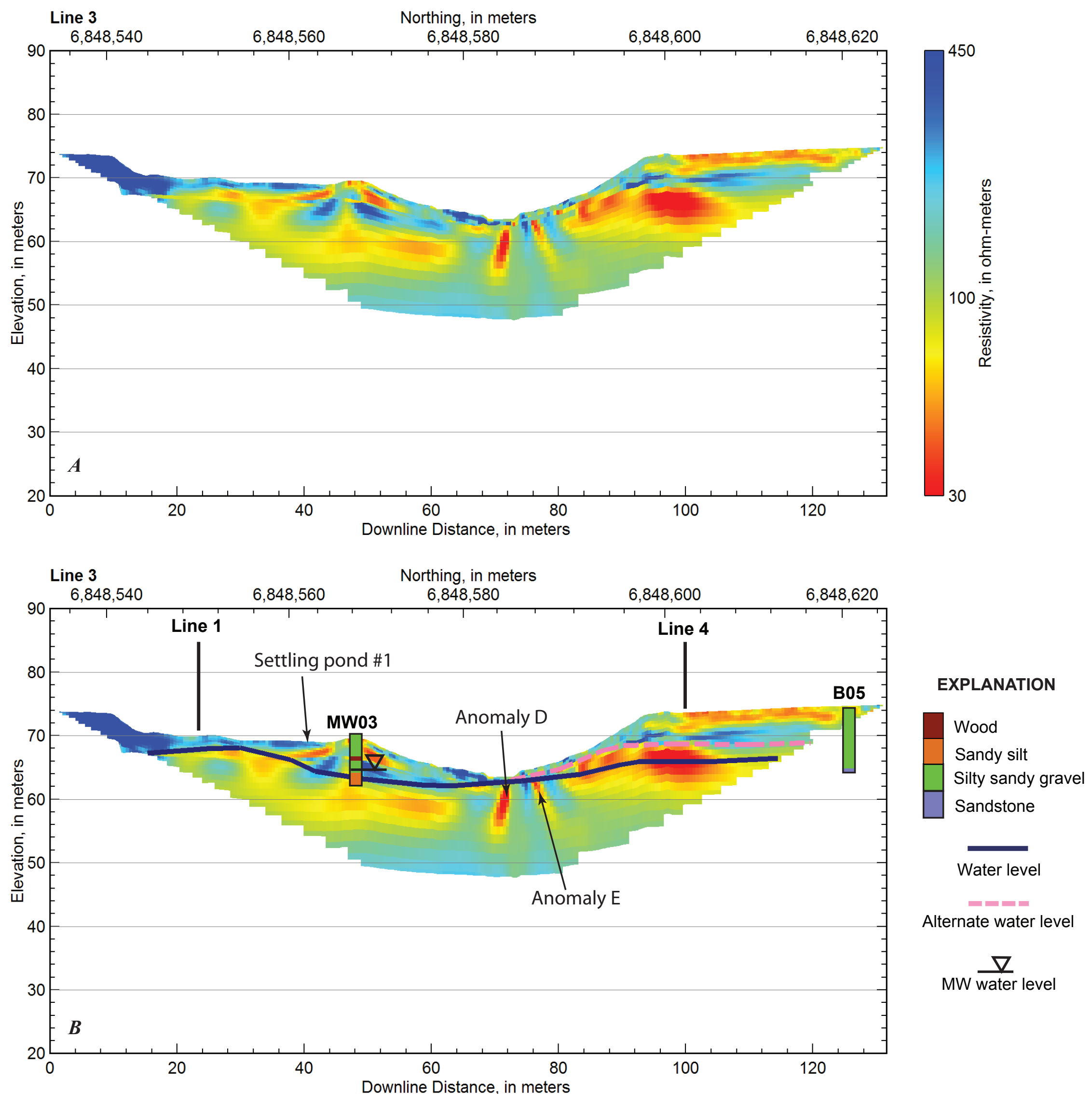

Figure 11. Line 3 inverted resistivity profiles that are $(A)$ uninterpreted and $(B)$ have interpretive annotations and soil boring logs displayed for well

MW03 and soil boring B05. The locations of the cross-line intersections are shown. The blue water level interpretation abides by the MW04 measured water

level, and the pink dashed alternate water level is based on similar resistivity transitions observed on the south side of the creek. 
consistent with the line 1 interpretation. The high resistivity feature observed from $0-20 \mathrm{~m}$ downline distance is interpreted to be a result of the road construction and loose material present on the slope down to the settling pond.

Line 3 passes over the western side of settling pond \#1, where the surface layer is more resistive than the highly conductive surface layer observed on the eastern half of the pond crossed by line 1 . For all three ponds, the conductive surface anomaly observed on line 1 (fig. 6) is strongest on the downgradient side of the pond against the berm.

Line 4

Line 4 was acquired across the pre-1955 retort area as close as possible to the spring feeding into Red Devil Creek (fig. 12). The objective was to image a possible spring source, but no source was observed on this profile (fig. 13). Access for placement of a resistivity line was difficult owing to the steep slope and dense trees immediately above the spring. The line was located on the cleared pre-1955 retort area as close to the top of the slope that parallels the creek and as far northeast as possible, but access to the northeast was limited by trees.

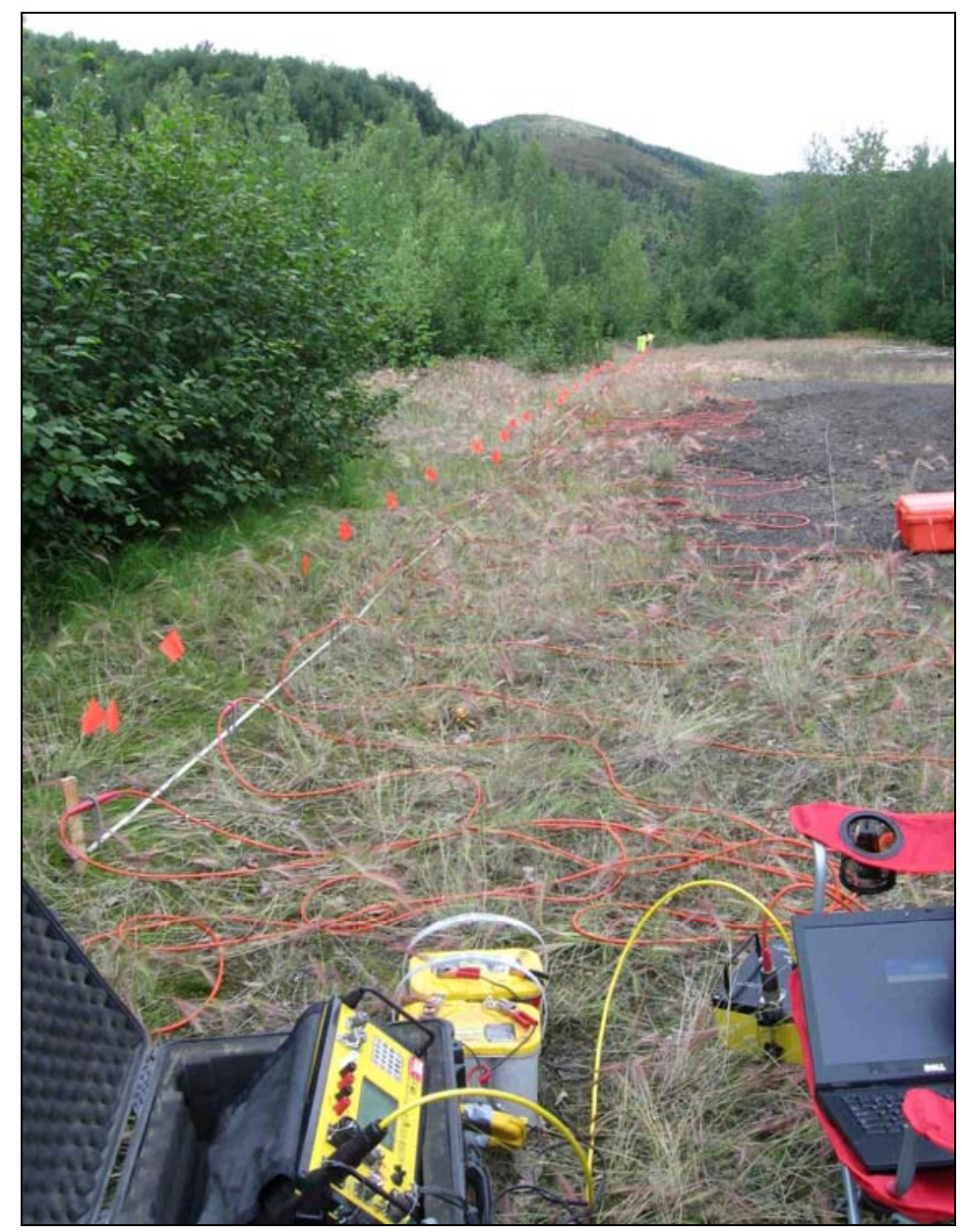

Figure 12. Photograph of the DC resistivity equipment deployed on line 4 across the pre-1955 retort area, looking southwest. 
Line 4

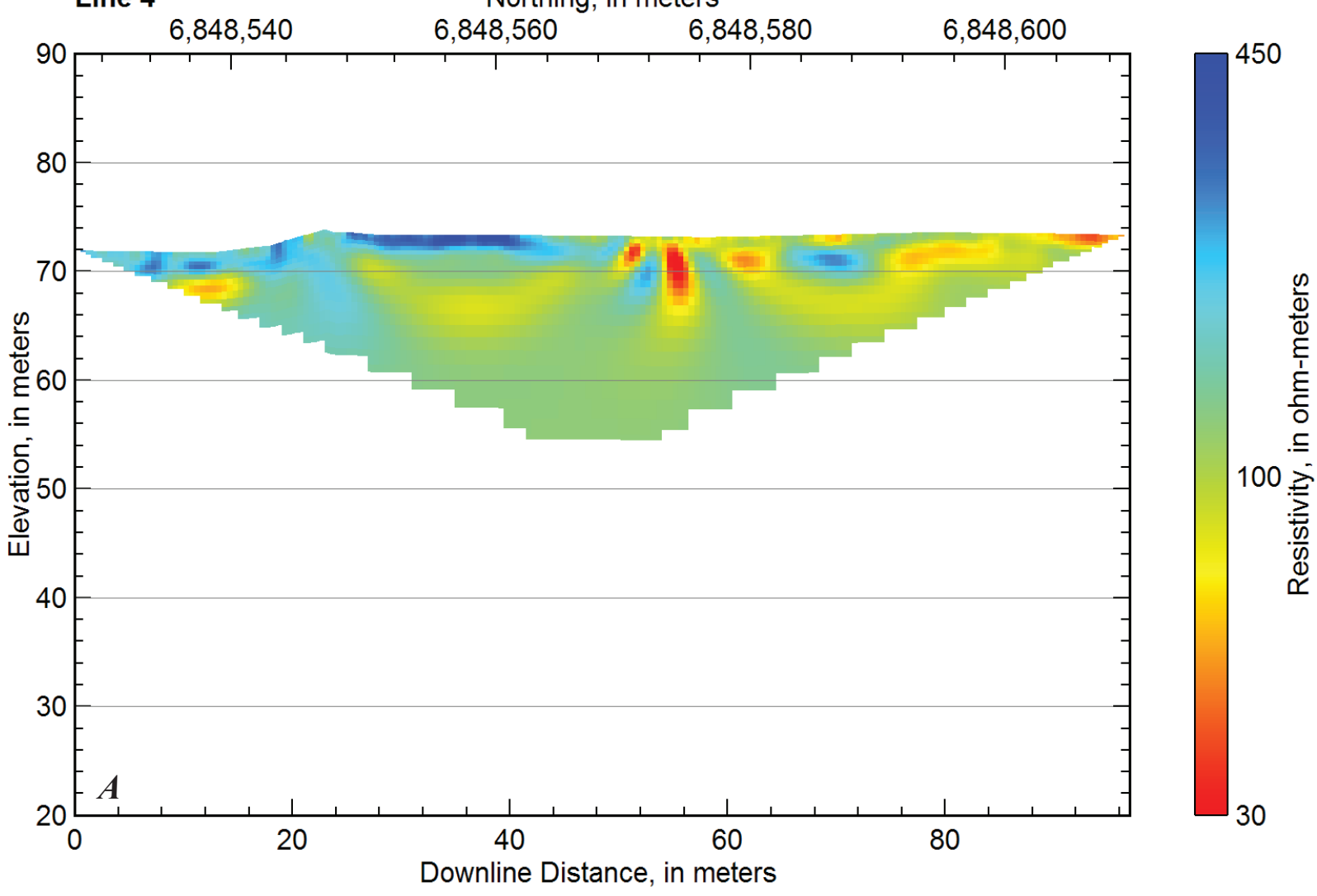

Line 4

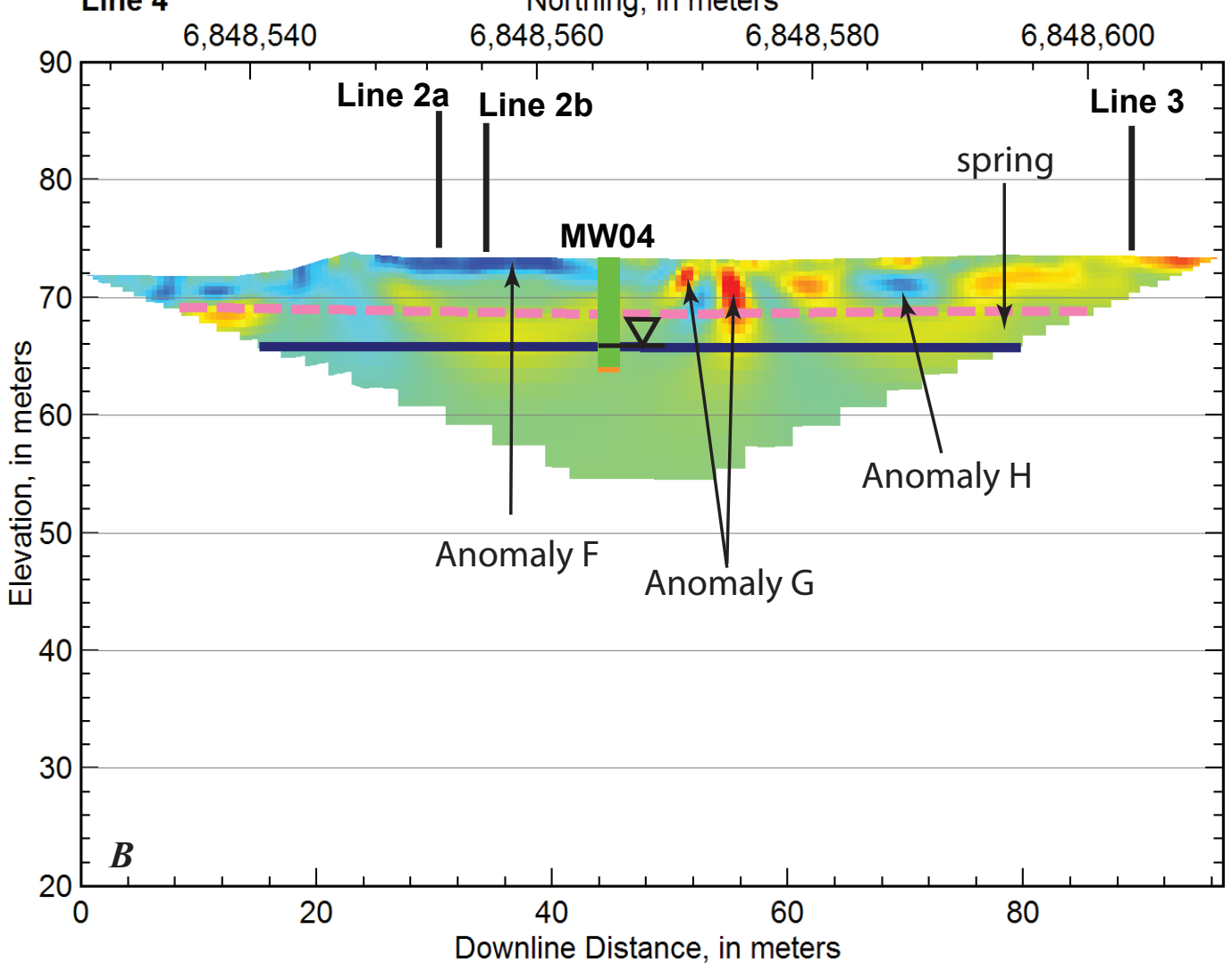

\section{EXPLANATION}

Sandy gravelly silt

Silty sandy gravel

Water level

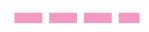

Alternate water level

MW $\frac{\nabla}{\text { water level }}$

Figure 13. Line 4 inverted resistivity profiles that are $(A)$ uninterpreted and $(B)$ have interpretive annotations and soil boring log displayed for well MW04. The locations of the cross-line intersections are shown. The blue water level interpretation abides by the well MW04 measured water level, and the pink dashed alternate water level is based on similar resistivity transitions observed on the south side of the creek. 
The water level that corresponds to well MW04 is presented but does not correlate with an increasingly conductive transition in the resistivity section as would be expected below the water table. An alternate water level is presented that correlates better with the resistivity section and is consistent with the alternate water levels interpreted on lines $2 a, 2 b$, and 3 .

There are several features observed in the top $5 \mathrm{~m}$ of this profile, but the ground surface across the profile did not indicate any obvious changes. There is a 2-m thick high resistivity feature (greater than $400 \mathrm{ohm}-\mathrm{m}$ ) on the surface (anomaly F) that may be a result of being reworked or regraded at some time. The two conductive anomalies (less than $30 \mathrm{ohm}-\mathrm{m}$; anomaly $\mathrm{G}$ ) with a resistor centered between would be interpreted as possible shallow buried metallic objects that are not well resolved, but the threedimensional dataset presented next better resolves this feature. Anomaly $\mathrm{H}$ exhibits the character of an 8-m wide trench or pit about $4 \mathrm{~m}$ deep, but it may only be lateral discontinuity due to grain size variations.

\section{Three-Dimensional Grid}

The three-dimensional resistivity dataset was acquired (fig. 14) after observing the complicated resistivity structure exhibited by the two-dimensional resistivity lines $2 a, 2 b, 3$, and 4 on the north side of Red Devil Creek. The objectives were to better resolve the resistivity structure of what appeared to be three-dimensional features in the two-dimensional profile data as well as an additional attempt to image the source of the spring.

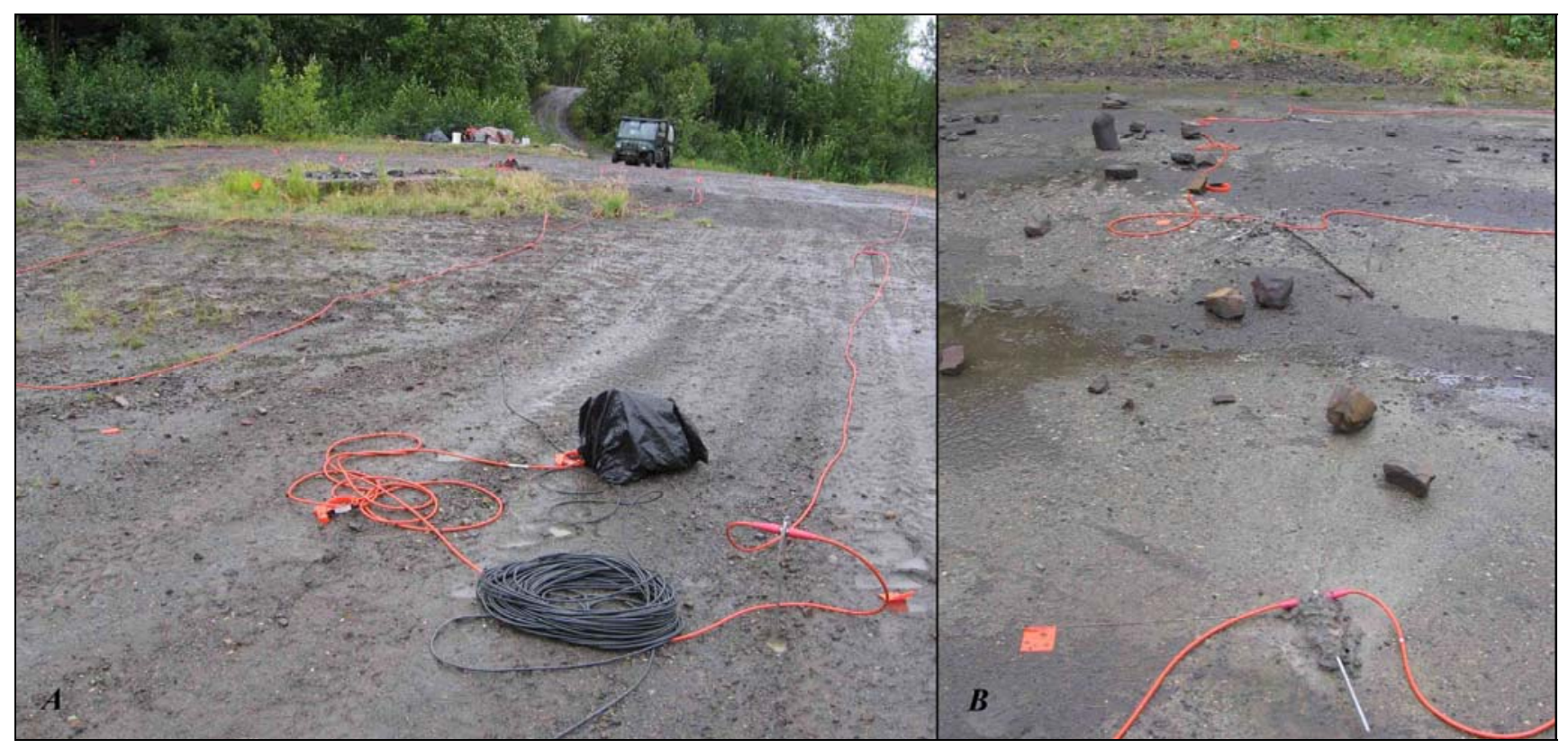

Figure 14. Photographs of the $(A) D C$ resistivity equipment deployed on the three-dimensional grid across the pre-1955 retort area, from the southeast corner of the grid looking northeast and $(B)$ the three electrodes along the southwest edge of the grid placed on the concrete using bentonite mud, looking northwest.

The maximum modeled depth of investigation is $13.5 \mathrm{~m}$. The depth of investigation is shallower than for the profiles because of the reduced maximum possible separation between the current and potential electrode pairs. The origin is on the southeast corner with negative $\mathrm{x}$ along the short axis in the northwest direction and positive $\mathrm{y}$ along the $\mathrm{x}$-axis in the northeast direction. 
The surface resistivity of the block exhibits similar trends to the 93,030 Hz apparent conductivity data with lower resistivity areas in the southwest corner and north of the main shaft (fig. 15a). There are several discrete resistive features throughout the volume, and only one of these features extends to the bottom of the model. This anomaly is below the concrete pad (centered at about $-20 \mathrm{~m}$ on the $\mathrm{x}$ axis) along the southwest side and may be an artifact of the presence of the pad. The bottom of the anomaly becomes shallower and ends at about $10 \mathrm{~m}$ along the y axis, indicating that it may be due to the three electrodes placed on the concrete pad not properly resolving the subsurface below the concrete. The resistive anomaly centered at $18 \mathrm{~m}$ on the y axis is below anomaly $\mathrm{G}$ on line 4 (fig. 13). There is an indication of two conductive features above the resistor that may correspond with the anomaly $\mathrm{G}$ conductive bodies, and the size of about $8 \mathrm{~m}$ depth by $8 \mathrm{~m}$ wide roughly corresponds with the total size of the two anomaly $\mathrm{G}$ conductors. Although the character of the anomaly in the three-dimensional volume is much different than the character of anomaly $\mathrm{G}$ in the line 4 profile, it is expected that the three-dimensional dataset more correctly imaged the feature, and it is therefore interpreted as a potential trench or landfill that extends north to about $-10 \mathrm{~m}$ on the $\mathrm{x}$ axis. This interpretation is also consistent with a discrete low apparent magnetic susceptibility anomaly in this location presented in the electromagnetic induction results section. There are additional resistive anomalies in the vicinity of the concrete pad that are also consistent with lower measured apparent magnetic susceptibility data (fig. $15 \mathrm{c})$.

It also appears that the main shaft in the upper 5-6 $\mathrm{m}$ is imaged as a resistive anomaly that is about $6 \mathrm{~m}$ square (fig. 15c). At about $-7 \mathrm{~m}$ depth, the resistive feature transitions to a consistent conductive layer that is observed throughout most of the northern half of the volume. There are a couple of shallow resistive features from 30-60 $\mathrm{m}$ along the y axis that also terminate at this conductive layer and may be due to increased water content. This would be consistent with the water level measured in well MW04. However, the conductive layer at depth is not as consistent from 0-30 $\mathrm{m}$ in the y direction but that may be due to the high density of resistive anomalies observed in this region.

\section{Line 5}

The south end of line 5 begins at the base of the steep slope north of the access road on the south side of Red Devil Creek. The line continues immediately east of settling pond \#3, crosses line 1 and Red Devil Creek, and continues across the access road north of the creek and ends about $20 \mathrm{~m}$ short of the clearing of where the petroleum-contaminated soil was seeded earlier in the summer of 2010 . The vegetation was very dense in this area on both sides of the creek (fig. 16), so the orientation of the line was determined by a relatively clear path through the woods that required the minimum amount of tree clearing and that still intersected line 1.

The average resistivity for the profile is moderate (100-200 ohm-m) to depth (fig. 17). Although there are high resistivity layers (greater than $400 \mathrm{ohm}-\mathrm{m}$ ) observed below the interpreted water level, these areas are not consistent enough to make a confident competent bedrock interpretation across the entire profile. Where line 1 intersects line 5, the bedrock appears to drop sharply, and the resistivity structure in line 5 at $38 \mathrm{~m}$ downline distance may possess the same trend. This is also consistent with the absence of highly resistive bedrock on line 3 on the south side of the creek. Bedrock is interpreted to exist, however, from about 80-111 m downline distance on line 5, which corresponds with the north side of the access road to the end of the profile. This section exhibits a very high resistivity (greater than 1,000 ohm-m) with the top 2-3 m consistently higher than the underlying layer. The interpreted 


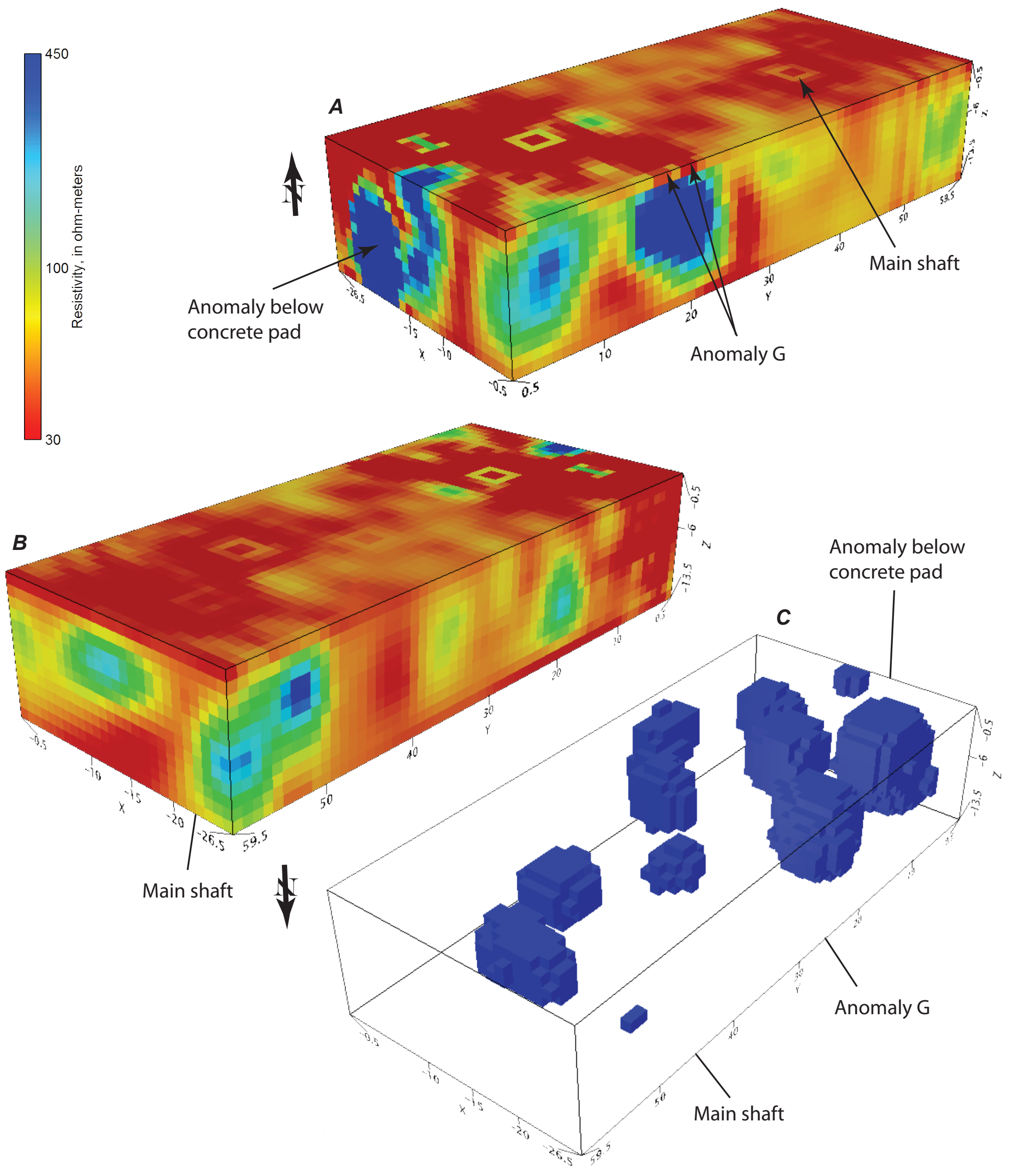

Figure 15. Oblique views of the three-dimensional resistivity inverted volume: $(A)$ looking north, $(B)$ looking south, and (C) a threshold limit of $450 \mathrm{ohm}-\mathrm{m}$ and greater displayed, looking south. 


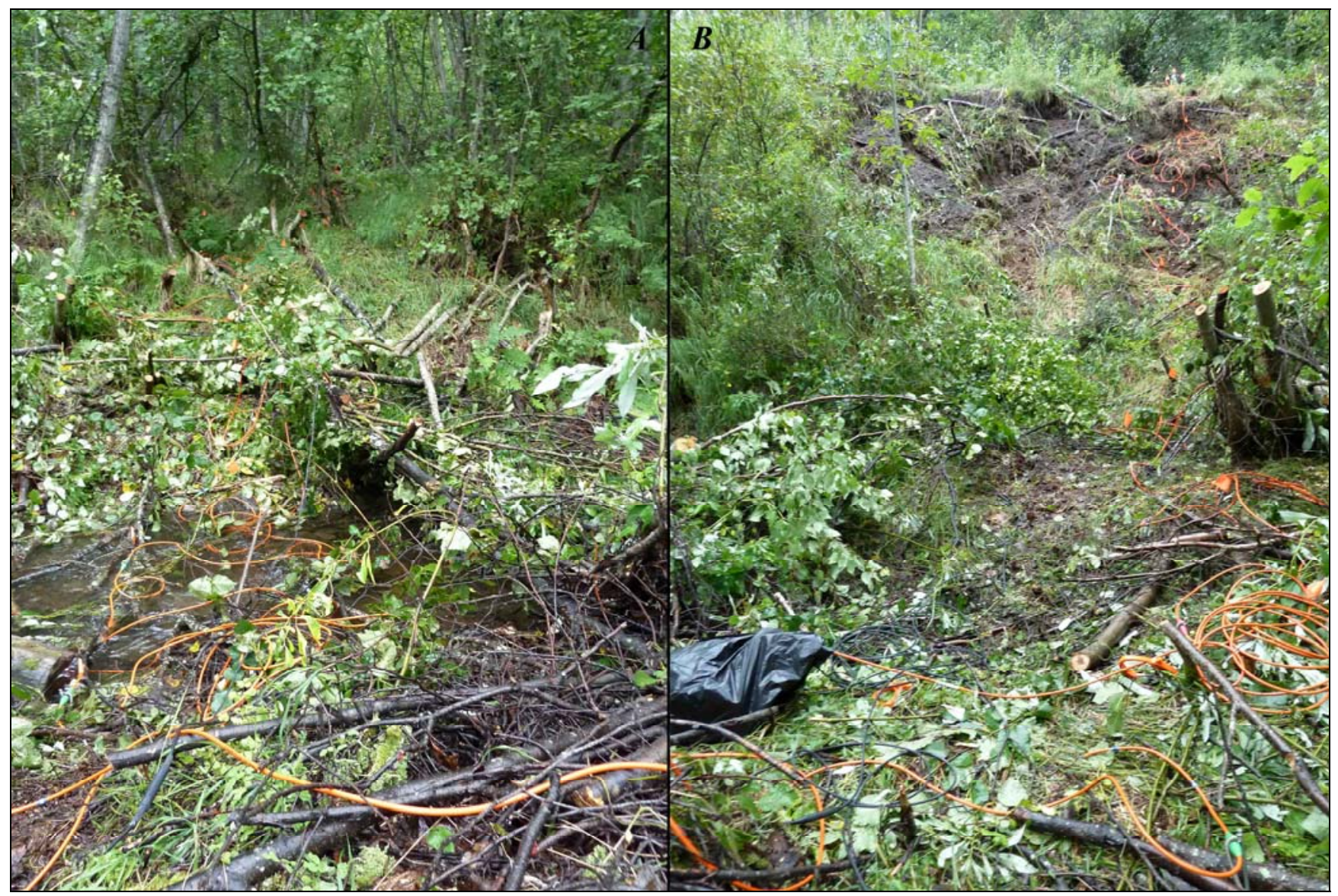

Figure 16. Photographs of the DC resistivity equipment deployed on line $5(A)$ across Red Devil Creek facing the low end of the line toward the southeast and $(B)$ from the same position looking northwest up the steep slope to the access road.

resistivity section in figure $17 \mathrm{~b}$ has a stretched color scale to better display this contrast. The interpretation is a water level that generally follows topography through the bedrock, but another possibility is a relatively consistent soil horizon overlying bedrock with a water level remaining deeper, near $62 \mathrm{~m}$ elevation, across the last quarter of the resistivity profile. The well MW06 lithology log indicates gravel throughout, which would generally show as a resistor, but no additional data are available to aid in the interpretation.

The surface topography along the high resistivity section from $80 \mathrm{~m}$ to the end of the profile appears terraced but is interpreted as artificial terracing from mining activity. The terraced topography is observed on line 6 as well, but the absence of similar terracing along the banks of McCally Creek, located about $1.1 \mathrm{~km}$ downstream (north) on the Kuskokwim River from Red Devil Creek, is not observed.

There is a discrete, vertical conductive feature at $90 \mathrm{~m}$ downline distance that is coincident with the interpreted water level (anomaly I), but its cause is not known. There is also a conductive feature immediately north of the creek that is similar to anomaly D noted in lines $2 a, 2 b$, and 3 but much shallower and has slightly higher resistivity $(30-50 \mathrm{ohm}-\mathrm{m})$. 

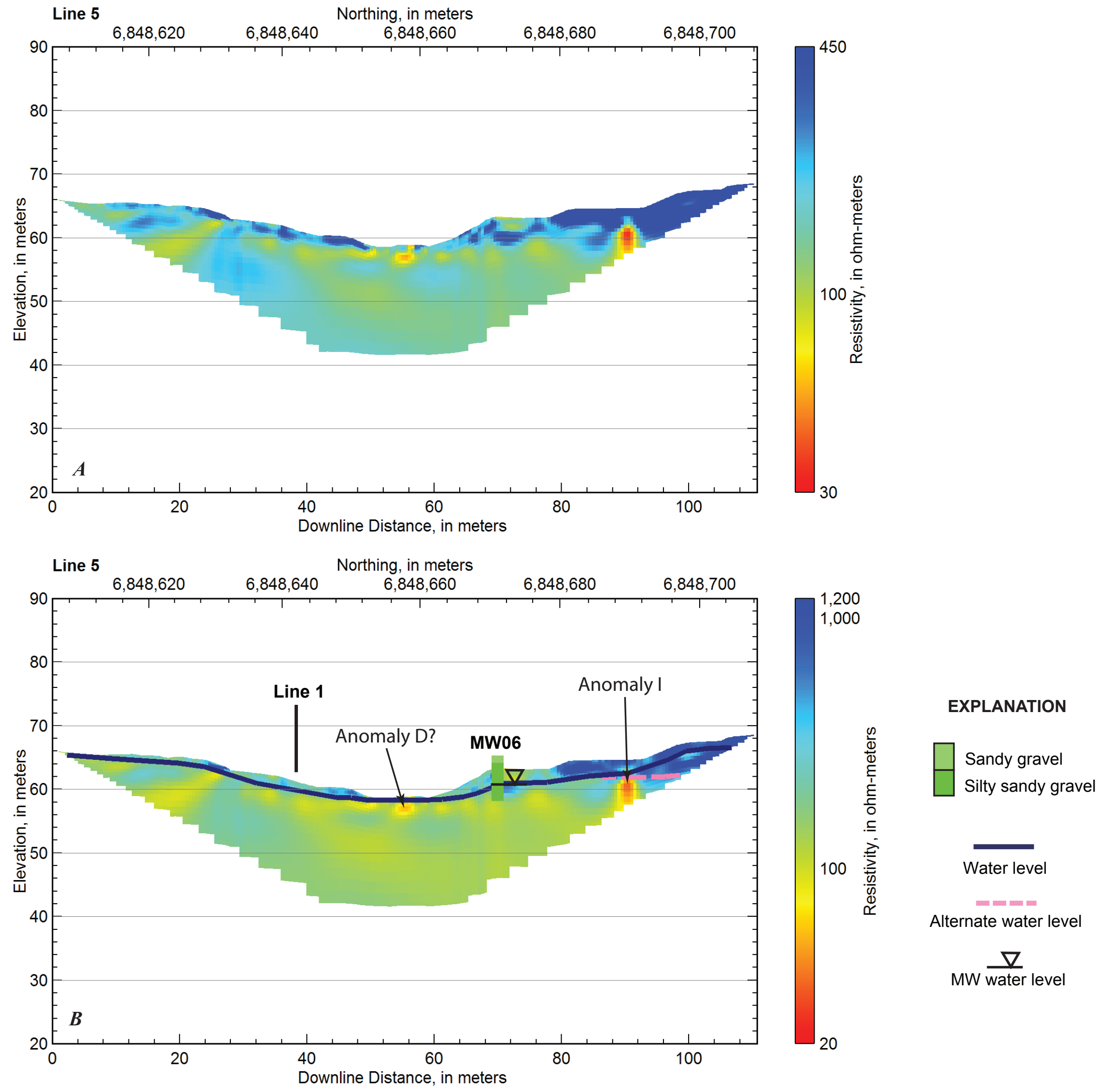

Figure 17. Line 5 inverted resistivity profiles that are $(A)$ uninterpreted and $(B)$ have interpretive annotations and soil boring log displayed for well MW06 with a stretched color scale to better display the variations in the high resistivity section on the north side of Red Devil Creek. The location of the line 1 intersection is shown. 


\section{Line 6}

Line 6 was located further downstream than originally proposed, because the original location was densely forested with no obvious path through the trees to deploy the equipment. The construction of the bridge across Red Devil Creek earlier in the summer provided a clear route across the creek in an area that was still upstream of the creek delta. Line 6 , from southeast to northwest, started in the moderately forested section, continued over a pile of rock, fine sediments, and small pieces of wood debris, continued across the support slope of the bridge that was mostly cobble-sized rip-rap or ballast material with minor amounts of finer grained sediments, crossed the creek and access road, and proceeded up a near-vertical slope to the more gently sloped and thinly forested area for the remainder of the profile (fig. 18).

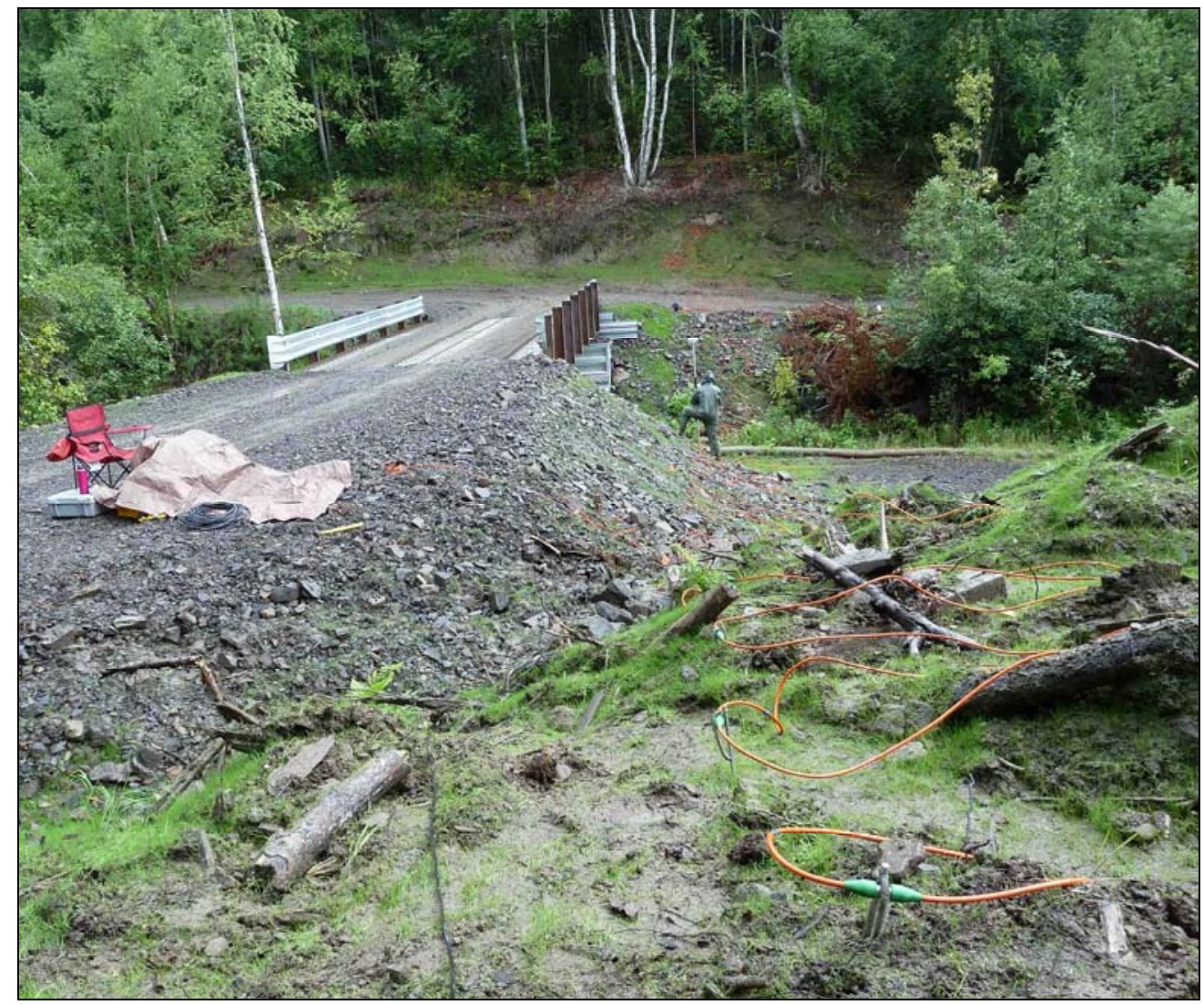

Figure 18. Photograph of the DC resistivity equipment deployed on line 6, looking northwest.

The line 6 resistivity section has an overall higher resistivity than any other profile acquired at the site. Figure $19 \mathrm{~b}$ presents the interpreted section of line 6 with the same stretched color scale used for line 5 to better show detail, but there is no resistivity cross-line to compare this profile with and no monitoring wells or soil borings. As observed on line 5, the area north of the access road is highly resistive (greater than 1,000 ohm-m) and is interpreted as bedrock. The very conductive anomaly (less than $20 \mathrm{ohm}-\mathrm{m}$ ) centered below the creek (anomaly J) is much wider than the anomaly D feature discussed on the previous lines that crossed the creek, and it may be an unrelated feature. The shape of the conductor is most likely not well resolved, because its upper surface tends to mimic the topographic features. 

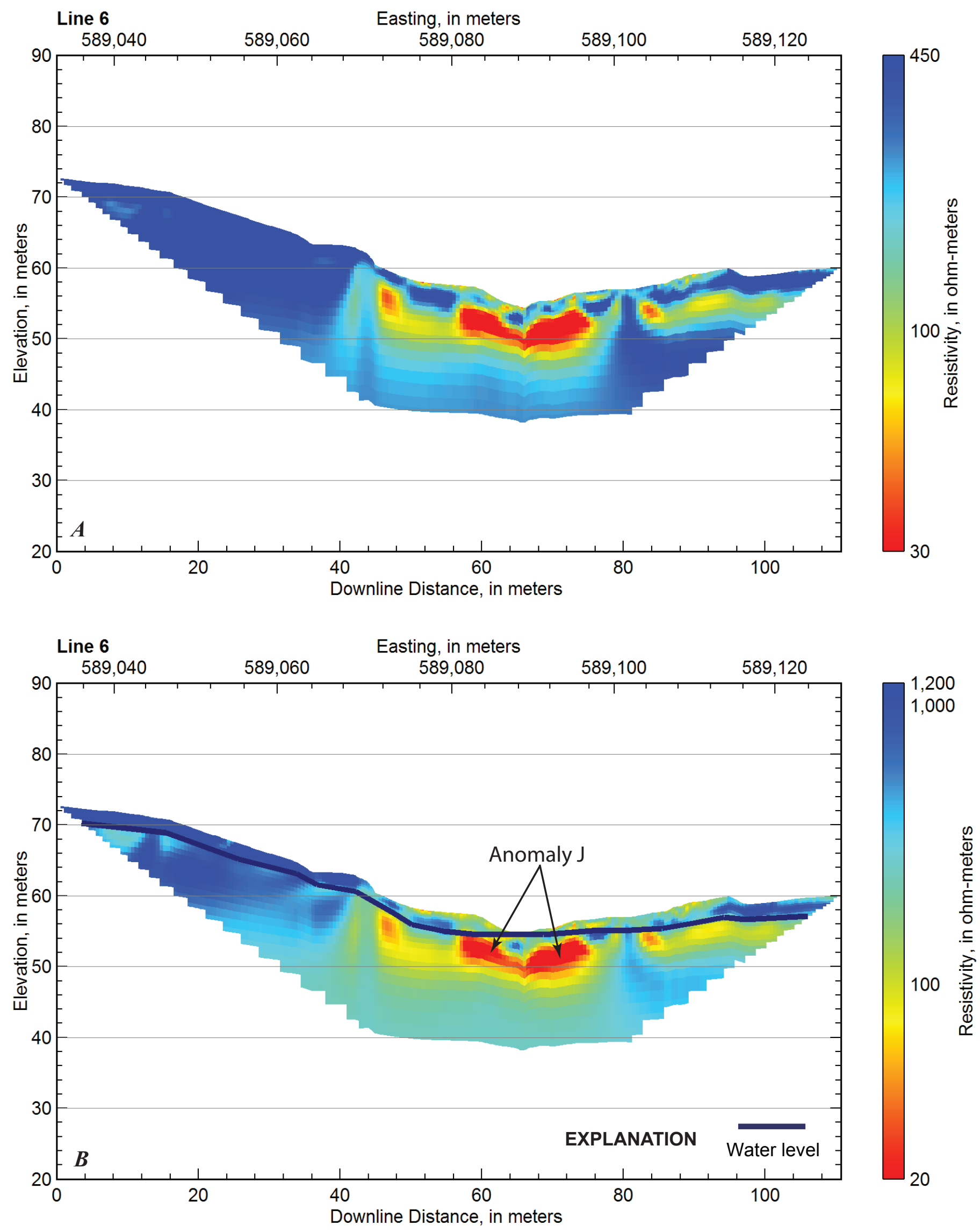

Figure 19. Line 6 inverted resistivity profiles that are $(A)$ uninterpreted and $(B)$ have interpretive annotations with a stretched color scale to better display the variations throughout the profile. There are no nearby soil borings and no line intersections. 
Although this line contained noisier data than the other profiles, it is thought to be due to the nearly vertical slope on the north side of the access road at $44 \mathrm{~m}$ downline distance. It was necessary to smooth the topography across the slope in order to complete the inversion. The resolution of the features at depth below this slope is questionable, because data were removed to achieve a better inverted model fit (see the pseudosection in appendix A).

A water level was interpreted across the profile with depths to the saturated zone between 0 and $3 \mathrm{~m}$. The water level is interpreted in a consistent manner with line 5 and follows topography from 0-44 $\mathrm{m}$ downline distance through what is interpreted to be bedrock. The water level is interpreted to intersect with the creek bed for consistency with the other DC resistivity profiles that cross the creek, but the presence of highly resistive areas (greater than $450 \mathrm{ohm}-\mathrm{m}$ ) between the ground surface and anomaly $\mathbf{J}$ make this interpretation less certain. If the entire section is composed of bedrock with varying degrees of saturation and weathering, then the water level may intersect the creek bed because competent, saturated bedrock can have such high resistivity values.

An interpreted bedrock surface is not presented for this line, however, because the low resistivity values of anomaly $\mathrm{J}$ may be masking the real resistivity structure at depth below the anomaly. Current will preferentially flow through conductive zones and may not properly resolve the subsurface below strong conductors. The resistivity structure from 80-111 $\mathrm{m}$ downline distance is also highly resistive but with a moderately resistive $(80-150 \mathrm{ohm}-\mathrm{m})$ layer that is interpreted to be saturated alluvium or weathered bedrock. Without the aid of lithologic logs, it is impossible to make confident interpretations of the features observed in this profile.

\section{Line 7}

Line 7 was acquired across the upper part of the Red Devil Creek delta below the narrow creek valley. The line was located along the access road that parallels the Kuskokwim River and extended across the creek to a densely wooded area (fig. 20).

The resistivity section generally contains a two-layer resistivity structure with a more resistive (300-450 ohm-m) layer ranging in thickness from 2 to 5 m overlying a moderately resistive layer (70$150 \mathrm{ohm}-\mathrm{m}$ ) that extends to depth (fig. 21). This section is interpreted to be unsaturated and saturated alluvial deposits. Variations observed in the saturated section may be due to differences in grain size distributions within the alluvium.

There is an indication at the base of the resistivity section (about $35 \mathrm{~m}$ elevation) of a more resistive layer at depth. The lower layer is interpreted as weathered bedrock but could also be more consolidated alluvium. Because resolution of resistivity profiles decreases with increasing depth of investigation, a specific interpreted contact for this lower layer is not possible. The creek bed elevation corresponds precisely with the measured river level within two days of acquiring line $7(51.5 \mathrm{~m}$ elevation). There are no nearby soil borings or monitoring wells with which to correlate this resistivity profile. 


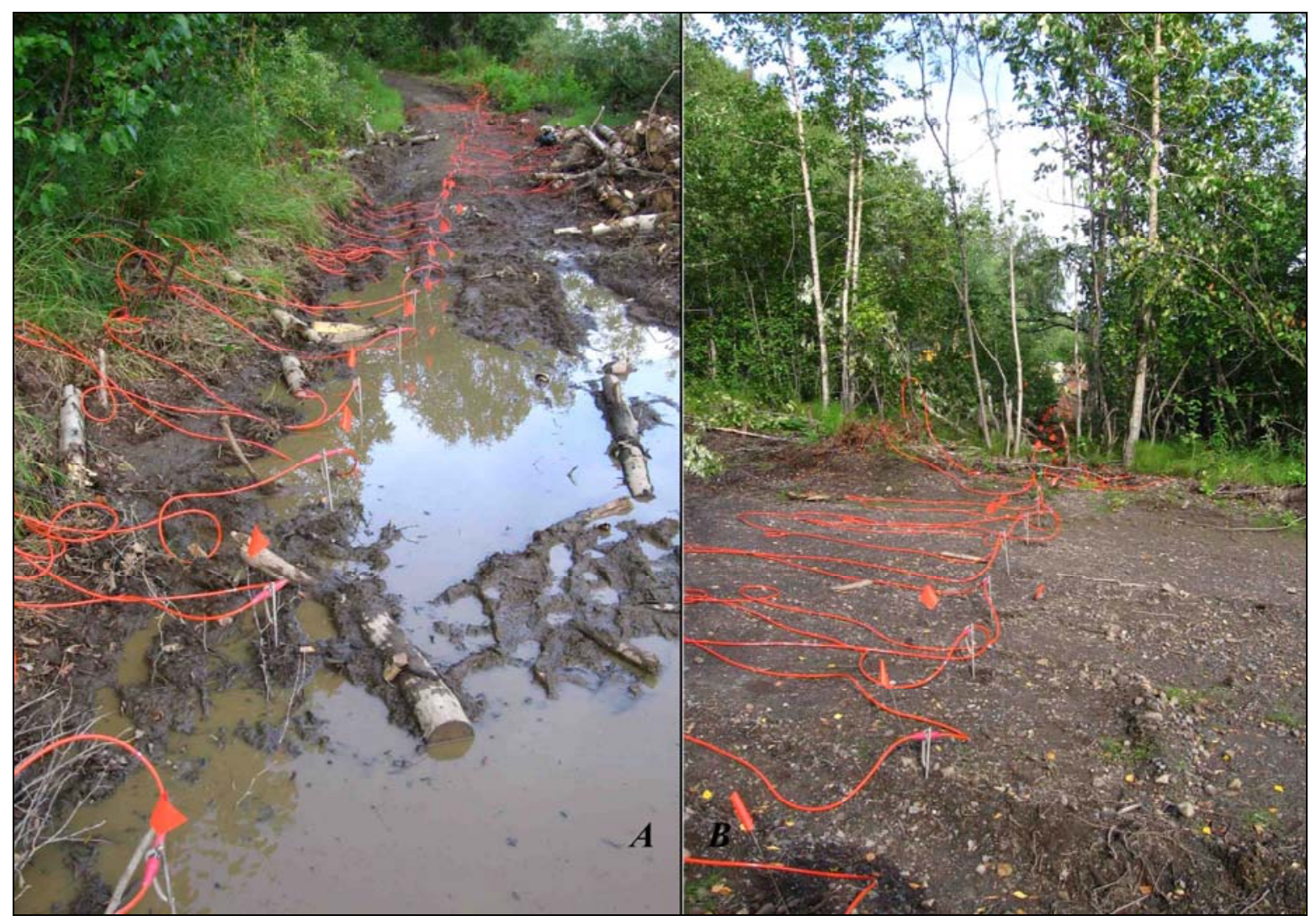

Figure 20. Photographs of the DC resistivity equipment deployed on line 7, $(A)$ looking northwest along the access road and $(B)$ from the southeast end of the line looking northwest toward Red Devil Creek in the trees.

\section{Electromagnetic Induction}

The apparent conductivity maps of the site are presented for two frequencies: the highest frequency, 93,030 Hz (fig. 22), and a middle frequency, 19,110 Hz (fig. 23). A 93,030 Hz apparent magnetic susceptibility map is also presented. The EMI data have been drift-leveled and filtered, but without calibration, the absolute calculated apparent conductivity and magnetic susceptibility values are not correct. The relative variations in these values, however, are useful in mapping anomalies and correlating with the DC resistivity data. Figures 22 and 23 are plotted on the same color scale for direct comparison between the two datasets. The most prominent conductive anomalies observed on the 93,030 Hz dataset, however, are very similar between the two datasets.

The highest-frequency apparent conductivity data contain the highest conductivity values over monofill \#2 and in the vicinity of monofill \#1 and the two concrete pads (fig. 22). Much of the pre-1955 retort area has higher conductivity values than the majority of the site and is not confined to monofill \#1 and the concrete pads, which is consistent with the consistent conductive surface layer observed along DC resistivity lines $2 \mathrm{a}$ and 3 in this area (figs. 8 and 11). The very low conductivity area (dark blue) between the northeast side of the L-shaped concrete pad and soil boring B05 are measured values, but the extension of the low conductivity data along the northwest side of the concrete pad along the edge of the grid is a gridding extrapolation artifact. Because both B05 and well MW04 are described as mostly sandy silty gravel and because the same low values are not observed in the apparent conductivity map 

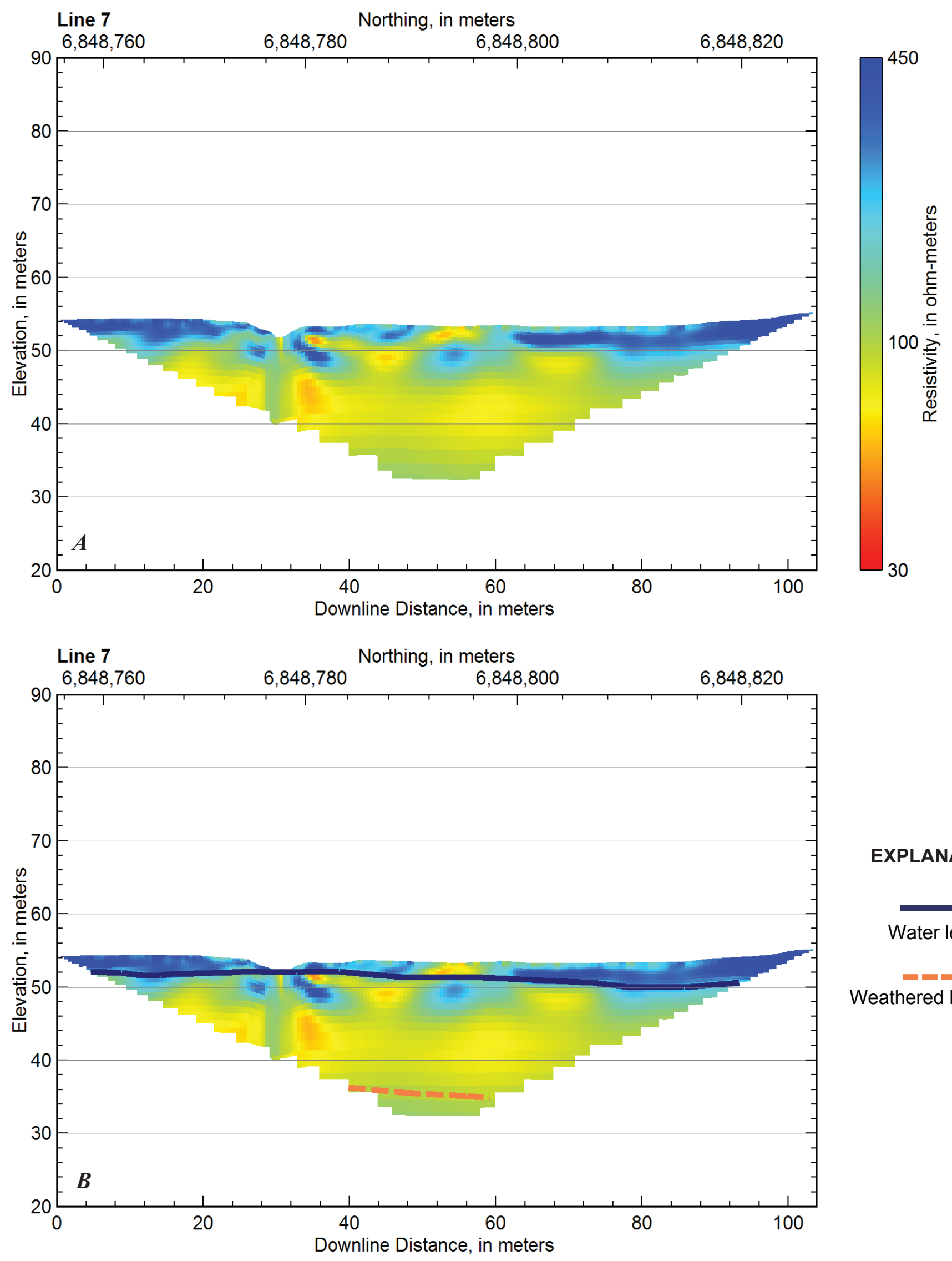

EXPLANATION

Water level

뜸ㅁㅁ

Weathered bedrock

Figure 21. Line 7 inverted resistivity profiles that are $(A)$ uninterpreted and $(B)$ have interpretive annotations. The interpreted weathered bedrock is an approximate contact. There are no nearby soil borings and no line intersections. 


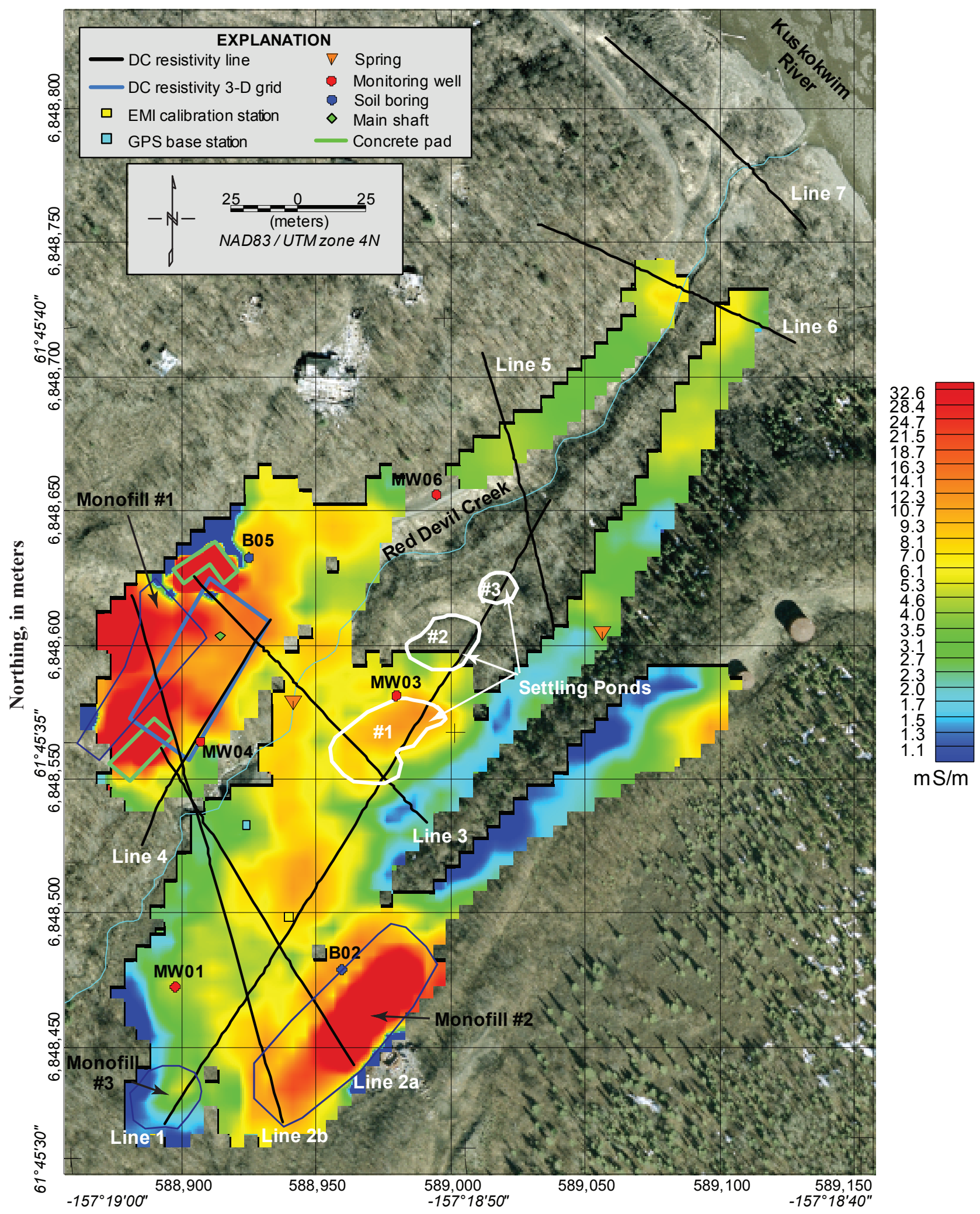

Easting, in meters

Figure 22. Map showing apparent conductivity data for $93,030 \mathrm{~Hz}$. The absolute apparent conductivity values are not correct because they have not been calibrated with the DC resistivity data, but the relative variations are useful for identifying anomalies. The monofill and settling pond outlines are approximate and based on historical photographs. 


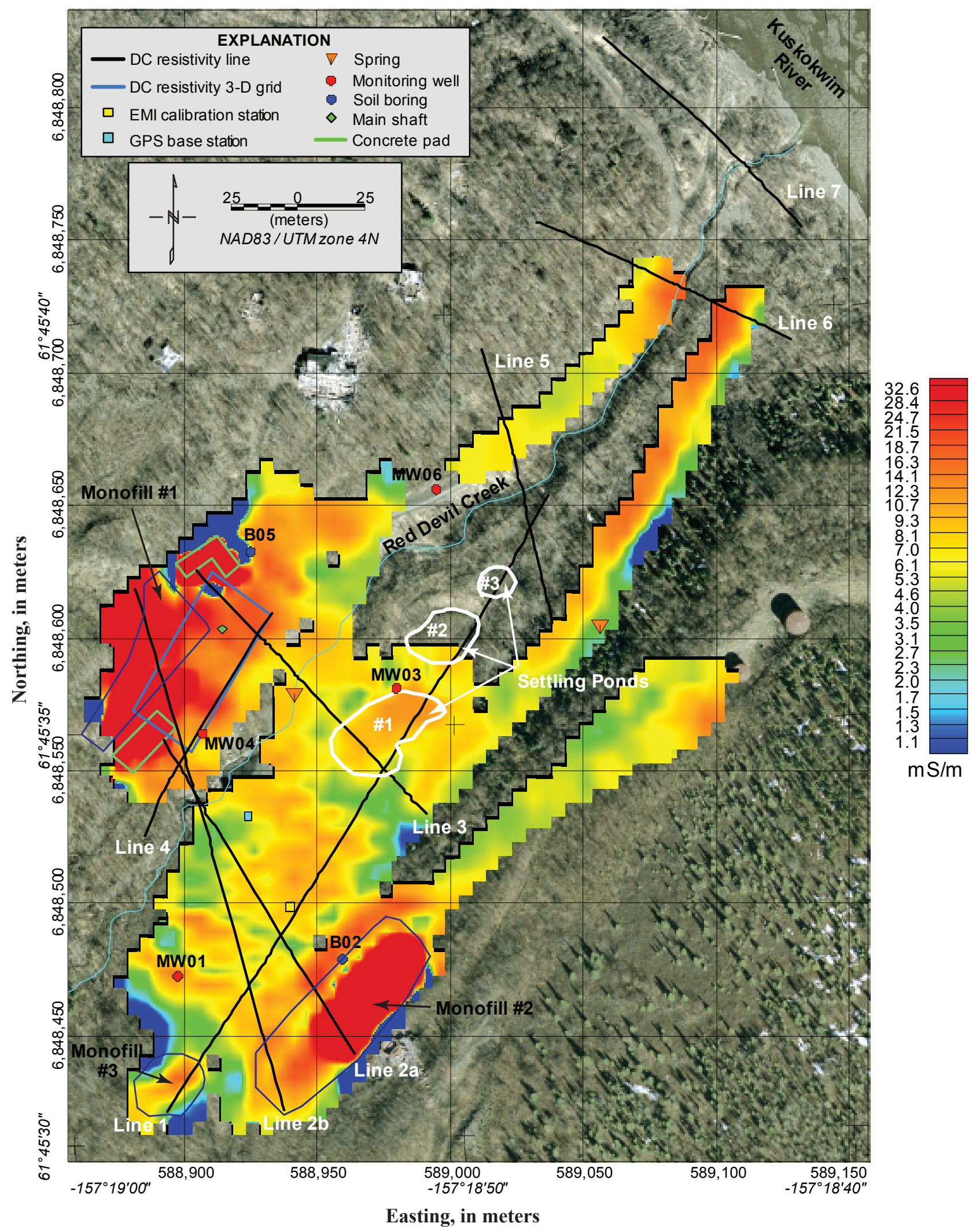

Figure 23. Map showing apparent conductivity data for $19,110 \mathrm{~Hz}$. The absolute apparent conductivity values are not correct because they have not been calibrated with the DC resistivity data, but the relative variations are useful for identifying anomalies. The monofill and settling pond outlines are approximate and based on historical photographs. 
near MW04, the observed low conductivity anomaly near B05 is not related to grain size and is most likely not due to changes in water content because of its discrete nature.

On the south side of Red Devil Creek, the boundary of settling pond \#1 is well defined and has moderately more conductive values compared to the surrounding area. Similar conductivity values exist in the recently regraded area to the north and east of the EMI calibration station where the petroleumcontaminated soil was stored for several years before disposal (anomaly A), along the road leading down to the creek, and along the creek past the spring. On the basis of line 1, anomaly A increases in conductivity below the interpreted water level, which may indicate that finer-grained sediments are present in this area.

The low conductivity (blue) areas along the road leading to the above-ground storage tank area and along the southern and western edges of monofill \#3 are interpreted as shallow bedrock. Although there is only a weak response from monofill \#3 in the $93,030 \mathrm{~Hz}$ dataset, it becomes better defined in the lower frequency $19,110 \mathrm{~Hz}$ dataset (fig. 23). In general, the 19,110 Hz dataset is more conductive than the highest $93,030 \mathrm{~Hz}$ dataset and is interpreted to be a result of increased water content at depth.

The 93,030 Hz apparent magnetic susceptibility data highlight all three monofills and the two concrete pads (fig. 24). The concrete pads most likely possess elevated magnetic susceptibilities owing to rebar. The monofills were expected to have elevated values as well, and in particular monofill \#3, because it contains the steel remains of the hopper and above-ground storage tanks. Monofills \#1 and \#2 were described as containing building debris, but a photo taken during construction of monofill \#1 (Bureau of Land Management, 2010) shows mostly wood debris with several tires as well as several metal drums. The drums do not appear to produce an elevated signature as expected. One possible explanation for the observed low values is that the tailings, waste rock, alluvium, or bedrock that existed in the areas of these monofills prior to construction was removed and replaced with lower-magneticsusceptibility material.

There is no indication in either the apparent conductivity or magnetic susceptibility datasets of a potential source for the spring that feeds into Red Devil Creek. No linear features or discrete conductive zones in the vicinity of the spring are observed. Delineation between waste rock and tailings is not feasible without additional borehole data to possibly help identify distinguishing electromagnetic characteristics between the rock types. Assuming that these data would produce similar results to the DC resistivity models when inverted and without the aid of additional soil borings with more specific descriptions identifying waste rock, tailings, and alluvium or weathered bedrock, a volume of tailings and waste rock cannot be estimated at this time.

\section{Summary and Discussion}

The DC resistivity and EMI data acquired in August 2010 at Red Devil mine have provided subsurface information about the site, but available soil borings that sample deeper than $2 \mathrm{~m}$ are sparse. Figure 25 displays the annotated anomalies from the DC resistivity data on a map to better illustrate the spatial relationships between those anomalies and other site features. A georeferenced .DXF file containing these anomalies is included in appendix B.

The EMI data were presented as frequency-dependent apparent conductivity and apparent magnetic susceptibility maps and have not been calibrated and inverted. Inverted EMI data provide resistivity depth images similar to the DC resistivity sections but at a generally lower resolution. The success of the inversion is dependent on the quality of the original EMI data acquired and the robustness of the DC resistivity inversions used to calibrate the EMI data. If successful, inverted EMI data can provide additional useful information to help distinguish between rock types in the shallow subsurface 


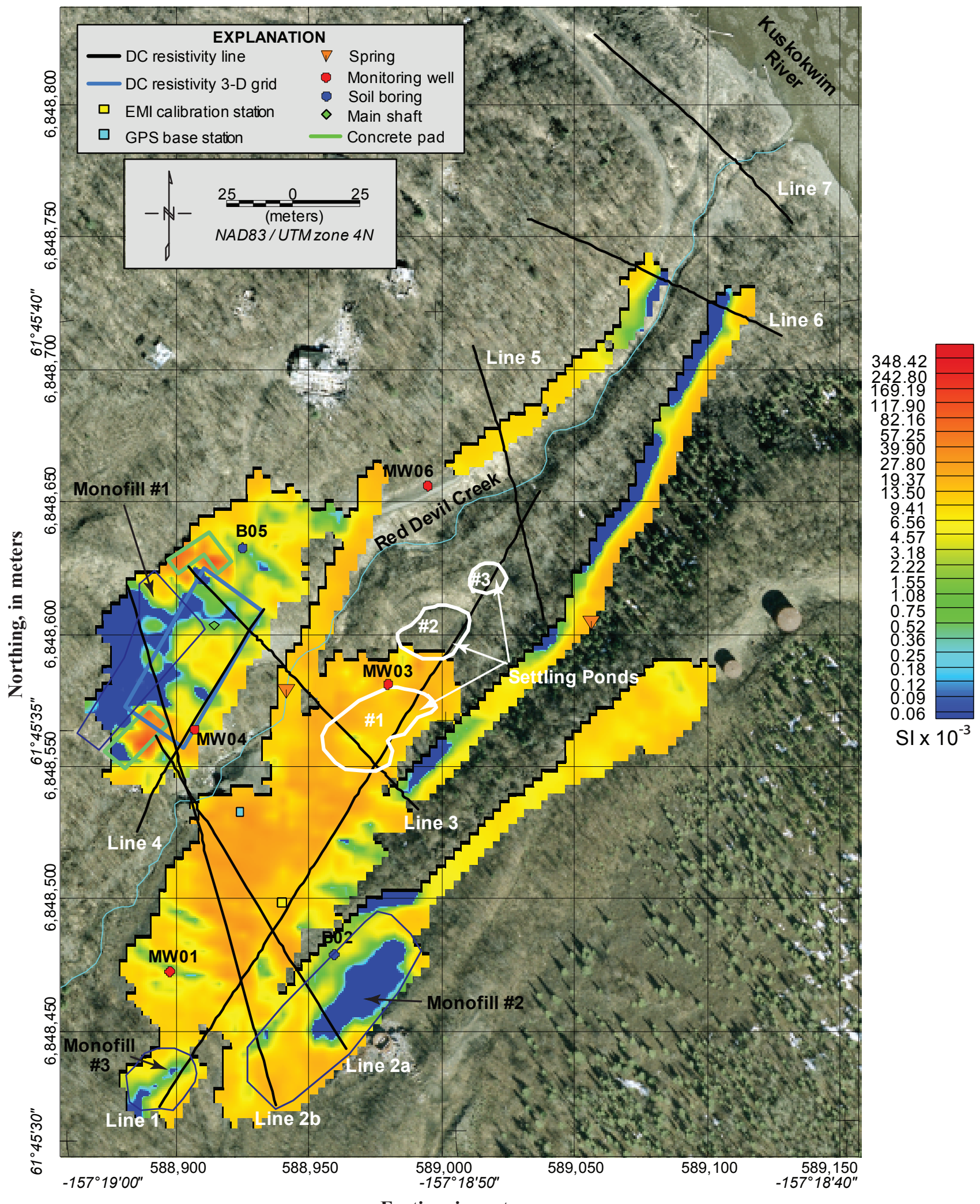

Easting, in meters

Figure 24. Map showing apparent magnetic susceptibility data for $93,030 \mathrm{~Hz}$. The absolute apparent magnetic susceptibility values are not correct because they have not been calibrated with the DC resistivity data, but the relative variations are useful for identifying anomalies. The monofill and settling pond outlines are approximate and based on historical photographs. 


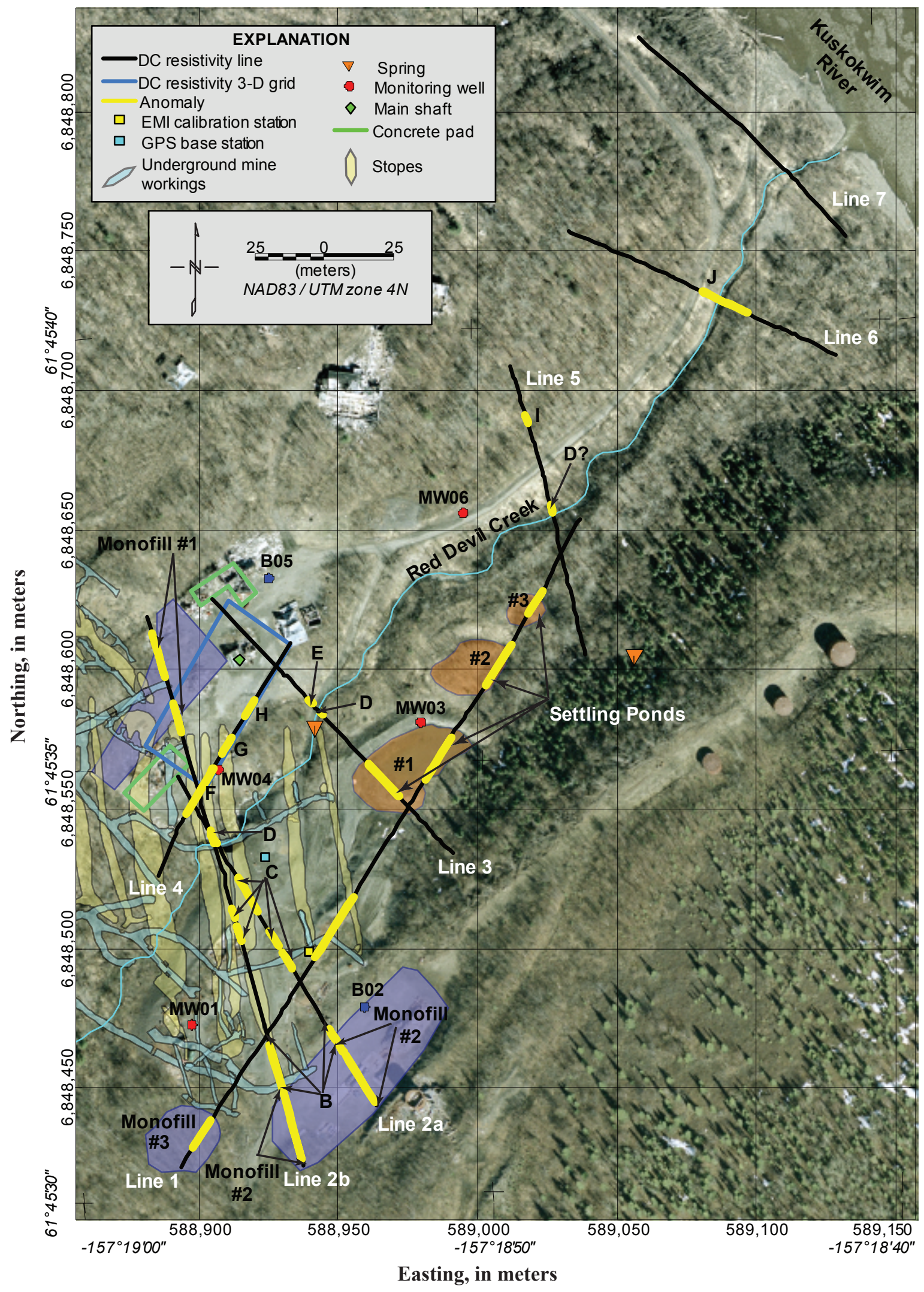

Figure 25. Map showing the locations of the annotated anomalies from the $D C$ resistivity profiles with the outlines of the approximate locations of the settling ponds (orange polygons) and monofills (purple polygons) included. 
or to help constrain the tailings volume estimate. This dataset would provide better constraints on interpretations of contacts over the entire site and fill in the gaps between the DC resistivity profiles down to a maximum depth of 10-15 $\mathrm{m}$. Additional soil borings from the site would also aid in the interpretation of this dataset.

On the basis of the measured water levels in four monitoring wells scattered throughout the site (MW01, MW03, MW04, and MW06), a water level was interpreted on the resistivity profiles. On the south side of Red Devil Creek, the water levels in monitoring wells MW01 and MW03 and an observed decrease in resistivity at depths typically ranging from 2-5 $\mathrm{m}$ depth were relatively consistent and tended to follow topography. The correlation of the water level in MW04 with the observed resistivity transitions in DC resistivity lines 2a, 2b, and 3 and the three-dimensional grid on the north side of Red Devil Creek, however, was difficult. The profiles in particular were affected by what appear to be threedimensional discrete features that are imaged much better with the three-dimensional dataset, but the apparent frequent reworking of the shallow subsurface in this area has complicated the interpretations of the observed features and even the water level.

The measured water level in well MW04 is below the elevation of Red Devil Creek and indicates that this stretch of Red Devil Creek is a losing stream. The measured water levels in the remaining wells are above the elevation of the creek bed, indicating that gaining conditions exist in other locations. If water levels in MW04 are representative of the aquifer, then the hydraulic interaction between the creek and the aquifer may be variable throughout the study area. Additional hydrologic data, such as those acquired through high-resolution stream gaging or tracer tests, may help quantify this interaction. Identifying the losing stream stretches may aid in determining which areas of the creek bed have experienced greater aggradation due to waste rock and tailings deposits.

There was no obvious shallow source of the spring that feeds into Red Devil Creek along its north bank in the DC resistivity or EMI data that was acquired over the spring in the pre-1955 retort area. DC resistivity line 3 passes within $5 \mathrm{~m}$ to the north of the spring and exhibits an interesting shallow, near-vertical feature (anomaly E) that is roughly consistent with the elevation at which the spring surfaces. This particular feature is not observed on lines $2 \mathrm{a}, 2 \mathrm{~b}$, or 5 . There is a similar but generally larger conductive anomaly imaged below the creek bed (anomaly D) that is also observed on lines $2 \mathrm{a}, 2 \mathrm{~b}$, and possibly 5 . This is another interesting anomaly whose source is not known but is not interpreted to be related to the spring because of its location below the level of the creek bed.

The three settling ponds that are located downgradient from the post-1955 retort and flotation facility produce a conductive anomaly in the unsaturated zone in DC resistivity line 1 . Because silt and sand deposits are expected in these ponds, a decrease in resistivity is logical since a relatively large deposit of fine grained material would have an increased water content in the vadose zone. The transition to higher resistivity below the water level may indicate that the base of the ponds did not extend below this depth. If the base of the ponds is expected to have extended below the water level, however, then the increase in resistivity may indicate that a secondary mechanism besides grain size is contributing to the resistivity structure observed.

A competent bedrock contact was interpreted on the south side of Red Devil Creek along DC resistivity lines $1,2 \mathrm{a}$, and $2 \mathrm{~b}$. This contact is characterized by resistivity generally greater than 200 ohm-m and is consistent with the depth at which shale was encountered at the bottom of soil boring soil boring B02. This is the only soil boring that indicates shale and also describes highly weathered shale existing about 3-4 $\mathrm{m}$ above the bottom of the hole. On DC resistivity line $2 \mathrm{a}$, there is not a strong resistivity contrast between what is described for B02 as sandy gravelly silt and weathered bedrock, so the variations observed in the resistivity sections above and near the competent bedrock interpretation are assumed to be those of grain size and degrees of weathering and fracturing in the bedrock. 
Competent bedrock is also interpreted to exist on the north side of Red Devil Creek from DC resistivity lines 5 and 6, which possess very high resistivity values (greater than 1,000 ohm-m) that approach the surface. Line 6 may indicate that competent bedrock dominates much of the area through which the line crosses, but is difficult to confidently interpret because the resistivity section is so dissimilar to the other sections and there are no borings that far downstream along Red Devil Creek.

There is a large range in observed resistivity values in what is interpreted as bedrock between the upstream and downstream portions of the site. The higher resistivity values (greater than 1,000 ohm-m) observed on lines 5 and 6 may be due to unsaturated conditions if the water level does not follow topography closely on the north side of the creek, to increased competency, or to a change in lithology (for example, dominated by a more sand-rich greywacke instead of shale).

An indication of weathered bedrock is interpreted at depth on DC resistivity line 7 but the resistivity section is dominated by moderately resistive values $(70-150 \mathrm{ohm}-\mathrm{m})$ that are interpreted to indicate alluvial material deposited from the creek and river. Distinctions between alluvial material and possible tailings or waste rock that have been transported downstream the creek cannot be made with the available data.

There is not an obvious electrical signature contrast between the tailings, waste rock, and bedrock, and the soil borings do not provide enough detail as described to help differentiate these rock types in the DC resistivity data. The tailings and waste rock may be too mixed to be able to differentiate these rock types, but additional deep soil borings that have more detailed descriptions of the rock type encountered may help to identify characteristic electrical or electromagnetic signatures that would help differentiate these rock types from the bedrock in the geophysical data. A useful additional analysis would be to analyze surface and downhole soil and rock samples from throughout the site with petrophysical laboratory equipment to determine how water content affects the bulk resistivity values. Well-described lithologic logs accompanied by borehole geophysical logs (particularly resistivity or induction logs) would also be beneficial to constraining interpretations of the data presented in this report. By defining a range of expected resistivity values for each rock type, further information may be gained from the surface geophysical data.

\section{Acknowledgments}

This work was completed in cooperation with the Bureau of Land Management under intergovernmental order L10PG00707. We are grateful for the overall logistical support provided by Mike McCrum and Larry Beck from the Bureau of Land Management and by Bryan Lund from Marsh Creek, LLC. We thank Starling Rogers from Marsh Creek, LLC, for providing necessary field support during the data acquisition phase of the project. Mark Longtine of Ecology and Environment, Inc. provided water sample and GIS data to aid in the interpretation of the data. Jeff Lucius and Jared Abraham, U.S. Geological Survey, provided helpful comments and suggestions through their review of the report. 


\section{References Cited}

Abraham, J.D., Deszcz-Pan, M., Fitterman, D.V., and Burton, B.L., 2006, Use of a handheld broadband EM induction system for deriving resistivity depth images, in 19th Annual Symposium on the Application of Geophysics to Engineering and Environmental Problems, Seattle, Washington, April 2-6, 2006, 18 p.

Advanced Geosciences, Inc., 2008a, Instruction manual for EarthImager 2D version 2.3.0 - resistivity and IP inversion software: Austin, Tex., Advanced Geosciences, Inc., 139 p.

Advanced Geosciences, Inc., 2008b, Instruction manual for EarthImager 3D version 1.5.3-resistivity inversion software: Austin, Tex., Advanced Geosciences, Inc., 100 p.

Alaska Division of Community and Regional Affairs, 2010, Alaska community database community information summaries: Red Devil website [accessed December 2010 at http://www.commerce.state.ak.us/dca/commdb/CIS.cfm?Comm_Boro_Name=Red\%20Devil].

Bailey, E.A., and Gray, J.E., 1997, Mercury in the terrestrial environment, Kuskokwim Mountains region, southwestern Alaska, in Dumoulin, J.A., and Gray, J.E., eds., Geologic studies in Alaska by the U.S. Geological Survey, 1995: U.S. Geological Survey Professional Paper 1574, p. 41-56.

Bureau of Land Management, 2009, Bureau of Land Management Red Devil mine environmental investigation update, November 2009 informational flyer [accessed December 2010 at http://www.blm.gov/pgdata/etc/medialib/blm/ak/afo/hazmat/red_devil_mine_site0.Par.99253.File.dat/ FINAL\%20Red\%20Devil\%20Mine\%20mailer\%2011.09.09.pdf].

Bureau of Land Management, 2010, Bureau of Land Management CERCLA administrative record for the Red Devil mine cleanup website [accessed December 2010 at http://www.blm.gov/ak/st/en/fo/ado/hazardous_materials/RDV_AR.html].

Butler, D.K., ed., 2005, Near-surface geophysics-Investigations in geophysics 13: Tulsa, Okla., Society of Exploration Geophysicists, 732 p.

Frischknecht, F.C., Labson, V.F., Spies, B.R., and Anderson, W.L., 1991, Profiling methods using small sources, in Nabighian, M.N., ed., Investigations in geophysics 3-Electromagnetic methods in applied geophysics, volume 2 (Application, parts A and B):, Tulsa, Oklahoma, Society of Exploration Geophysicists, p. 105-270.

Harding Lawson Associates/Wilder Construction, 2001, Red Devil mine retort building demolition and limited site investigation, Volume 1, March 2001 report, 195 p. [accessed January 2011 at http://www.blm.gov/pgdata/etc/medialib/blm/ak/afo/hazmat/RDV_CERCLA_AR.Par.15267.File.dat/RDV \%202001-03-30\%20Source\%20Area\%20Removal\%20and\%20Investigation\%20Volume\%201.pdf].

Loke, M.H., 2010, Tutorial-2-D and 3-D electrical imaging surveys: Penang, Malaysia, Geotome Software, 157 p. [accessed January 2011 at http://www.geoelectrical.com/downloads.php].

Lowrie, William, 1997, Fundamentals of geophysics: Cambridge, United Kingdom, Cambridge University Press, 354 p.

MacKevett, E.M., and Berg, H.C., 1963, Geology of the Red Devil quicksilver mine, Alaska: U.S. Geological Survey Bulletin 1142-G, 16 p. [available online at http://pubs.er.usgs.gov/djvu/B/bull_1142_g.djvu].

Reynolds, J.M., 1997, An introduction to applied and environmental geophysics: Chichester, England, Wiley, $796 \mathrm{p}$.

Rytuba, J.J., 2000, Mercury mine drainage and processes that control its environmental impact: The Science of the Total Environment, v. 260, p. 57-71.

Sharma, P.V., 1997, Environmental and engineering geophysics: Cambridge, United Kingdom, Cambridge University Press, 475 p. 
Spies, B.R., and Frischknecht, F.C., 1991, Electromagnetic sounding, in Nabighian, M.N., ed., Investigations in geophysics 3-Electromagnetic methods in applied geophysics, volume 2 (application, parts A and B): Society of Exploration Geophysicists: Tulsa, Oklahoma, p. 285-425.

Tryck, Nyman, and Hayes, 1987, Red Devil mine CERCLA Site Inspection Report, AKD-980495618, September 1987: Tryck, Nyman, and Hayes and Shannon and Wilson, Inc., 62 p. [accessed January 2011 at http://www.blm.gov/pgdata/etc/medialib/blm/ak/afo/hazmat/RDV_CERCLA_AR.Par.77612.File.dat/RDV\%20198709-01\%20Red\%20Devil\%20Mine\%20AKD\%20980495618\%20CERCLA\%20Site\%20Inspection\%20Report.pdf].

Webber, B.S., Bjorklund, S.C., Rutledge, F.A., Thomas, B.I., and Wright, W.S., 1947, Mercury deposits of southwestern Alaska: U.S. Bureau of Mines Report of Investigations 4065, 86 p.

West, F.F., and Macnae, J.C., 1991, Physics of the electromagnetic induction exploration method, in Nabighian, M.N., ed., Investigations in geophysics 3-Electromagnetic methods in applied geophysics, volume 2 (application, parts A and B): Tulsa, Oklahoma, Society of Exploration Geophysicists, p. 5-45.

Weston, 1989, Red Devil mine site inspection final report, Red Devil, Alaska, June 1989, Roy F. Weston, Inc., 107 p. [accessed January 2011 at http://www.blm.gov/pgdata/etc/medialib/blm/ak/afo/hazmat/RDV_CERCLA_AR.Par.62940.File.dat/RDV \%201989-06-00\%20Site\%20Inspection\%20Report.pdf]. 


\section{Appendix A. DC Resistivity Pseudosections}

DC resistivity measured data apparent resistivity pseudosection (top image), calculated forward model apparent resistivity pseudosection (middle image), and inverted resistivity section (bottom image) are shown for each two-dimensional line. For each figure, the vertical axis on the two pseudosections is estimated depth, in meters, of the apparent resistivity datum and on the inverted section is the NAVD88 elevation, in meters. The horizontal axis for all three images is the downline distance, in meters, with electrode locations represented by the black squares near the top of each figure. The black dots in the two pseudosections are individual apparent resistivity datums, and missing datums indicate areas where noisy data were removed using the percent data misfit threshold removal tool to improve the inverted model fit. 
RDM DC resistivity Line 1
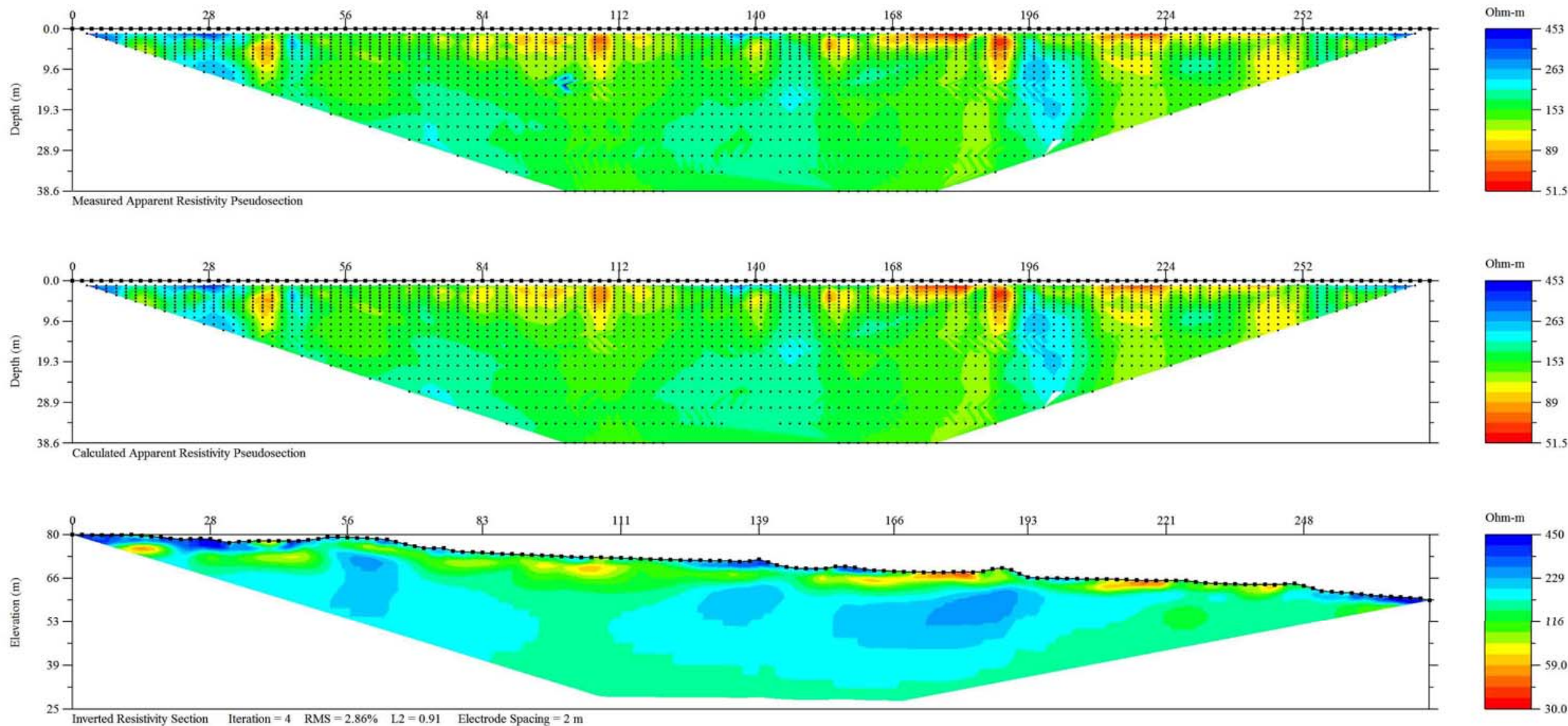

Ohm-m

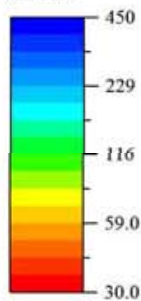


RDM DC resistivity Line 2a
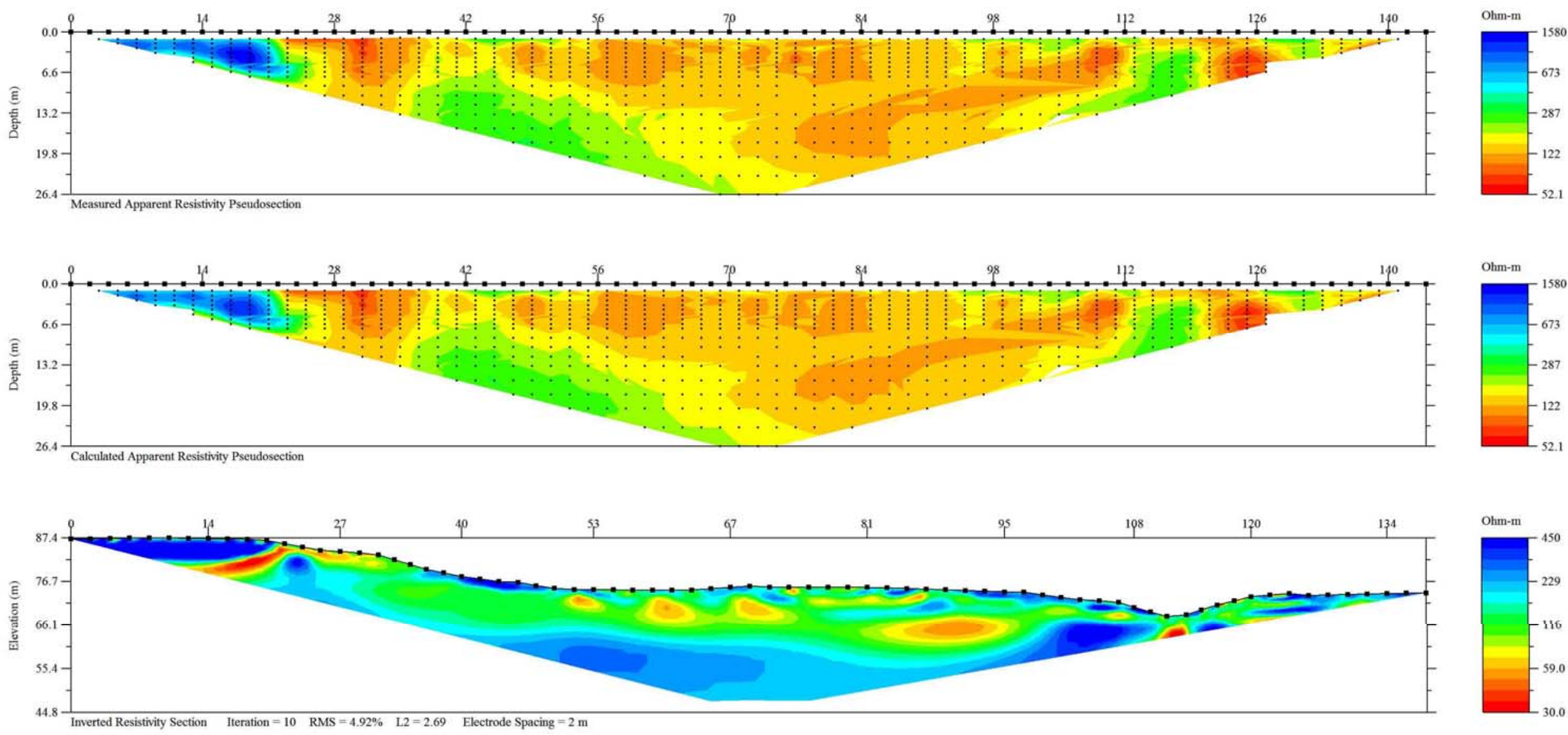
RDM DC resistivity Line 2b
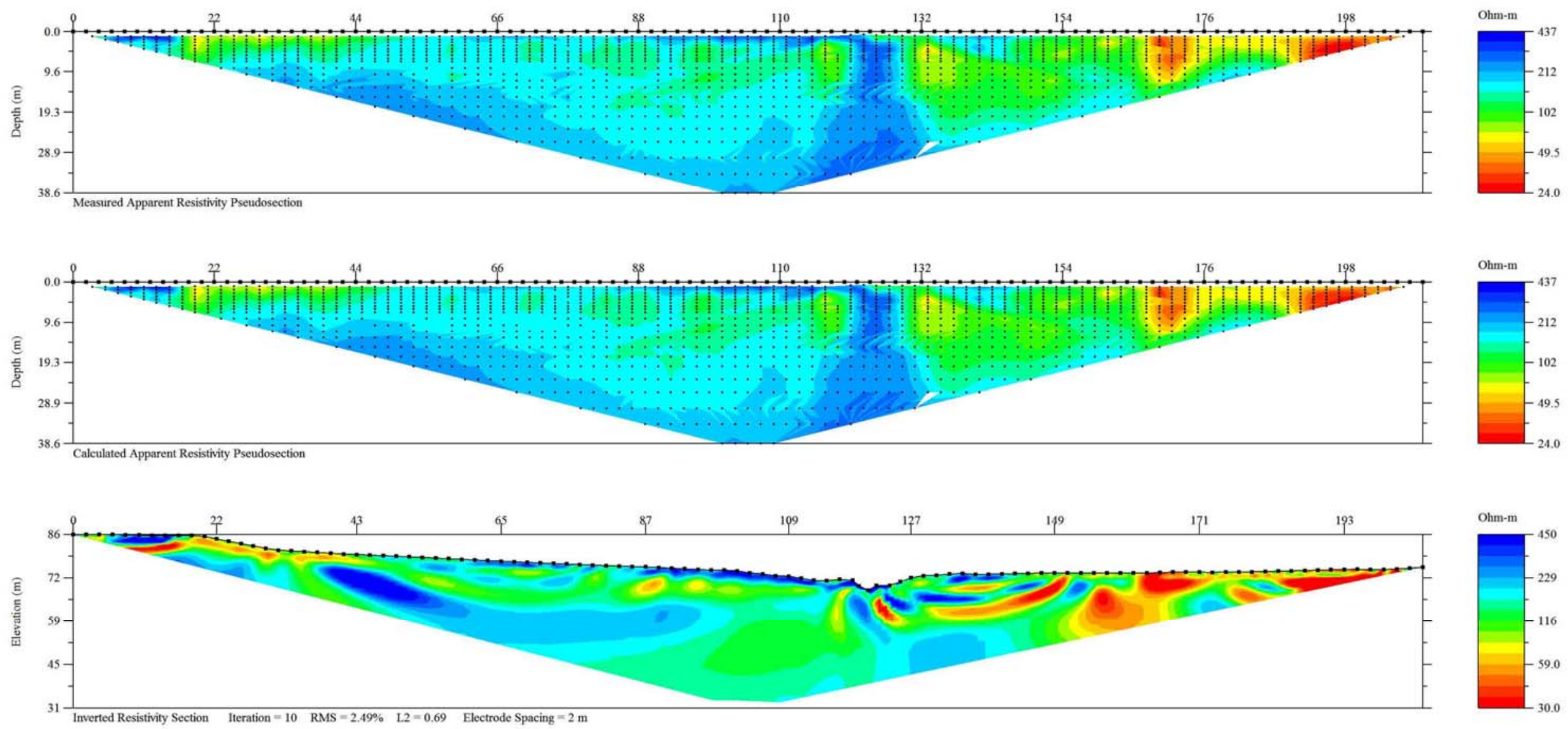

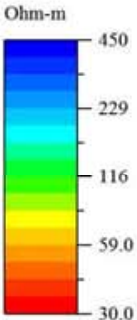




\section{RDM DC resistivity Line 3}

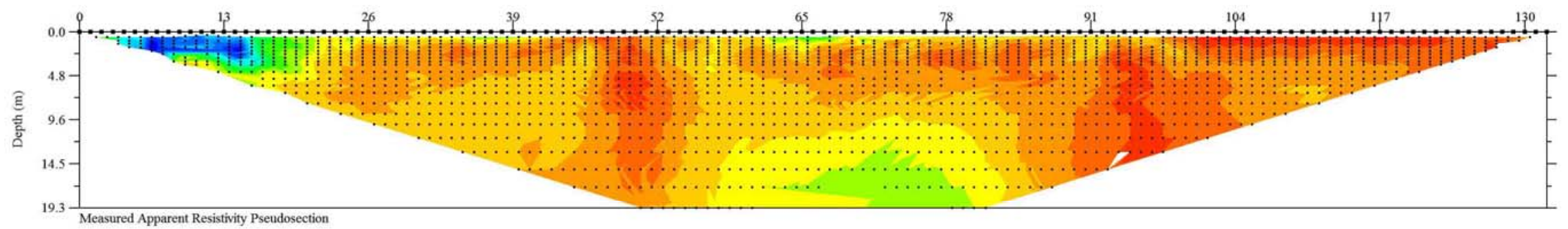

Ohm-m
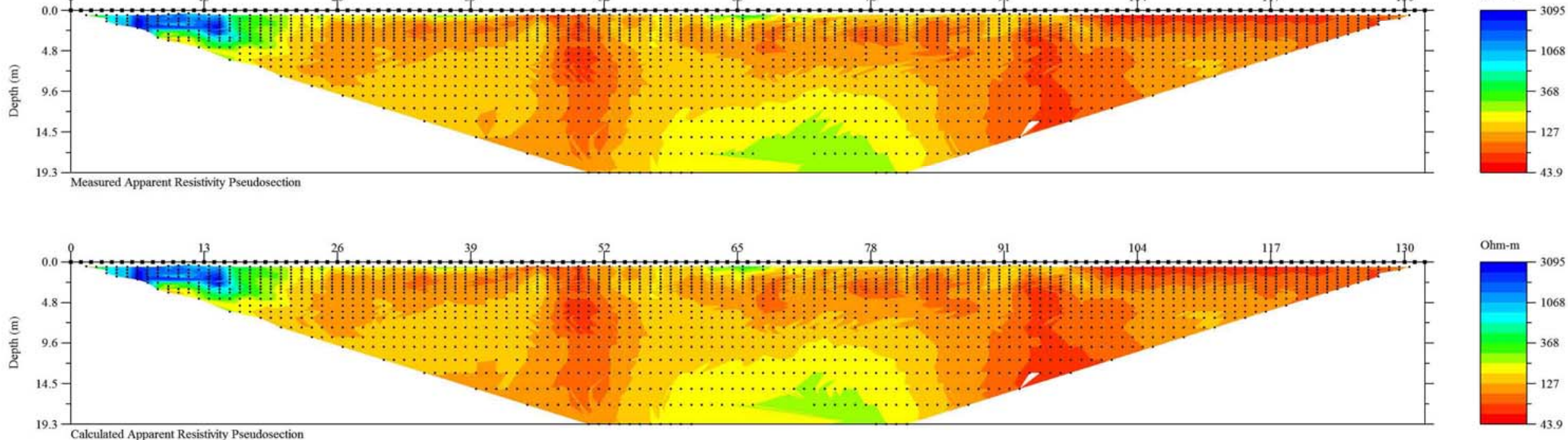

Ohm-m
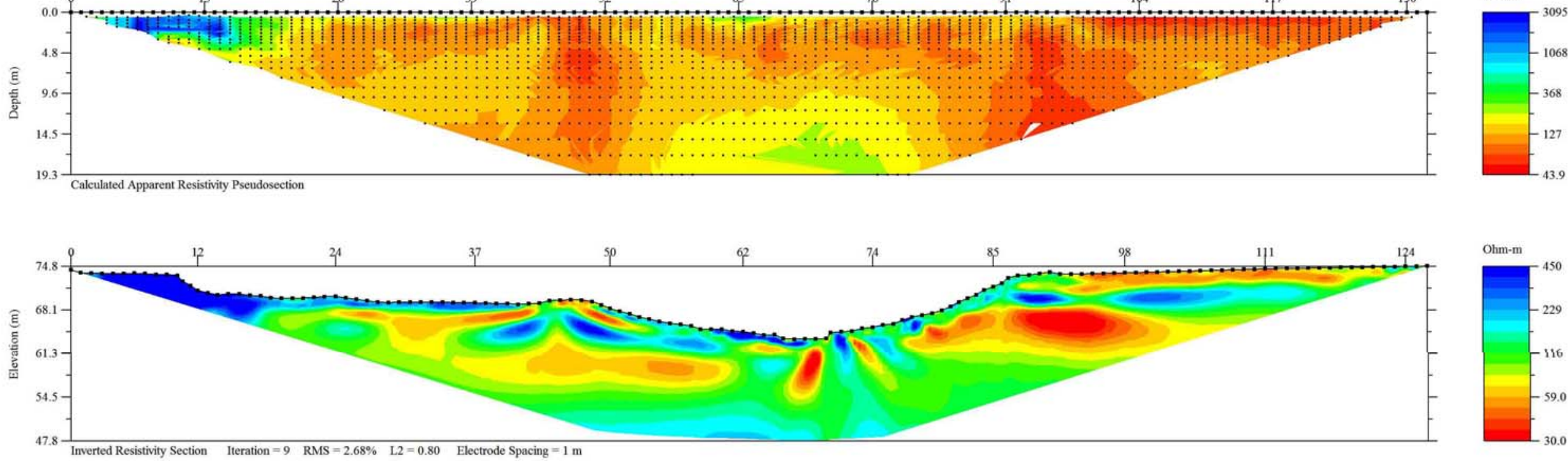
RDM DC resistivity Line 4
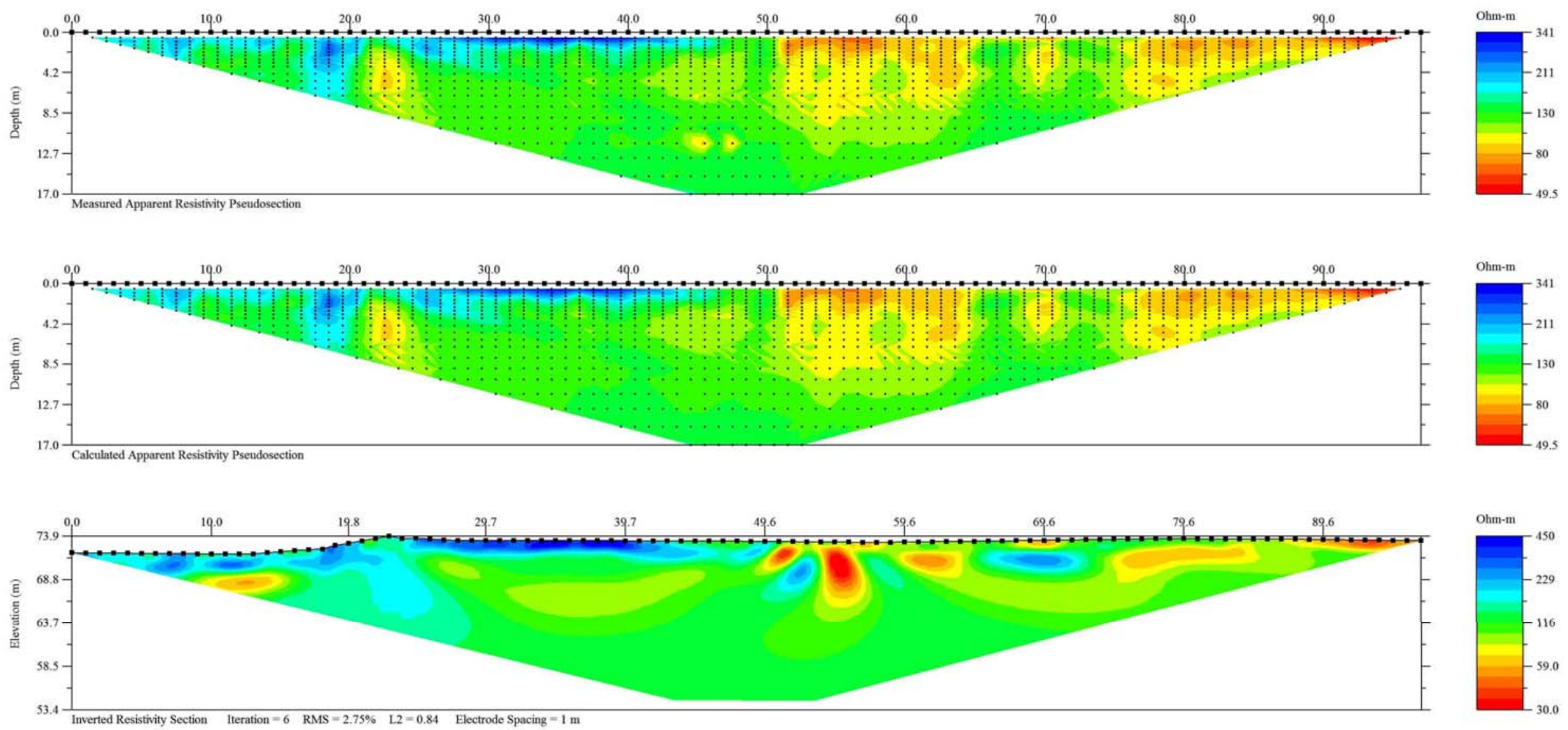
RDM DC resistivity Line 5
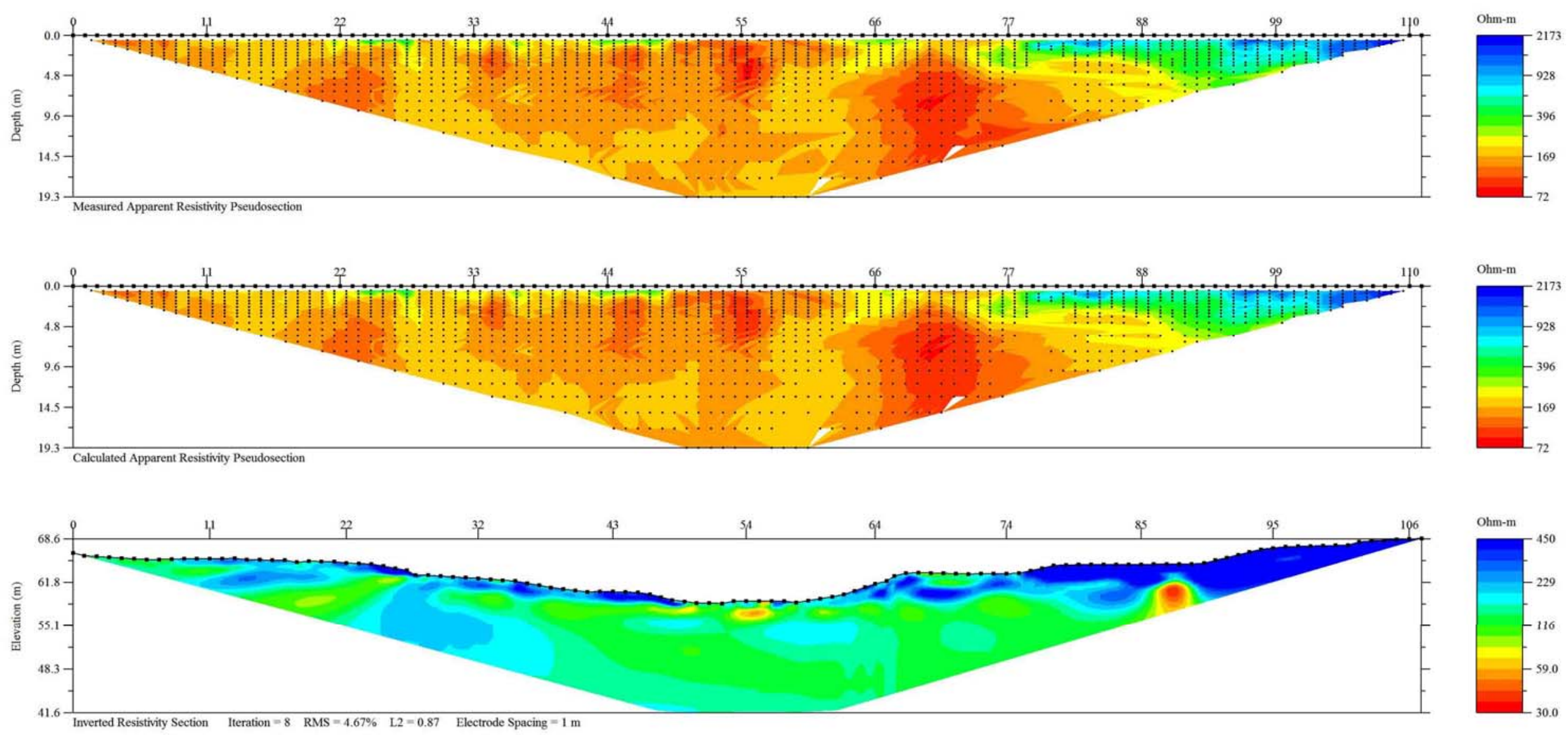
RDM DC resistivity Line 6
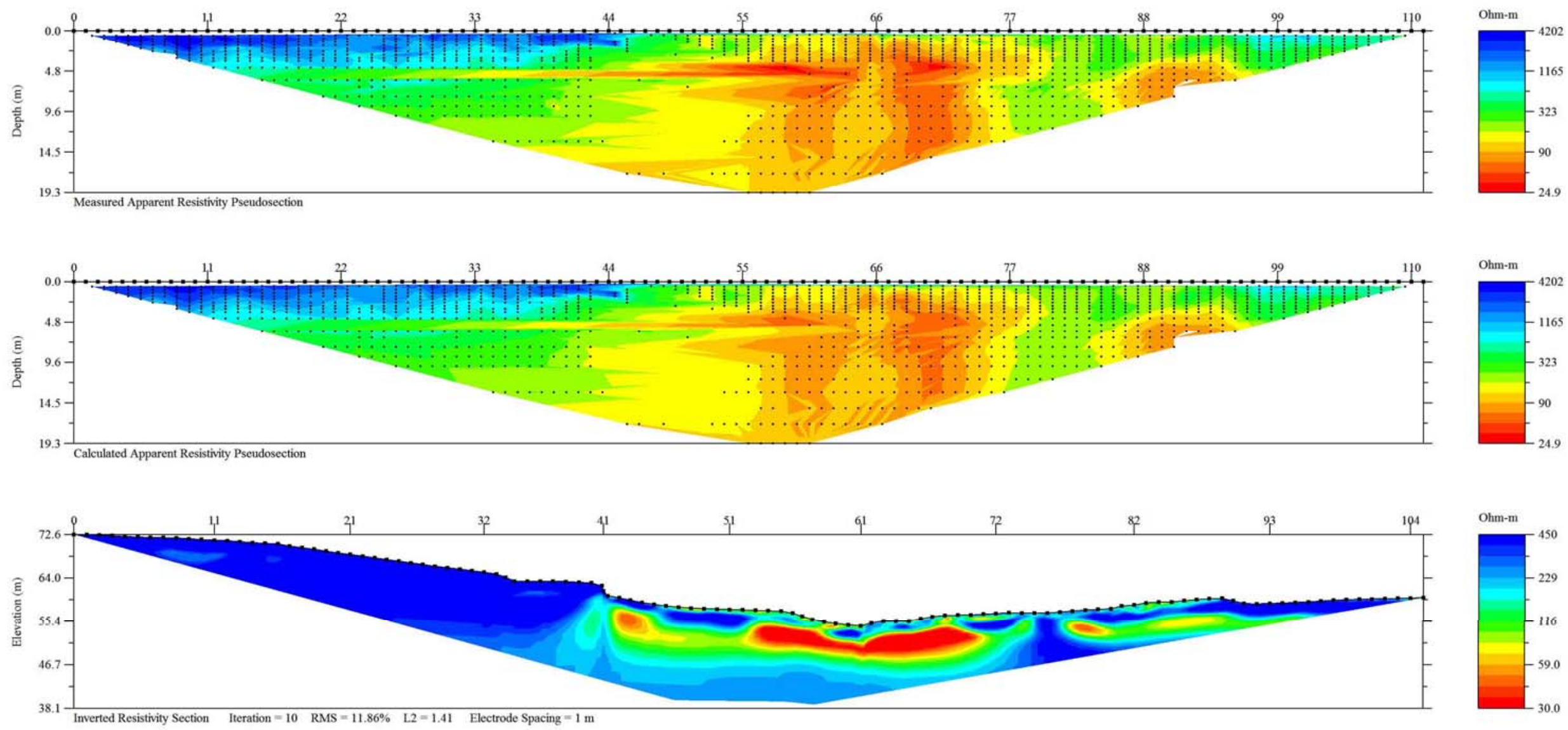

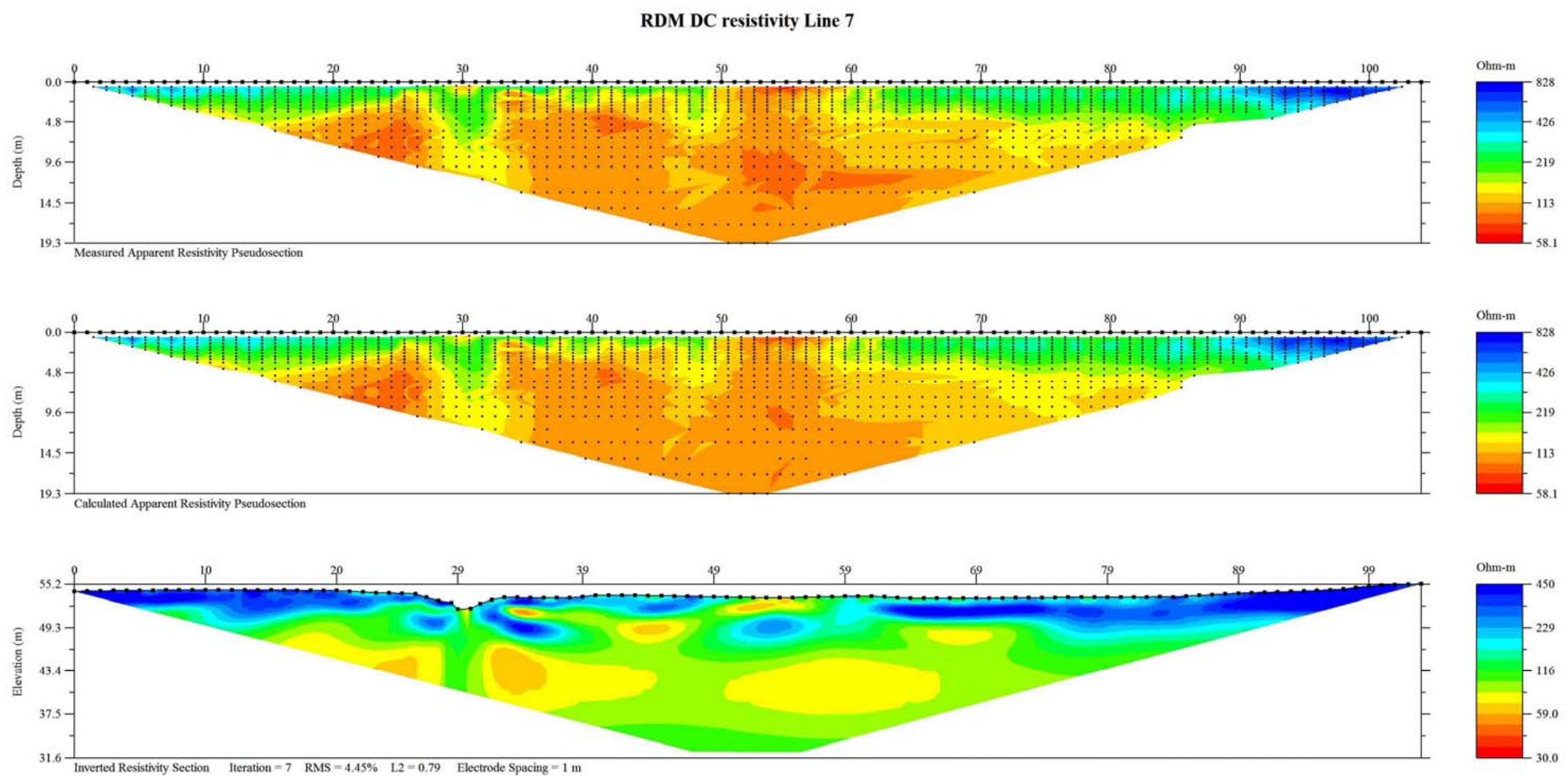


\section{Appendix B. Digital Data}

\section{Direct-Current Resistivity Data}

Digital direct-current resistivity data are provided in two compressed files:

1. Raw data: RDM_DCres_RawData.zip and

2. Inverted data: RDM_DCres_InvData.zip.

The raw data compressed file contains 4 files, 1 for the profiles and 3 for the three-dimensional grid. The inverted data compressed file contains 2 files, 1 for the profiles and 1 for the three-dimensional grid data.

The raw profile data are provided in an ASCII, comma-separated, format

(RDM_2D_DCres_RawData.csv). The data headings are as follows:

- Line: line number,

- Dist: local downline distance, in meters,

- Depth: negative depth below the ground surface, in meters,

- $X$ and $Y$ : easting and northing coordinates of resistivity data in NAD83, UTM zone 4N, in meters, and

- $Z$ : surface elevation of resistivity data in NAVD88, in meters.

The raw three-dimensional grid data are provided in three ASCII Advanced Geosciences, Inc., data formats:

- RDM3D.stg: raw data file containing the acquisition parameters and measurements,

- RDM3D.crs: contact resistance readings file, and

- RDM3D.cmd: command file that contains the electrode configurations used for each measurement and the electrode locations in local coordinates, with electrode \#1 located at coordinate $(0,0)$ in the southeast corner of the grid and the $\mathrm{x}$-coordinates increasing to the northwest and y-coordinates increasing to the northeast.

The inverted profile data are provided in an ASCII array, comma-separated, format RDM_2D_DCres_InvData.CSv. Unavailable or null data are denoted by a -9990.00 value. The data headings are as follows:

- Line: line number,

- $X$ and $Y$ : easting and northing coordinates of resistivity data in NAD83, UTM zone 4N, in meters,

- Z: surface elevation of resistivity data in NAVD88, in meters,

- Dist: local downline distance, in meters,

- elev[\#]: elevation horizontal array containing 25 elements, in meters, and

- res[\#]: modeled resistivity value horizontal array containing 25 elements, in ohm-m. 
The inverted three-dimensional grid data are provided in an ASCII comma-separated format with the following data headings (RDM_3D_DCres_InvData.csv):

- $X$ and $Y$ : easting and northing coordinates of resistivity data in NAD83, UTM zone 4N, in meters, and

- NAVD88: elevation of resistivity data in NAVD 88, in meters,

- Res: modeled resistivity values, in ohm-m,

- Xlocal and Ylocal: local grid coordinates of resistivity data as originally acquired, in meters, and

- $\quad Z$ : negative depth below the ground surface of resistivity data, in meters.

\section{Electromagnetic Induction Data}

The digital electromagnetic induction data are provided in a compressed ASCII, commaseparated, file RDM_EMI_Data.zip. The data headings are as follows:

- Line: line type and number,

- Sample: sample number,

- $X$ and $Y$ : easting and northing coordinates of EMI data in NAD83, UTM zone 4N, in meters,

- Z: surface elevation in NAVD88, in meters,

- Date: acquisition date in yyyy/mm/dd format,

- Time_ms: GPS time of the measurement, in milliseconds of the day,

- Time_hhmmss_sss: GPS time of the measurement in hours, minutes, seconds,

- I_\#Hz: raw in-phase measurement for a single frequency, in parts per million (ppm), and

- Q_\#Hz: raw quadrature measurement for a single frequency, in ppm.

Individual I_\#Hz and Q_\#Hz headings exist for each of the seven acquired frequencies: 3,930 Hz, 6,630 $\mathrm{Hz}, 11,310 \overline{\mathrm{Hz}}, 19,110 \mathrm{~Hz}, 32,430 \mathrm{~Hz}, 54,930 \mathrm{~Hz}$, and 93,030 Hz. The line name prefixes indicate either line data $(L)$ or calibration data acquired at the calibration station $(P)$. A line number followed by .1 indicates data acquired during the first acquisition event on Aug. 7, 2010, and a .2 indicates data acquired during the second data acquisition event on that day. Line numbers without these indications were acquired on Aug. 6, 2010.

\section{Digitized Anomalies}

The annotated anomalies from the DC resistivity profiles have been digitized and are provided in a .DXF AutoCAD ${ }^{\circledR}$ drawing interchange file format, RDM_DCres_anomalies.DXF. The ASCII .DXF format retains the horizontal and vertical extents in NAD83 UTM zone 4N, in meters and NAVD 88, in meters, respectively. 